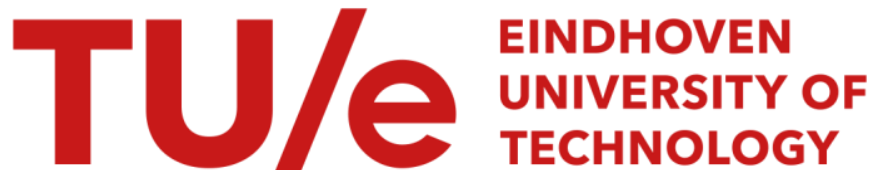

\section{Metal hydride electrodes stability of LaNi5-related compounds}

Citation for published version (APA):

Willems, J. J. G. S. A. (1984). Metal hydride electrodes stability of LaNi5-related compounds. [Phd Thesis 2 (Research NOT TU/e / Graduation TU/e), Chemical Engineering and Chemistry]. Technische Hogeschool Eindhoven. https://doi.org/10.6100/IR97016

DOI:

10.6100/IR97016

Document status and date:

Published: 01/01/1984

\section{Document Version:}

Publisher's PDF, also known as Version of Record (includes final page, issue and volume numbers)

\section{Please check the document version of this publication:}

- A submitted manuscript is the version of the article upon submission and before peer-review. There can be important differences between the submitted version and the official published version of record. People interested in the research are advised to contact the author for the final version of the publication, or visit the $\mathrm{DOI}$ to the publisher's website.

- The final author version and the galley proof are versions of the publication after peer review.

- The final published version features the final layout of the paper including the volume, issue and page numbers.

Link to publication

\section{General rights}

Copyright and moral rights for the publications made accessible in the public portal are retained by the authors and/or other copyright owners and it is a condition of accessing publications that users recognise and abide by the legal requirements associated with these rights.

- Users may download and print one copy of any publication from the public portal for the purpose of private study or research.

- You may not further distribute the material or use it for any profit-making activity or commercial gain

- You may freely distribute the URL identifying the publication in the public portal.

If the publication is distributed under the terms of Article 25fa of the Dutch Copyright Act, indicated by the "Taverne" license above, please follow below link for the End User Agreement:

www.tue.nl/taverne

Take down policy

If you believe that this document breaches copyright please contact us at:

openaccess@tue.nl

providing details and we will investigate your claim. 


\section{Metal Hydride Electrodes Stability of LaNis-related Compounds}

\section{Proefschrift}

ter verkrijging van de graad van doctor in de technische wetenschappen aan de Technische Hogeschool Eindhoven, op gezag van de rector magniffcus, prof. dr. S. T. M. Ackermans, voor een commissie aangewezen door het college van dekanen in het openbaar to verdedigen op vrijdag 2 november 1984 te 16.00 uur

door

Johannes Jozef Gerardus Stephanus Adrianus Willems

geboren te Eindhoven 
Dit proefschrift is gocdgekeurd door de promotoren prot. E. Barendrecht en prof. dr. A. R. Micdema 
gan Marié-Jose

Linda en Tom 
Dit proefschrift is ook versehenen als Supplement No. 1 van Philips Journal of Rescarch Vol. 39 (1984). 


\section{CONTENTS}

1. SCOPE OF THIS THESIS . . . . . . . . . . . . . . . 1

2. METAL HYDRIDE ELECTRODES . . . . . . . . . . . , 3

2.1. Rechargeable batteries. . . . . . . . . . . . . . . 3

2.1.1. Introduction . . . . . . . . . . . . . . . . . 3

2,1.2, Principle and terminology . . . . . . . . . . . . 3

2.1.3. Thermodynamic and kinetic stability. . . . . . . . 5

2.1.4. Charge/discharge mechanism, . . . . . . . . . . . 7

2.1.5. Reactions in scaled cells . . . . . . . . . . . . 9

2.1.6. Conclusions . . . . . . . . . . 10

2.2. Hydrogen in metals. . . . . . . . . . . . . . . . . 11

2.2.1. Introduction . . . . . . . . . . 11

2.2.2. Absorption and desorption phenomena. . . . . . . 12

2.2.3. Stability of metal hydrides . . . . . . . . . . . . 16

2.2.4. Conclusions . . . . . . . . . . . . . . 17

2,3. Metal hydride electrodes. . . . . . . . . . . . . 17

2.3.1. Concept . . . . . . . . . . . . . . . . 17

2.3.2. Electrochemical pressure-composition isotherms . . . 18

2.3.3. Conclusions . . . . . . . . . . . . . . . . . 20

References . . . . . . . . . . . 21

3. $\mathrm{LaNi}_{5}$ AND LaNi $\mathrm{Cu}$ ELECTRODES _ _ . . . . . . . 22

3.1. Introduction . . . . . . . . . . . . . . . . 22

3.2, Galvanostatic charge/discharge cycling. . . . . . . . . . 23

3.2.1. Sample preparation and measuring equipment . . , 23

3.2.2. Results. . . . . . . . . . . . . . . . . . . 23

3.2.3. Discussion . . . . . . . . . . . 32

3.3. X-ray diffraction analysis . . . . . . . . . . . . . . 35

3.3.1. Results . . . . . . . . . . . . . . . . . 35

3.3.2. Discussion . . . . . . . . . . . . . . . . . 39

3.4. Specific surface area measurements . . . . . . . . . . . 40

3.4.1. The BET method . . . . . . . . . . . . . . . 40

3.4.2. Results and discussion . . . . . . . . . . . 44

3.5. Electron microscopy . . . . . . . . . . . . . . . . 47

Results and discussion. . . . . . . . . . . . . . . . 47

3.6. Conclusions. . . . . . . . . . . . . . . . . . . . 51

References . . . . . . . . . . . . . . 52 
4. MUITICOMPONENT ELECTRODES. . . . . . . . . . $\$ 4$

4.1. Introduction . . . . . . . . . . . . . . . . . . . 54

4.2. Lattice expansion and stability. . . . . . . . . . . . . 56 4.2.1. Electrochemical data. . . . . . . . . . . . . . 56 4.2.2. Crystallographiç dat.a . . . . . . . . . . . . . 58

4.2.3. Discussion. . . . . . . . . . . . . . . . . 62

4.3. Specific surface area . . . . . . . . . . . . . . 64

Results and discussion . . . . . . . . . . . . . . . . 65

4.4. Interrupted galvanostatic cycling . . . . . . . . , 65 Results and discussion. . . . . . . . . . . . . . . . 65

4.5. Conclusions, . . . . . . . . . . . . . . . . . . . 69

Retereness . . . . . . . . . . . . . . . . . 70

5. SEALED NICKEL-HXDRIDE BATTERIES . . . , . . . , , 71

5.1. Cell concept . . . . . . . . . . . . . . . . . . . 71

5.2. Electrode materials . . . . . . . . . . . . . . . . . 72

5.2.1. Introduction. . . . . . . . . . . . . 72

5.2.2. Negative electrode. . . . . . . . . . . . . , , 72

5.2.3. Positive slceltode . . . . . . . . . . . . . . . . 75

5.3. Electrode and cell construction . . . . . . . . . . . . 75

5.3.1. Electrode preparation . . . . . . . . . . . . 75

5.3.2. Cell design . . . . . . . . . . . . . . . . . 77

5.3.3. Cell construction . . . . . . . . . . . . . . . 78

5.4. Results and discussion. . . . . . . . . . . . . . . . 80

5.4.1. Cell A; high-rate cycling . . . . . . . . . . . . 80

5.4.2. Cell B; IEC test. . . . . . . . . . . . . . . . 83

5.4.3. Cell $C$, high-rate cycling . . . . . . . . . . . . 84

5.4.4. Cell D; overcharging and overdischarging . . . . . . 87

5.5. Conclusions. . . . . . . . . . . . . . . . . . . . 89

References . . . . . . . . . . . . . . . . . . . . 90

6. FINAL CONCLUSIONS , . . . . . . . . . . . . . . . . 91

ACKNOWLEDGEMENT . . . . . . . . . . . , . 92

List of symbols . . . . . . . . . . . . . . . . . . . . . 93

Summary . . . . . . . . . . . . . . . . . 95

Samenvatting . . . . . . . . . . . . . . . . . . . . 97

Levensloop. . . . . . . . . . . . . . . . . . . . . . . 99

Dankwoord . . . . . . . . . . . . . . . . . . . . 100 


\section{SCOPE OF THIS THESIS}

Batteries are the power source for many products and the number of applications will certainly increase as the performance of batteries is improved. There exist primary (non-rechargeable) and secondary (rechargeable) batteries. The two most well-known secondary battcries are the lead-acid and the nickelcadmium cell. Important features required for a new rechargeable battery are: higher energy density, higher power density, longer durability, maintenancefree operation, lower costs and non-polluting. Evidently, many of these features are determined by the physico-chemical properties of the battery, such as the storage capacity of the electrodes, the stability of the electrode/electrolyte system and the charge/discharge mechanism of the clectrode reactions.

As a result of the discovery of intermetaltic compounds which are capable of absorbing and desorbing hydrogen at pressures around 1 atm and near roon temperature a new type of rechargeable battery electrodes has become reatizable: the metal hydride electrode. During the charging of such an electrode, hydrogen is formed by the electrochemical reduction of water and is subsequently absorbed by the intermetallic compound. During discharging, the stored hydrogen is releascd and oxidized. The considerations which have led to the concept of a metal hydride electrode ate given in chap. 2 .

$\mathrm{LaNi}_{5}$ and $\mathrm{LaNi}{ }_{4} \mathrm{Cu}$ have been most-promising materials for application in rechargeable battery clectrodes because of the rapid and reversible storage of large quantities of hydrogen in these intermetallic compounds. However, the storage capacity of both $\mathrm{LaNi}_{6}$ and $\mathrm{LaNi}_{4} \mathrm{Cu}$ electrodes declines drastically during repeated charge/discharge cycling. This detcrioration process has been investigated by means of $\mathrm{X}$-ray diffraction analysis, gas adsorption (BET) measurements and electron microscopy. Based upon our findings we hypothesized that hydride electrodes, made of an intermetallie compound which shows less lattice expansion than $\mathrm{LaNi}_{5}$ on hydriding, should be more stable than LaNin clectrodes (chap. 3).

More than twenty different intermetallic compounds, in which lanthanum and nickel had been partially replaced by similar clements, have been prepared to examine this hypothesis. The volume expansion of these LaNis-related compounds on hydrogen gas absorplion, as determined from $X$-ray diffraction measurements, and the stability of the corresponding electrodes are indeed correlated. The stability of these multicomponent electrodes was evaluated from capacity loss measurements in half-cells in series of approximately six hundred charge/discharge cycles. Several multicomponent electrodes exhibited an excellent stability. The effect of the specific surface area and of the charge/ discharge cycle regime on the stability has also been investigated. Chapter 4 
is concluded with a description of a possible mechanism for the degradation of metal hydride electrodes.

The combination of the metal hydride clectrode and the rechargeable nickel electrode provides a nickel-hydride battery. Based upon the behaviour of both clcctrodes, a sealed nickel-hydride cell is expected to have several advantages, e.g. the capability of being charged and discharged at high rates and during many cycles. Also, prolonged overcharging and overdischarging should be feasible without detrimental effects. Several sealed nickel-hydride wells which comprise a hydride electrode made of one of the stable intermetallic compounds have been constructed. The properties of these first sealed nickelhydride batteries are diseussed in chap. 5 . 


\section{METAL HYDRIDE ELECTRODES}

\subsection{Rechargeable batteries}

\subsubsection{Introduction}

In 1800 Allessandro Volta ${ }^{1}$ ) reported a device for converting chemical energy into electricity. This device, which is now known as the Volta pile, was the first chemical power source or galvanic battery. In Volta's cells, zinc was oxidized at the negative electrode and hydrogen gas was evolved at the positive, silver or copper, electrode. In 1860, more than half a century atter Volta's discovery, Gaston Planté ${ }^{2}$ ) demonstrated the first rechargeable battery: the lcad-acid cell. This cell consisted of two spirally wound lead shcets separated by flannel strips and inserted into sulphuric acid. Flante formed his electrodes by repeated charging with primary cells and discharging. At the turn of the century alkaline accumulators were invented. In 1899 Waldemar Jungner presented his ideas concerning the advantages of alkaline systems in a patent ${ }^{5}$ ). In this patent $\mathrm{Ag}_{2} \mathrm{O}_{2}, \mathrm{Mn}(\mathrm{OH})_{4}$ and $\mathrm{CuO}$ are mentioned as positive electrode materials and $\mathrm{Cu}$ and $\mathrm{Fe}(\mathrm{OH})_{2}$ as negative active materials. Also in $1899, \mathrm{~T}$. de Michalovski patented his findings on the nickel-zine cell ${ }^{4}$ ). The first patent on nickel-cadmium and nickel-iron accumulators was granted to Jungner in 1901 ${ }^{5}$ ). These rechargeable cells were also patented by Thomas Edison; the nickel-iron cell in $1901^{6}$ ) and the nickel-cadmium cell in 1902 7 ).

Since these early discoveries many combinations of redox couples have been investigated for application in galvanic cells and many electrochemical systems are still being studied ${ }^{8-18}$ ). The purpose of this section is not to present a comprehensive review. Instead, some well-known rechargeable slectrodes are discussed primarily to illustrate our major considerations in the choice of a new battery system. Here, the emphasis will be on the relation between physico-chemical properties and performance. Aspects of cost and producibility are not discussed.

\subsubsection{Principle and terminology}

A galvanic cell is a device that converts chemical energy directly into electrical energy. Such a cell consists of two electrodes, spatially separated from each other but in ionic contact via an electrolyte. This is illustrated in fig. 1 . Whereas one of the electrodes is rather easily oxidized, releasing electrons (the negative electrode), the other one is preferentially reduced, accepting electrons (the positive clcctrode). When the electrons flow through an external load from the riegative to the positive clectrode, the cell is dischanged and electrical energy is generated. A cell is rechargeable if all reactions can be made to proceed in the opposite direction by imposing an external potential difference. 


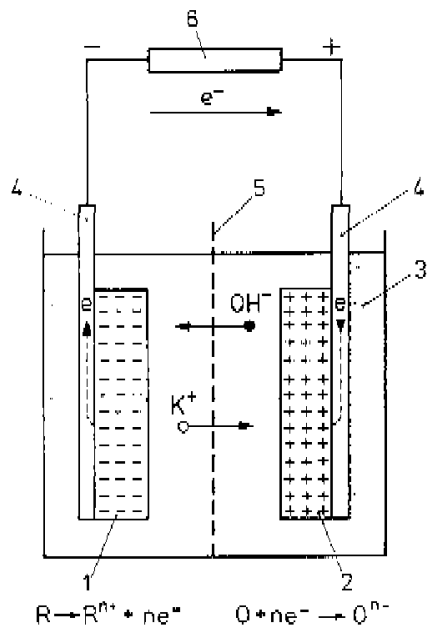

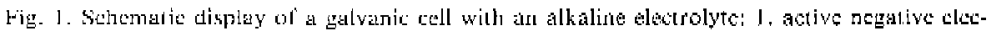

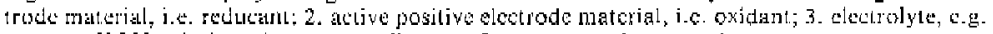
dudenu $\mathrm{KOH}$ solution; 4. eurrent collectors; 5 . separator; 6. cxicrnal load.

The theoretical energy density of a galvanic coll $\left(\mathrm{Wh}_{\mathrm{h}}-\mathrm{kg}^{-1}\right.$ or $\left.\mathrm{Wh} \cdot \mathrm{dm}^{-3}\right)$ is equal to the storage capacity of the two electrodes multiplied by the cell voltage. The storage cupacity of an electrode, i.e. its coulombic storage density, means the amount of charge that can be stored and released via an electrochemical (Faradaic) reaction by an unit weight or unit volume of active material. Values for some well-known cells are given in table $\mathrm{I}$. As is shown in this table, the actual

TABI.E I

Characteristics of some well-known primary ( $\mathrm{P}$ ) and secondary (S) colls.

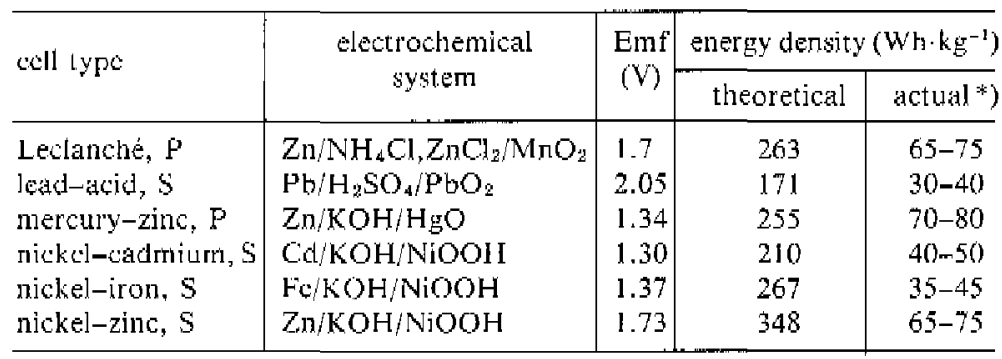

*) data liom reli, 12 
energy density of primary (non-rechargeable) and secondary (rechargeable) cells is approximately 30 and $20 \%$ of the theoretical value, respectively. This huge reduction is a consequence of the weight of excess active material, electrolyte and additional components and of the voltage loss duc to current flow. It therefore depends on the construction of the cell and the magnitude of the current drain.

The power density of galvanic cells ( $\mathrm{W} \cdot \mathrm{kg}^{-1}$ or $\mathrm{W} \cdot \mathrm{dm}^{-8}$ ) is determined by the ability of the cell to be discharged at high rates and by the degree of utilization of active material at these rates. The power density varies strongly with the electro" chemical system (rate of electrode reactions) and the cell construction (transport phenomena).

The decisive parameter for many applications is the durability, which may be expressed as service life, i.c. number of years, or as cycle life, i.e. number of charge/discharge cycles. The durability is strongly influenced by both the stability of the electrode/electrolyte combination and the charge/discharge mechanism.

\subsubsection{Thermodynamic and kinetic stability}

Each electrolyte is characterized by a certain potential region, in which it is thermodynamically stable. If the potential of an electrode lies outside this region, the solution will be decomposed. Aqueous solutions arc stable within a potential range of $1.23 \mathrm{~V}$, the potential difference between the reversible oxygen and hydrogen electrodes. Generally, non-aqueous electrolyte solutions háve a wider existence range, but their ionic conductance is much lower. The relative positions of a number of battery electrodes in aqueous electrolytes are shown in fig. 2 .

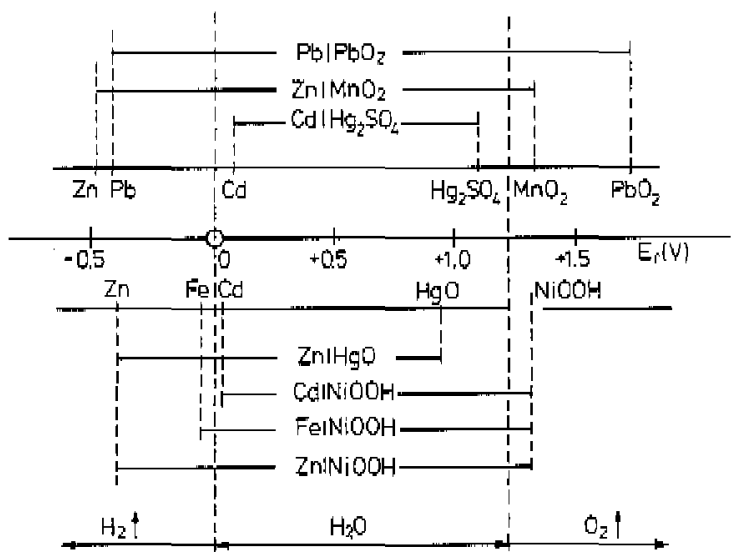

Fig. 2. The electrode potentiels of a number of electrodes with respect to the potcntial of the hydrogen clectrode in the same solution; dala from ref. 11. 
The only thermodynamically stable cell shown in this figure is the Weston cell, i.e. $\mathrm{Cd}(\mathrm{Hg}) \mid \mathrm{CdSO}_{4}$ (sat.) $\mid \mathrm{HgSO}_{4}$ (sat.) $\mid \mathrm{Hg}$. The open circuit potential of this standard cell is $1.01864 \mathrm{~V}$ at $20^{\circ} \mathrm{C}$ and both electrode potentials lie within the existcnce range of water.

Most galvanic cells are thermodynamically unstable and their reactants will therefore be consumed without generating electrical energy. This process is called self-discharge. The rates of these side reactions determine whether a cell may be considered kinetically stable or not. The zinc electrode potential is 0.4 to $0.5 \mathrm{~V}$ more negative than that of the hydrogen electrode. However, hydrogen gas evolution can be suppressed by the use of amalgamated zinc. Both electrodes of the lead-acid cell exceed the boundarics of the stability region severely and can thus react with the atqueous solution. Due to the large overpotentials required for the hydrogen and oxygen evolution reactions the self-discharge of new lead-acid cells is practically negligible. On the other hand, during cycling antimony, usually added to the positive electrodegrid, dissolvcs and is deposited at the active mass of both electrodes. This facilitates the evolution of hydrogen and oxygen considerably ${ }^{14}$ ). Several other impurities, e.g. $\mathrm{Co}, \mathrm{Fe}, \mathrm{Cu}, \mathrm{Ag}$, also catalyze the water decomposition reactions. Moreover, lead dioxide may react with the curren(-collecting grid (- lead), forming divaleril lcad conpounds. As a result, the stored capacity of the positive electrode decreases and its grid degrades. This leads to shedding of the active material. In a similar way, the separator in a silver-zinc ell becomes oxidized by the high electrode potential of the AgO/Ag ${ }_{2} \mathrm{O}$ couple $(+1.43 \mathrm{~V})$.

Another example illustrating the importance of thermodynamic stability is the difference between the widely used cadmium electrode and the less suitable iron electrode. The equilibrium potential of the cadmuium electrode is $+0.02 \mathrm{~V}$ versus the reversible hydrogen electrode and that of the iron electrode $-0.05 \mathrm{~V}$. Although the quantitative difference is small, this potential difference has a significant consequence: in the non-working state the iron electrode corrodes and the cadmium electrode is corrosion-resistant. Nevertheless, to a lesser extent hydrogen evolution also occurs at the cadmium electrode, particularly during charging at high rates and after ageing of the electrode.

The position of the $\mathrm{NiOOH}$ electrode potential at the potential axis, just exceeding the upper boundary of the stability region, results in oxygen evolution during charging and in rapid self-discharge of fully charged electrodes.

Thus, the lack of thermodynamic stability of galvanic cells causes a decrease of the coulombic efficiency of the electrodes and degradation of cell components sueh as the current collector and the separator. In gencral, the rates of the side reactions arc not nccessarily the same ar both electrodes and thus the reactants in the elcetrodes are unequally consumed. This will hinder further cycling of re* 
chargeable cells. Furthermore, maintenance of the cell is required by the loss of electrolyte and the evolved gases must be able to escape. This prohibits hermetical sealing of the cells.

\subsubsection{Charge/discharge mechanism}

A large group of electrodes in aqueous solutions is charged and discharged according to a dissolution-precipitation mechanism. This group comprises the following electrodes: $\mathrm{Pb}_{2} \mathrm{PbSO}_{4}, \mathrm{PbO}_{2} / \mathrm{PbSO}_{4}, \mathrm{Zn} / \mathrm{ZnO}, \mathrm{Fe} / \mathrm{Fe}(\mathrm{OH})_{2}$, $\mathrm{Cd} / \mathrm{Cd}(\mathrm{OH})_{2}, \mathrm{Ag} / \mathrm{Ag}_{2} \mathrm{O}$ and $\mathrm{Ag}{ }_{2} \mathrm{O} / \mathrm{AgO}$. The dissolution-precipitation mechanism involves the intermediate formation of a dissolved species, i.e. metal ion or metal ion complex, which precipitates from the solution to form a new solid phase. For instance, the discharge process of the lead dioxide electrode may be described by the equations ${ }^{11,14}$ ):

$$
\begin{aligned}
\mathrm{PbO}_{2}+4 \mathrm{H}^{+}+2 \mathrm{e}^{-} & \rightarrow \mathrm{Pb}^{2+}+2 \mathrm{H}_{2} \mathrm{O} \\
\mathrm{Pb}^{2+}+\mathrm{HSO}_{4}^{-} & \rightarrow \mathrm{PbSO}_{4} \downarrow+\mathrm{H}^{+},
\end{aligned}
$$

and in a similar way the charge process of a cadmium electrode in alkaline solu$\left.\operatorname{tion}^{11,18}\right)$ :

$$
\begin{gathered}
\mathrm{Cd}(\mathrm{OH})_{2}+2 \mathrm{OH}^{-} \rightarrow\left[\mathrm{Cd}(\mathrm{OH})_{4}\right]^{2-} \\
{\left[\mathrm{Cd}(\mathrm{OH})_{4}\right]^{2-}+2 \mathrm{e}^{-} \rightarrow \mathrm{Cd} \downarrow+4 \mathrm{OH}^{-} .}
\end{gathered}
$$

The electrolyte not only serves as an ionic conductor, but also participates in the electrode reactions, as is shown by these equations. The conductivity of the solution may therefore depend on the state of charge of the electrodes, as for example in tead-acid cells. Furthernore, the accessibility of the internal surface may be rate-determining.

Because of the low concentration of the dissolved metal ion species $\left(\mathrm{C}_{\mathrm{eq}}=\right.$ $10^{-4}-10^{-5}$ mole $\left.\cdot 1^{-1}\right)$ high surface areas and small diffusion paths are required in order to obtain reasonable charge/discharge rates. However, inherent in the dissolution-precipitation mechani\$m is the change that takes place in the porous structure of the electrodes during cycling as a result of redistribution of the active material. A notorious example is the shape change of the zinc electrode ${ }^{15}$ ). Generally, the major morphological changes involve:

- mucleation and growih of the new solid phase at the surface of the active material, already present:

- passivation, which consists of shielding the active material by a thin layer of dense fine-grained discharged material, e.g. the sulphation of lead and lead dioxide electrodes;

- recrystallization, especially after long waiting periods, which leads to the formation of larger grains and/or more stable modifications, e-g. memory effect of nickel-cadmium cells; 
- dendrite fomation, due to mass transport limitation, which may cause failure by internal short-circuiting.

Thus, the magrit ude of the active surface area and its accessibility are decreased during cycling. The detrimental cffects of the morphological changes increase strongly with the charge and discharge rates and with the depth of discharge. The cycle lite decreases exponentially with increasing depth of discharge ${ }^{17}$ ), Therefore, the optimal degree of active material utilization lies between 25 and $45^{1 \%}$ at medium rates, i.e. during discharge periods of 5 to 20 bours. At higher current densities, e.g. discharging in less than one hour, the utilization of active material is progressively reduced. Electrodes without soluble intermediates, such as the nickel (hydroxide) electrode, do not suffer such limitations.

The solid state transitions that take place in the nickel electrode can be sumnmarized by the Bodc diagram ${ }^{26}$ ):

$$
\begin{gathered}
\beta-\mathrm{Ni}(\mathrm{OH})_{2} \\
\uparrow d \\
\alpha-\mathrm{NiOOH}+\mathrm{H}^{+}+\mathrm{c}^{-} \\
\alpha-\mathrm{Ni}(\mathrm{OH})_{2} \\
\frac{b}{\rightleftarrows} y-\mathrm{NiOOH}+\mathrm{H}^{+}+e^{-} .
\end{gathered}
$$

Well-crystallized $\beta-\mathrm{Ni}(\mathrm{OH})_{2}$ has a layered structure with an interlayer distance of $4.605 \AA$ A. Each layer consists of a hexagonal planar arrangement of $\mathrm{Ni}(11)$ ions with an octahedral coordination of oxygen, three oxygen atoms lying above the nickel plane and threc lying below. The $\alpha$ - and $\beta$-nickel hydroxides, used in batteries, atso have a lamellar structure, but the erystal tattice is highly disordered. This low crystallinity is considered to be essertial for the clectroactivity. Moreover, the intersheet distance of the $\alpha$-modification is expanded by the intercalation of water molecules, $d=8-8.5 \hat{\mathrm{A}}$, which additionally inproves the kinetics of the redox reaction.

$\beta \mathrm{NiOOH}$ has practically the same layered structure, $d=4.85 \AA$, as $\beta-\mathrm{Ni}(\mathrm{OH})_{2}$ and can be formed from the latter by direct reaction on removing one proton and one elcetron, according to eq. (3a) $\gamma$-NiOOH represents a whole lamily of compounds exhibiting a large intersheet distance, $d \geqslant 7 \AA$, with the oxidation state of nickel ranging from +3.3 to +3.75 . Both water molecules and alkali ions are intercalated between the $\mathrm{NiO}_{2}$ layers.

If overcharging is avolded, the nickel electrode can be eycled betweer $\beta-\mathrm{Ni}(\mathrm{OH})_{2}$ and $\beta-\mathrm{NiOOH}$ (eq. $3 a$ ). During prolonged overcharging and at high charge rates $\beta-\mathrm{NiOOH}$ is converted into $\gamma-\mathrm{NiOOH}\langle\mathrm{cq} .3 c\rangle$, which possesses a larger storage capacity. Ageing of $\beta-\mathrm{NiOOH}$ also favours the formation of the more stable $\gamma$-modification. Because of the expanded intersheet distance of both $\alpha-\mathrm{Ni}(\mathrm{OH})_{2}$ and $\gamma-\mathrm{NiOOH}$, these substances can be directly interconverted, even at higher rates than the $\beta^{\mu} / \beta^{\mu \prime}$ transition. Due to the poor conductivity of divalent nickel hydroxide, $x$ is about $10^{-6} \Omega^{-1}+\mathrm{em}^{-1}$, the discharge 
process stops at an avcrage oxidation state of +2.3 . The complete active mass may be discharged to this level without affecting the cycle life. This enables an overdischarge mechanism, comprising very negative overpotentials (sec. 2.1.5). The $\alpha-$ to $\beta-\mathrm{Ni}(\mathrm{OH})_{2}$ transformation involves an increasing crystallinity upon ageing ( $\mathrm{eq} .3 d$ ).

The rates of the charge and discharge reactions are considered to be controlled by transport of protons and, possibly, of hydroxyl ions in the solid phase. The proton diffusion coefficients are reported to be $3.1 \times 10^{-10} \mathrm{~cm}^{2} \cdot \mathrm{s}^{-1}$ during charging, i.e. $D_{\mathrm{H}}+\left(\beta^{\mathrm{ul}}\right)$, and $4.6 \times 10^{-11} \mathrm{~cm}^{2} \cdot \mathrm{s}^{-1}$ during discharging, i.e. $\left.D_{\mathrm{H}^{+}}\left(\beta^{11}\right)^{17}\right)$. Therefore, diffusion of the intercalated protons only becontes rate-limiting at high discharge currents. Depending on the structure, the electrode may be discharged in less than half an hour.

The structural stability makes the solid state transition mechanism much more favourable than the more common dissolution-precipitation mechanism. This is demonstrated both by the remarkable cycling durability of several thousand cycles and the high rate charging and discharging capability of the nickel clectrode.

\subsubsection{Reactions in sealed cells}

The aim underlying the development of sealed cels is to obtain batteries that will operate in any position and without reguiring maintenance. The build-up of hazardous gas pressures, due to oxygen and hydrogen evolution (sec. 2.1.3), and the loss of electrolyte must therefore be prevented.

In nickel-cadmium cells this was achieved by adding uncharged ncgative electrode material, i.e. $\mathrm{Cd}(\mathrm{OH})_{2}$ to both electrodes, es is illustrated in fig. 3. At the

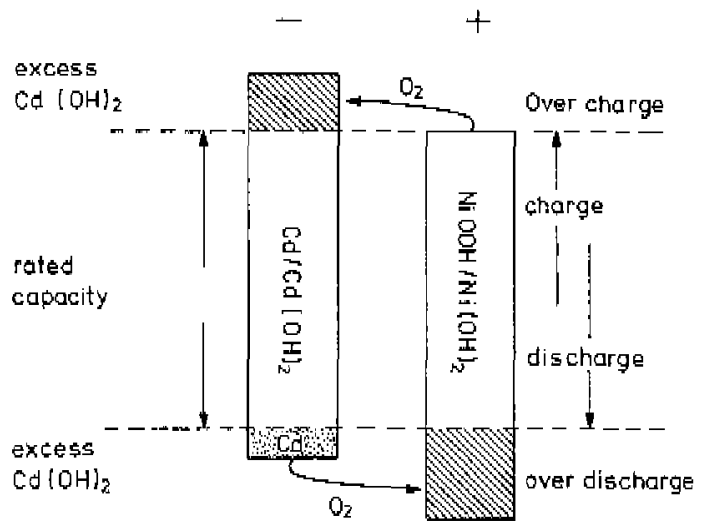

Fig. 3. Schematic diagram of a sçiçd niçkel-cadmium çcli, showing the electrode dimensions and the oxygen cycles during overcharging and overdischarging. 
end of charging oxygen is evolved at the positive electrode before the negative electrode is completely charged, because of the excess of active material in this clcetrode Subseguently, the oxygen formed is reduced at the negative electrode. In this oxygen recombination process the transport of oxygen is rate-determining. Therefore, the cell contains as little electrolyte as possible, wetted electrodes are used instead of flooded ones, and the $\mathrm{O}_{2}$-permeability of the wetted separator plays a major role. If the oxygen cycle functions well, the state of charge of both electrodes does not change during overcharging and the total input of electrical energy is dissipated as heat. In a similar way, the oxygen cvolved at the positive clectrode as a result of side reactions is consumed at the negalive electrode.

Owing to manufacturing variations, not all cells have exactly the same storage capacity, In at battery, comprising several cells connected in series, the weakest cell may therefore be overdischarged by the current which is imposed by the other cells. Without suitable precautions such an occurrence is accompanied by the decomposition of the electrolyte, while the cell voltage is reversed. However, the addition of $\mathrm{Cd}(\mathrm{OH})_{2}$ to the nickel electrode provents the cathodic evolution of hydrogen gas. Instcad, metallic cadmium is formed and this reacts with oxygen, now evolved at the cadmium electrode. (This electrode thus reaches its maximum depth of discharge!) Again the cell is protected by an oxygen recombination cycle.

Despite the excess of $\mathrm{Cd}(\mathrm{OH})_{2}$ in both electrodes and the thermodynamic stability of cadrium in aqueous electrolytes, hydrogen gas is evolved ${ }^{\text {18 }}$ ) due to the poor charge acceptance of aged $\mathrm{Cd}(\mathrm{OH})_{2}$ and during charging at high current densities. Because the oxidation of hydrogen at the nickel electrode is practically negligible, the electrode capacities become unbalanced and the cell pressure rises. Sealed eells are therefore equipped with safety valves which open at about 20 atm.

The development of entirely sealed lead-acid cells is severely hindered by the gassing of the electrodes (sec, 2, 1,3). Catalytic recombination of hydrogen and oxygen in the gas space above the clectrolyte is only successful if the gas evolution occur's stoichiometrically $\left(\mathrm{F}_{2}+\frac{1}{2} \mathrm{O}_{2}\right)$. The utilization of auxiliary clectrodes is not suitable for small cells. An oxygen cycle analogous to that in sealed nickel-cadmiun cells may also be establishcd in lead-acid cells, provided that the electrolyte is inmobilized ${ }^{14}$ ). However, the cycle life of such cells is reduced by the elcetrolyte immobilization to only $50-100$ cycles $^{11}$ ).

\subsubsection{Conciusions}

In our battery research, we aimed at a small rechargeable cell, which could be charged and discharged at high rates and would function in any position for several years without requiring maintenance. Tho small-sized, sealed nickel- 
cadmium cell resembles this type of cell most closely. However, for reasons given above the performance of the nickel-cadmium cell would be improved if the cadmium electrode could be replaced by a different rechargeable negative clectrode, in which the following requirements are fulfilled:

(a) charging and discharging occurs via a solid state transition mechanism, analogous to that of the nickel electrode, and

(b) hydrogen gas, possibly evolved during overdischarging, is prevented from unbalancing the cell or giving rise to hacardous pressures.

\subsection{Hydrogen in metals}

\subsubsection{Introduction}

Hydrogen reacts with elements from most groups of the periodic system to form hydrides. Well-known compounds are $\mathrm{LiH}, \mathrm{MgH}_{2}, \mathrm{AlH}_{3}, \mathrm{CH}_{4}, \mathrm{NH}_{3}$, $\mathrm{H}_{2} \mathrm{O}, \mathrm{HCl}$ and $\mathrm{PdH}_{x}$. Although the distinetion is not always sharp, these different binary hydrides are usually classified in three categories ${ }^{10}$ ):

- ionic or saline hydrides, e.g. $\mathrm{LiH}, \mathrm{MgH}_{2}$ and $\mathrm{HCl}$;

- covalent hydrides: the prototype is $\mathrm{CH}_{4}$, but $\mathrm{AlH}_{3}$ also belongs to this class;

- metallic hydridcs: this group comprises the hydrides formed by transition metals.

Our study is concerned with metallic hydrides. In particular, we are interested in metals which are capable of absoring and desorbing hydrogen reversibly in the pressure range around $l$ atm and near toom temperature.

At $20^{\circ} \mathrm{C}$ palladium, the most thoroughly investigated hydride-forming element, absorbs hydrogen at an equilibrium pressure of $6 \times 10^{-3} \mathrm{~atm}$ to form the hydride $\mathrm{PdH}, 6$. A review of the palladium-hydrogen system up to $1966 \mathrm{can}$ be found in the book by Lewis ${ }^{20}$ ). The hydrides of vanadium and niobium, $\mathrm{VH}_{2}$ and $\mathrm{NbH}_{2}$, decompose partially to $\mathrm{VH}$ and $\mathrm{NbH}$, respectively, near or somewhat above room temperature at $1 \mathrm{~atm}$. The hydrides of the metals of group IIIA and IVA, e.g. $\mathrm{YH}_{2}, \mathrm{LaH}_{3}, \mathrm{TiH}_{2}$ and $\mathrm{Zr}_{2}$, are extremely stable and therefore decompose only at very high temperatures. On the other hand, $\mathrm{Cr}, \mathrm{Mn}, \mathrm{Co}, \mathrm{Ni}$ and Mo only form hydrides at very high pressures, For example, $\mathrm{CrH}$ is stable at $25^{\circ} \mathrm{C}$ and 700 atm. Recently, extensive reviews of the binary hydrides of transition metals have been published ${ }^{21}$ ). Clearly, the number of suitable binary metal-hydrogen systems is severely limited by the requirement of reversibility at ambient temperatures and pressures.

The discovery of the hydriding properties of intermetallic compounds such as $\mathrm{LaNi}_{\mathrm{s}}{ }^{22},{ }^{28}$ ) and $\mathrm{TiFe}^{24}$ ) has provided many new metallic hydrides. Generally, intermetallic compounds of transition metals form ternary hydrides if at least one of their constituents forms a stable binary hydride. LaNi 5 is the exponent 
of a family of $A B_{s}$ compounds, cach number consisting of one or more lanthanide elements (A) and $3 d$ transition metal elements $(B)$. Most of these $A_{5}$ compounds are capable of storing reversibly large quantities of hyclrogen ${ }^{2 \mathrm{a}, 26}$ ).

A characteristic property of many hydrides is their relatively large hydrogen content ${ }^{27}$ ). In table 11 both the volumetric density and the weight fraction of

\section{TABLE II}

Comparison of the hydrogen content of various hydrogen compounds. $N_{\mathrm{H}}$ represents the number of hydrogen atoms per unit volume and $C_{H}$ gives the weight percentage of hydrogen in the various materials.

\begin{tabular}{l|c|c}
\multicolumn{3}{c}{ (alter ref, 27) } \\
\hline material & $N_{\mathrm{H}} \times 10^{-3 \mathrm{~m}}\left(\mathrm{~cm}^{-8}\right)$ & $C_{\mathrm{H}}(\mathrm{wt} \%)$ \\
\hline $\mathrm{H}_{2}$ gas, $150 \mathrm{~atm}$ & 0.7 & 100 \\
liquid $\mathrm{H}_{2}, 20 \mathrm{~K}$ & 4 & 100 \\
liquid $\mathrm{CH}_{4}$ & 6 & 25 \\
$\mathrm{TiH}_{2}$ & 9 & 4 \\
$\mathrm{LaH}_{3}$ & 6.5 & 2.1 \\
$\mathrm{MgH}_{2}$ & 6.5 & 7.6 \\
$\mathrm{TiFeH}_{2}$ & 6 & 1.9 \\
$\mathrm{LaNi}_{5} \mathrm{H}_{6}$ & 5.5 & 1.4 \\
\hline
\end{tabular}

hydrogen in representative metal hydrides are compared with those in liquid hydrogen and methane. The hydrogen density in these metal hydrides cxeceds that in liquid hydrogen by a lactor of 1.5 to 2 . The weight fraction of hydrogen in metal hydrides is always considerably lower than in liquid hydrogen because of the weight of the metallic host.

\subsubsection{Absorption and desorption phentoment}

The absorption and desorption of hydrogen by metals is most conveniently represented by pressure-composition isotherrns. A sehematic diagram of such isotherms is given in fig. 4, which comprises the following features.

A small amount of hydrogen ges dissolves in the original metallic host without forming a second phase:

$$
\mathrm{M}+\frac{1}{2} y \mathrm{H}_{3} \rightleftharpoons \mathrm{MH}_{y}
$$

The absorbed hydrogen atoms occupy interstitial sites in the metal lattice and their concentration depends strongly on the hydrogen pressure. This hydrogenpoor solid solution is denoted by the $\alpha$-phase. The next stage involves the absorption of hydrogen after the solid solution is saturated:

$$
\mathbf{M H}_{j}+\frac{1}{2}(x-y) \mathrm{H}_{2} \rightleftarrows \mathrm{MH}_{x} \text {. }
$$




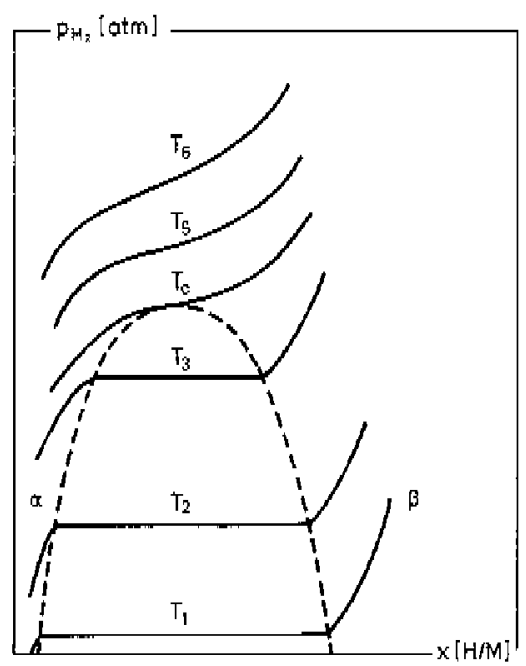

Fig. 4. Schematic phase diagram of a metal-hydrogen system, comprising the pressurc-composition isotherms at various temperatures; $T_{r}: T_{x-1}$.

Now, a new solid phase, referred to as the $\beta$-phase, nucleates and grows. This is accompanied by a discontinuous change in the lattice parameters. Ideally, during the $\alpha / \beta$-phase transition the equilibrium pressure remains constant according to Gibbs' phase rule: $F=C-P+2$. Two components $C\left(\mathrm{H}_{2}\right.$ and $\left.\mathrm{M}\right)$ and three phases $P$ (two solid and one gaseous) are present, so the number of degrees of freedon $F$ is one. Thus, at a given temperature the pressure is fixed. This constant pressure level is often called the plateau pressure. Even if the host metal consists of an intermetallic compound, in this context, it is considered to be only one component because of the immobility of its constituents at low temperatures. The concentration region between the saturated solid solution $\alpha_{s}$ and the newly formed $\beta$-phase $\beta_{0}$ can be regarded as a miscibility gap between two well-defined phases.

After the $\alpha$-phase has been completely converted into the $\beta$-phase, further increase of the hydrogen concentration in the metal is accompanied by an increasing equilibrium pressure. Similar to the hydrogen dissolution in the 'empty' host, i.e. the $\alpha$-phase, hydrogen dissolves in the hydrided $\beta$-phasc.

At higher temperatures the influence of the entropy counteracts the tendency to form two separate phases. As a consequence, the miscibility gap becomes smaller with rising temperature and uItimately disappears at the critical temperature $T_{\varphi}$. 


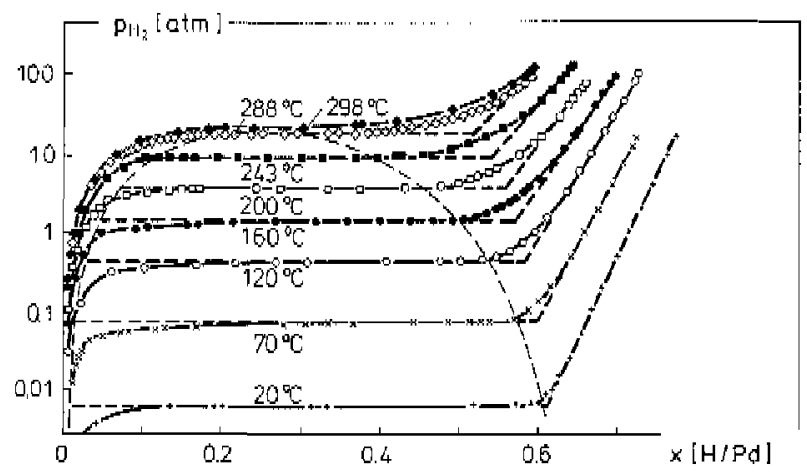

litg. 5. Phase diugram lor the palladium-hydrogen systern; from ref, 28.

As an example of a very precisely determined phase diagram, the isotherms for the palladium-hydrogen system ${ }^{26}$ ) are shown in fig. 5. The analogy between the schematic diagram of fig. 4 and that of the real system is obvious. The platcau pressures increase with increasing temperature according to the relation of Van 't. Hoff:

$$
\ln p_{\mathrm{H}_{2}}=\frac{\Delta H_{\alpha / R}^{\circ}}{R T}-\frac{\Delta S_{Q_{j} / R}^{\circ}}{R}
$$

where $R$ is the gas constart and $\Delta H^{\circ}$ and $\Delta S^{\circ}$ are the enthalpy and entropy change per mole $\mathrm{H}_{z}$, respectively. Applying this equation to the data of fig. 5

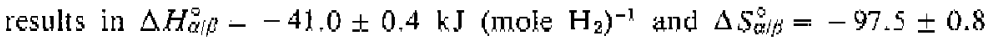
$\mathrm{J}\left(\mathrm{K} \text {-mole } \mathrm{H}_{2}\right)^{-1}$ for the palladiun-hydroger system in the temperature range from $2010300^{\circ} \mathrm{C}$. The position of the critical point has also been determined with high precision: $T_{\mathrm{s}}-291+2{ }^{\circ} \mathrm{C}, x_{\mathrm{c}}-0.250 \perp 0.005 \mathrm{H} / \mathrm{Pd}$ and $p_{\mathrm{s}}=$ $19.7+0.2 \mathrm{~atm}$.

Several hydrogen-absorbing materials, e.g. 'TiFe and $\mathrm{LaCo}_{i}$, form more than onc ordercd hydride phasc. In the metal-hydrogen phase diagram the second hydride phase shows up as an additional plateau in the pressure-composition isotherms. Fig. 6 displays the isotherms for the $\mathrm{TiFe}-\mathrm{H}_{2}$ system ${ }^{24}$ ) which illustrate this phenomenon. Furthermore, it is seen that both hydrides, i.e. TiFeH and $\mathrm{TiFeH}_{2}$, have dissociation pressures of more than 1 atm at $0^{\circ} \mathrm{C}$. The critical temperature of the $\mathrm{TiFeH}-\mathrm{TiFeH}_{2}$ two-phase region is approximately $60^{\circ} \mathrm{C}$. This explains the disappearing second platean in the isothcrms with increasing temperature. 


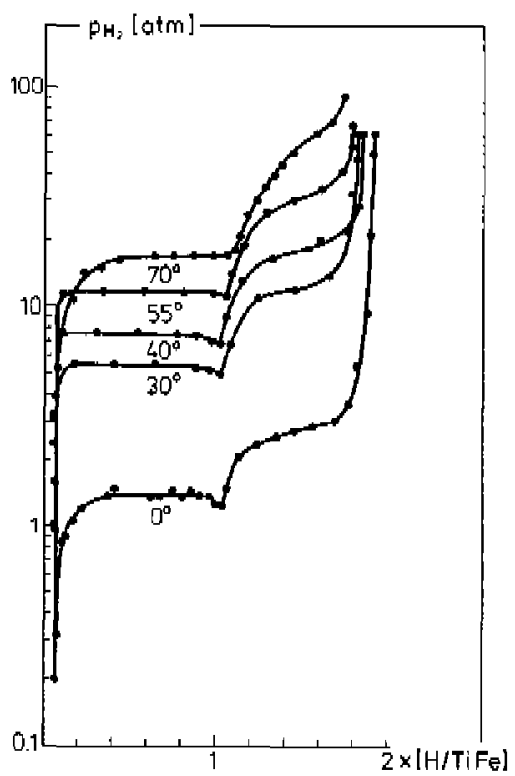

Fig. 6. Desorption isotherms for the Tire- $\mathrm{H}_{3}$ system at various temperatures; from raf. 24 .

The isotherms presented in both fig. 5 and fig. 6 have been determined during the desorption of hydrogen. For most materials the absorption process takes place at higher plateau pressures than those at which hydrogen is released. This hysteresis is not caused by a lack of equilibriurn. Instead, most investigators have related this effect to the volume expansion during hydriding. The hysteresis in the absorption/desorption isotherms for $\mathrm{TiFe}-\mathrm{H}_{2}$ is rather large. For example, at $40^{\circ} \mathrm{C}$ the first hydride phase $\mathrm{TiFeH}$ is formed at the equilibrium pressure of 15 atm, while the desorption pressure is only $7.5 \mathrm{~atm}$. In practical applications, rapid hydrogen uptake is obtained by an applicd pressure of 30 atron at $20^{\circ} \mathrm{C}$.

The absorption and desorption isotherms for $\mathrm{LANi}_{5}-\mathrm{H}_{2}$ at 20,40 and $80^{\circ} \mathrm{C}$ are shown in fig. 7. At $20^{\circ} \mathrm{C} \mathrm{LaNi}$ absorbs six hydrogen atoms at a plateau pressure of $2 \mathrm{~atm}$, while the hydride formed decomposes at a constant pressure of $1.6 \mathrm{~atm}$. The absorption/desorption hysteresis of the $\mathrm{LaNi},-\mathrm{H}_{2}$ system is characterized by a nearly constant $\Delta p / p$-ratio for different temperatures. How ever, the pressure difference is only 3 atm at $80^{\circ} \mathrm{C}$. Moreover, even at temperatures as high as $80^{\circ} \mathrm{C}$, large amounts of hydrogen can be stored reversibly in 


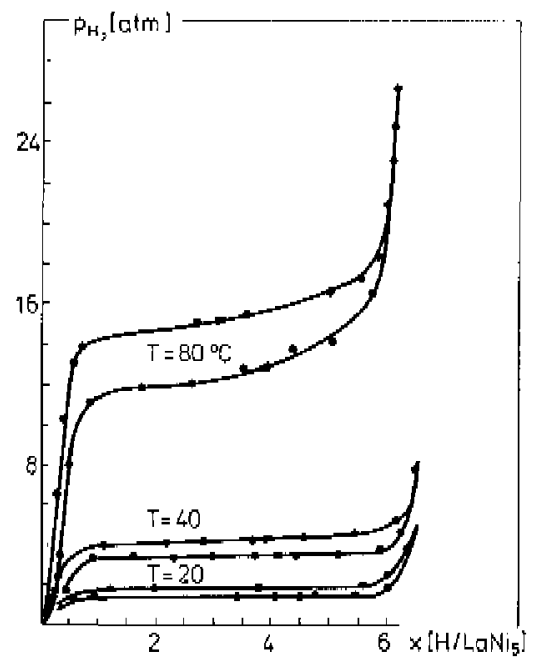

Fig. 7. Absorption and desorption jsorherms for LaNi $\mathrm{I}_{5}-\mathrm{H}_{2}$ at 20,40 and $80{ }^{\circ} \mathrm{C}$, from reC. 26.

$\mathrm{LaNi}_{0}$ at equilibrium pressures below $20 \mathrm{~atm}$. The reaction rates at room temperature for both absorption and desorption are very high for pulverized $\mathrm{LaNi}{ }_{5}$. Van Vucht et al. ${ }^{23}$ ) measured the rate of hydrogen desorption in 1 atm of hydrogen gas at different temperatures. At $25^{\circ} \mathrm{C}$ the complete desorption took only $15 \mathrm{~min}$, while the underpressure was less than 1 atm.

The values of the enthalpy and entropy change for the $\alpha / \beta$-transition of $\mathrm{LaNi} \mathrm{Ni}_{3}-\mathrm{H}_{2}$, derived from the pressure-composition isotherms according to eq. (6), are $-31 \mathrm{~kJ}\left(\text { mole } \mathrm{H}_{2}\right)^{-1}$ and $-109 . \mathrm{I}\left(\mathrm{K}^{\prime} \text { mole } \mathrm{H}_{4}\right)^{-1}$, respectively. Almost the same values have been determined from calorimetric measurements $\left.{ }^{29}\right\rangle$ :

$$
\begin{aligned}
& \Delta H_{i / f}^{\circ}(298.15 \mathrm{~K})=-30.40 \pm 0.35 \mathrm{~kJ}\left(\text { mole H}_{2}\right)^{-1} \text { and } \\
& \Delta S_{\text {sif }}^{\mathrm{e}}(298.15 \mathrm{~K})=\cdots 111.5 \pm 0.5 \mathrm{~J}\left(\mathrm{~K} \cdot \text { mole }_{2}\right)^{-1} \text {. }
\end{aligned}
$$

\subsubsection{Stability of metal hydrides}

The purpose of this subsection is not to discuss the resistance of metal hydrides to corrosion, but rather to present some statements concerning the affinity of intermetallic compounds for hydrogen.

As already mentioned in sec. 2.2.1, transition metal compounds that form stable hydrides contain at least one metal that forms stable binary hydrides. Evidently, the stability is rclated to the free enthalpy change. For the various hydride-forming materials, the values of $\Delta H_{\alpha, \beta}^{\circ}$ can be widely different. On the 
other hand, the entropy effect is found to be fairly independent of the host metal. The reason is that the entropy change during hydrogen absorption is dominatcd by the loss of the entropy of hydrogern gas; the standard value $S_{\mathrm{H}_{2}}^{\circ}=130 \mathrm{~J}\left(\mathrm{~K} \cdot \mathrm{mole}_{2}\right)^{-1}$ at 1 atm and room temperature. The other entropy effects are relatively small compared with this term. This makes it possible to express the affinity of metals for hydrogen in terms of $\Delta H_{\alpha / \beta}^{\alpha}$ alone. If we assume $\Delta S_{\alpha / \beta}^{o}=-110 \mathrm{~J}\left(\mathrm{~K} \text { mole } \mathrm{H}_{z}\right)^{-1}$ and define a stable hydride as one for which the plateau pressure lies below 1 atm at $300 \mathrm{~K}$, a stable hydride is characterized by a formation enthalpy more negative than $-33 \mathrm{~kJ}$ (mole $\mathrm{H}_{2}$ ) ${ }^{-1}$. Sriall variations in $\Delta H_{\text {ort }}^{\circ}$ cause large shifts in the plateau pressures.

Miedema et al. formulated an empirical relation for estimating the hydride formation enthalpy of intermetallic $\mathrm{AB}_{n}$ compounds $\left.(n \geqslant 1)^{2 \mathrm{~B}, 27}\right)$

$$
\Delta H\left(\mathrm{AB}_{n} \mathrm{H}_{x+\gamma}\right)=\Delta H\left(\mathrm{AH}_{x}\right)+\dot{\Delta} H\left(\mathrm{~B}_{n} \mathrm{H}_{y}\right) \cdots(1 \cdots F) \cdot \Delta H\left(\mathrm{AB}_{n}\right) .
$$

The values of $x, y$ and $F$ vary smoothly with the composition of the intermetallic compound, i.e. with the value of $n$. These values are tabulated ${ }^{17}$ ). Equation (7) indicates that the stability of the ternary hydride $\mathrm{AB}_{n} \mathrm{H}_{x+y}$ increases with decreasing stability of the intermetallic compound $\mathrm{AB}_{n}$. This is known as the rule of reversed stability. With the help of eq. (7) the plateau pressure of an intermetallic compound can be adjusted by an appropriate choice of its constituents. For instance, at $40^{\circ} \mathrm{C}$ the desorption pressure for $\mathrm{LaNi}_{5} \mathrm{H}_{6}$ is $3 \mathrm{~atm}$ and for $\mathrm{LaNi}_{4} \mathrm{CuH}_{5.8}$ it is $1.5 \mathrm{~atm}^{30}$ ). The plateau pressure of $\mathrm{LaNi}_{4} \mathrm{M}-\mathrm{H}_{2}$ decreases progressively as $\mathrm{M}$ represents suceessively $\mathrm{Pd}, \mathrm{Ni}, \mathrm{Ag}, \mathrm{Cu}, \mathrm{Co}, \mathrm{Fe}, \mathrm{Cr}, \mathrm{Al}$ or Mn. Similarly, an increase of the plateau pressure has been found if La in $\mathrm{LaNi}_{5}$ is (partially) replaced by $\mathrm{Nd}, \mathrm{Gd}, \mathrm{Y}$ or $\mathrm{Er}$.

\subsubsection{Conclusions}

The number of metal-hydrogen systems has been markedly increased by the discovery of the hydriding properties of intermetalic compounds. Large amounts of hydrogen can be reversibly stored at pressures around 1 atm near room temperature. The volumetric hydrogen density often exceeds the hydrogen content in liquidi hydrogen.

Moreover, the insight gained into intermetallic compound-hydrogen systems enables us to match the properties to the specific requirements. Many applications have been suggested $\left.{ }^{21,26,31,32}\right\}$. Among these is the utilization of metal hydrides in rechargeable batteries ${ }^{39-86}$ ).

\subsection{Metal hydride electrodes}

\subsubsection{Concept}

At the end of sec. 2.1, we formulated the need for a negative battery electrode which can be charged and discharged via a solid state transition mechanism and 
is capable of coping with evolved hydrogen gas. In the previous section, it was concluded that many intermetallic compounds with interesting hydriding properties are available. The synthesis of these two conclusions leads to the concept of a rechargeable battery clcetrode based upon the electrochemical storage of hydrogen in intermetallic compounds. Such an electrode will be denoted as a metal hydride electrode.

Charging of a metal hydride electrode consists of the electrochemical reduction of water at the metal surface, resulting in the formation of adsorbed hydrogen atoms. Subsequently, these hydrogen atoms diffuse into the bulk of the host metal to form a metal hydride. Discharging of such an electrode consists of dehydriding, followed by oxidation of the released hydrogen atoms. Inherent in metal hydrides both the host and the hydride ate good electronic conductors. Thus charging and discharging proceeds according to

- a charge transfer reaction

$$
\mathrm{M}+\mathrm{H}_{2} \mathrm{O} \text { 列 } \mathrm{e}^{-} \rightleftarrows \mathrm{M}-\mathrm{H}_{\mathrm{uds}}+\mathrm{OH}^{-},
$$

- dissolution and diffusion in the solid state

$$
y \mathrm{M} \cdot \mathrm{H}_{\mathrm{a}: \mathrm{s}} \rightarrow \mathrm{MH}_{y},
$$

- and recrystallization of the condensed phase

$$
\frac{x}{y} \mathrm{MH}_{y} \rightleftharpoons \mathrm{MH}_{x}
$$

The complete electrods reaction can be described by

$$
\mathrm{M}+\mathrm{xH}_{2} \mathrm{O}+x \mathrm{e}^{-} \rightleftarrows \mathrm{MH}_{x}+x \mathrm{OH}^{-} \text {. }
$$

As is shown by these equations, the electrochemical storage capacity is proportional to the hydrogen content of the metal hydride and the electrode potential is close to that of the reversible hydrogen electrode. Decomposition of the aqueous clectrolyte is no longer an unwanted side reaction but is an essential step in the charging process. Moreover, evolved hydrogen gas can be expected to be absorbed or oxidized by the hydride electrode.

\subsubsection{Electrochemical pressure-composition isotherms}

The hydrogen absorption and desorption characteristics of metals are represented by pressurc-composition isotherms. Analogous plots for battery electrodes ate charge/discharge curves. These plots show the variations of the electrode potential $E$ as a function of the state of charge $Q$.

The equilibrium potential of the hydride clectrode, i.e. of the redox couple of eq. (9), is related to the equilibrium pressure for the absorption and desorption of hydrogen gas. With the help of the electrochemical cell in fig, 8 , this relation 


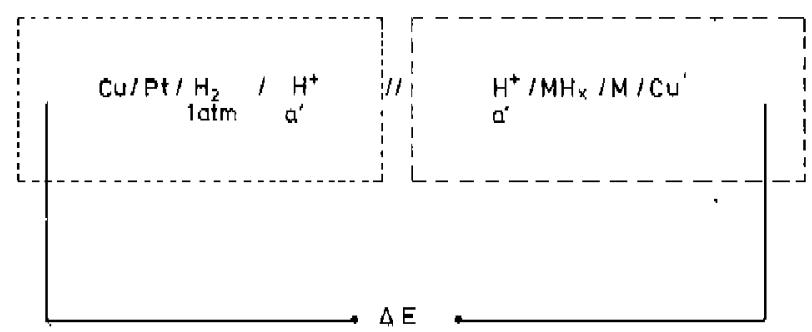

Fig. 8. Electrochenical cell, containing a metal hydride electrode (right) and a reversible hydrogen electrode (left).

is readily derived. The hypothetical cell of fig. 8 comprises a metal hydride electrode and a reversible hydrogen electrode, both immersed in the same aqueous electrolyte with $a_{\mathrm{H}^{*}}=a^{\prime}$. The cell voltage $\Delta E$ thus equals the required equilibrium potential $E_{\mathrm{r}}$ with regard to the reversible hydrogen electrode potential RHE. The cell reaction can be written as

$$
\mathrm{M}+\frac{1}{2} x \mathrm{H}_{2}(1 \text { atm })+x \mathrm{e}^{-}\left(C \mathrm{u}^{\prime}\right) \rightleftharpoons \mathrm{MH}_{x}+x \mathrm{e}^{-}(\mathrm{Cu})
$$

At equilibrium, one obtains:

$$
-x F \Delta E=\mu_{M \mathrm{H}_{x}} m \mu_{\mathrm{M}}-\frac{1}{2} x \mu_{\mathrm{H}_{\xi}}^{\circ},
$$

where $F$ is the Faraday constant and $\mu_{i}$ is the chemical potential of component $i$. Recognizing that the right-hand side of eq. (11) equals the free enthalpy change of the hydriding reaction at 1 atm and using $\Delta E=E_{\tau}$ vs. RHE, we obtain

$$
E_{:}=\frac{-R T}{2 F} \ln p_{H_{2}} v s . \text { RHE, }
$$

or at $\mathrm{T}=25^{\circ} \mathrm{C}$ :

$$
E_{\mathrm{r}}=-0.0296 \log p_{\mathrm{H}_{\mathrm{g}}} \mathrm{vs} . \mathrm{RHE} .
$$

Thus, at a hydrogen equilibrium pressure of 1 atm the metal hydride electrode potential is the same as that of the RHE, and its value changes by approximately $30 \mathrm{mV}$ for a ten-fold hydrogen pressure variation.

Furthermore, eq. (9) indicates that each absorbed hydrogen atom corresponds to the storage of one clectron. Consegunently, the state of charge $Q$ varies lincarly with the $H / M$ ratio $x$. For $\mathrm{LaNi}_{5}$, the relation $Q=62 . x \mathrm{mAh}-\mathrm{g}^{-\mathrm{t}}$ holds, as will be explained in sec. 3.2.2.

As an example, fig. 9 shows a charge and a discharge isotherm for $\mathrm{LaNi}_{5}$ at $16^{\circ} \mathrm{C}$ in $6 \mathrm{M} \mathrm{KOH}$. We determined these 'equilibrium' curves by imposing 


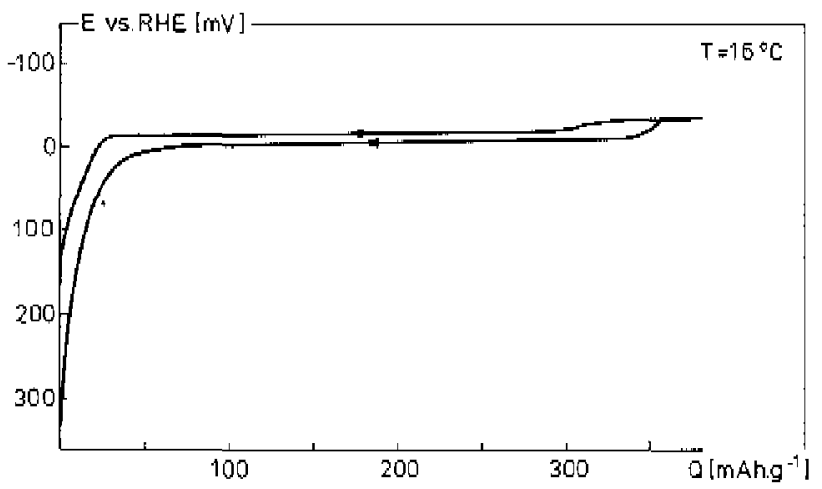

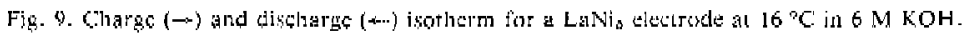

$100 \mathrm{~ms}$ current pulses and measuring $E_{\mathrm{r}}$ at the end of a relaxation period of $800 \mathrm{~ms}$. The amount of tharge passed during each pulse corresponded to only $8.33 \times 10^{-5} \mathrm{H} / \mathrm{LaNi}_{5}$. Comparison of figs 7 and 9 demonstrates the analogy and shows that LaNis is also capable of storing and releasing hydrogen clectrochemically. The corresponding theoretical storage capacity of a LaNi $i_{5}$ clectrode amounts to $372 \mathrm{mAn} \cdot \mathrm{g}^{-1}$, which is almost the same as the value for the cadmium electrode, i.e. $366 \mathrm{mAh} \cdot \mathrm{g}^{-1}$.

\subsubsection{Conchisions}

The utilization of intermetallic compounds as active materials in battcry elcetrodes provides a new type of rechargeable electrode: the hydride electrode. Such an electrode opcrates at potentials close to that of the reversibie hydrogen clcetrode. The charge and discharge process involves the reversible storage of large amounts of hydrogen in the metallic host. All reactions proceed in the condensed phase; no soluble intermcdiales are involved.

Soveral internctallic compounds have been studied for use in metal hydride clectrodes, c.g. (TiNi $\left.{ }^{3}\right)$, Tire ${ }^{34}$ ) and $\mathrm{LaNi}^{35}$ ). In our view, LaNi ${ }_{5}$ and related $\mathrm{AB}_{5}$ compounds are the most auspicious materials for electrochemical applications. These internetallic compounds combine a large reversible storage capacity at plateau pressures of approximately 1 atm at $20^{\circ} \mathrm{C}$ with high reaction rates and small absorption/desorption hysteresis. Moreover, LaNis is easily modifed by partial substitution to provide similar compounds with more favourable propertics. 


\section{REFERENCES}

') A. Volta, Phil. Trans, Roy, Soc, 90, 40,3 (1800).

i) G. Planis, Compt. Rend. Acad. Sci. 50,640 (1860).

3) W, Jungtaer, Swedish Patent 10,177 (1899).

4) T. de Michalowski, British Patent 15,370 (1899); German Patcnt 112,351 (1899).

s) W, Jungner, Swedish Paterle 15,567 (1901); Gcrman Patent 163,170 (1901).

4) T. A. Edison, German Patest 157,290 (1901); U.S. Paten 678,722 (1901).

7 T. A. Edison, U.S. Fatent 692,507 (1902).

8) G, Vianl, Storage Butteries, 4lh edicion, John Wilcy, Nçw York (1955).

*) S. U. Falk and A. J, Salkind, Alkaline Storage Balteries, John Wiley, Nçw York (1969).

10) H. Bode, Lead-Acid Battcrics, Johr: Wiley, New Yotk (1977).

11) V. S. Bapotzky and A. M. Skundin, Chemical Power Souress, Açademic Press, London (1980).

12) Comprehcnsive Treatise of Electiochemistry 3: Elcctrochemicat Energy Conversion and Storage, J, O'M. Bock ris et al. (eds.). Plenum Prsss, New York (1981).

13) Plocectings of the International Power Sources Symposium, held in Btighton (U.K.) every two ycars from 1962 .

14) P. Ructsehi, J. Power Sources 2, $3(1977 / 78)$.

18) J. L. H. M. Hendrikx. Thesis, Teqhniced Univcrsity, Einuhoven (1984),

w) P. Oliva et al., J. Power Sources 8, 229 (1982).

17) D. M. MecArthur. J. Electrocham, Soc, 117, 729 (1970); Power Solrces 3 , D. H. Colling (ed.), Oricl Press, Newcástle upon Tyne, 91 (1971).

18) J. Mrha, M. Musilova and J. Jindra, J, Power Sources 8, 403 (1982).

15 G. G. Libowitz, Inorganic Chernistry Series, Buttorworths, London (1972).

*) F. A. Lewis, Palladium-Hydrogen System, Açad. Press, London (1967).

2) G. Alefeld and J, Völk] (cd8.), Hydrogen in Metals I and II; Topics in Applied Physics 28 and 29, Springer-Verlag, Berlin (1978).

${ }^{21}$ H. Zijlutra and F. F. Westendorp, Solit Statc Conm. 7, 857 (1969).

23) J. H. N. yan Vucht, F. A. Kuijpers and H. A. G. M. Bruning, Philips Res, Repts, 25, 133 (1970).

34) J. J, Reilly and R. H. Wiswall, Inorg. Chem. 13, 218 (1974)

25) F, A. Kuij per5, Thesis, Universily of Technology, Delft (1973); also: Philips Res. Repts.. Suppl., No. 2 (1973).

27) H. H. van Mal, Thesis, Universicy of Technology, Delft (1976); also: Philipi Res. Repts. Suppl., No. ] (1976).

${ }^{27)}$ K.H. J. Buschow. F, C. P. Bouten and A. R. Micdema, Rep. Prog. Phys. 45, 937 (1982),

${ }^{28} \mathrm{H}$. Frieske and E. Wicke, Ber. Bunsenges. physik. Chem. 77,48 (1973).

29) D. Ohlendorf and H. E, Flotow, J. Chem. Phys. 73, 2937 (1980).

30) $\mathrm{H}, \mathrm{H}$. van Mal, K. H. J. Buschow and $\mathrm{A}$. R. Miedema, J. Less-Common Met. 35, 65 (1974).

31) H. Buchner, Proc. Int. Seminar Thermochemicel Energy Storage, Stokkolm, 151 (1980).

37) H. Wenzl, Int. Metall Rev. 27, 140 (1982).

43) E. W. Justi ti al., Energy Conversion 10, $183(1970)$.

s4) M. A. Guijahr, H, Buchner, K. D. Beceu and H. Säufferer, Power Sources 4, D. H. Collins (cd,), Oricl Pacss, Newcastle upon Tyne, 79 (1973).

as) P. A. Boter, German Offenlegungsschrift 2535091 (1976).

34) H. F. Bittner and C. C. Badeosk, J. Electrochem. Soc. 130, 193C (1983). 


\section{LANi AND LaNi $\mathrm{Au}_{4} \mathrm{CLECTRODES}$}

\subsection{Introduction}

The application of metal hydride electrodes in electrochemical cells involves the use of hydrogen as fuel, which is stored in the hydrogen-absorbing electrode. At the surface of such an electrode, hydrogen is formed by the electrochemical reduction of water, or stored hydrogen is oxidizęl

$$
\mathrm{M}+\mathrm{xH}_{2} \mathrm{O}+x \mathrm{e}^{-} \rightleftarrows \mathrm{MH}_{x}+x \mathrm{OH}^{-} \text {. }
$$

Thus, both aspects, hydrogen storage (bulk) and electrocatalytic properties (surface), play an important role in the choice of appropriate electrode materials. Morcover, chemical stability of the hydridc-forming compound in aqueous clectrolytes is an essential feature in attaining practical, rechargeable electrodes.

The possibility of rapid and reversible storage of large amounts of hydrogen gas in $\mathrm{LaNi}_{\mathrm{g}}$ at a plateau-pressure of about 2 atm at roora teraperature makes this intermetalic compound an attractive material ${ }^{1-4}$ ). Several investigators have also reported on the capability of $\mathrm{LaNi}_{5}$ to store and release hydrogen electrochemically ${ }^{5-8}$ ).

Ewe et al. ${ }^{8}$ ) found that the electrochemically determined storage capacity of LaNis is about half that calculated from the liniting composition $\mathrm{LaNi}_{5} \mathrm{H}_{6}$ and attributed this observation to a different method of preparation or pretreatment. In our view, this might be due to hot-pressing $\left(350^{\circ} \mathrm{C}\right)$ of the electrode peliets. Moreover, they concluded that the compound LaNis is resistant to corrosion in $6 \mathrm{M} \mathrm{KOH}$.

Boter ${ }^{6}$ ) constructed rechargeable cells, the negative electrode of which consisted of $\mathrm{L}_{\mathrm{aNN}} \mathrm{N}_{5}$ or one of the pseudo-binary derivates of this compound. An electrode made from $\mathrm{LaNi}_{1} \mathrm{Cu}$ proved to be especially suitable because of its lower plateatu pressure, i.e. $p_{\mathrm{H}_{3}}<1$ atm at room temperature, and its capability of high-rate charging and discharging.

The temperature dependence of the storage capacity of LaNi ${ }_{5}$-based electrodes in unsealed cells was studied by Bronoel et al. ${ }^{9}$ ). The electrochemically measured capacity values decreased with increased temperature as a result of a growing amount of hydrogen lost by spontancous hydrogen gas desorption. At $20^{\circ} \mathrm{C}$ the storage capacity of $\mathrm{LaNi}_{6}$ was found to be $320 \mathrm{mAh} \cdot \mathrm{g}^{-1}$, which is $85 \%$ of the theoretical value. In order to reduce hydrogen gas desorption in open celis, Percheron-Guegan ${ }^{10}$ ) et al. also used substituted LaN $\mathrm{i}_{5}$ compounds. They stated that electrodes made from these materials could undergo a great number of charge/dischargc cycles without change of their performance $\left(300 \mathrm{mAh} \cdot \mathrm{g}^{-1}\right.$ at temperatures between -10 and $50^{\circ} \mathrm{C}$ ) 
Van Rijswick ${ }^{\text {) }}$ concluded that the choice of intermetalics is severely limited by the required stability in contact with aqueous electrolytes. Only compounds in which the major component is thermodynamically stable against oxidation, i.e nickel and the noble metals, are suitable as metal hydride clectrodes.

The maximum storage capacity of the LaVis electrodes, studied by Markin et al. ${ }^{11-13}$ ) for application in satellite batteries, amounted to $240 \mathrm{mAh} \cdot \mathrm{g}^{-1}$. They also observed a loss of capacity during charge/discharge cycling in $6 \mathrm{M} \mathrm{KOH}$, which they attributed entirely to the presence of oxygen in the cell. On the other hand, Holleck et al. ${ }^{14}$ ) reported a continuous decrease of the storage capacity of $\mathrm{LaNi}_{6}$ due to the presence of water vapour. This instability of the storage material in the cell environment limits the cycle-life of a battery.

Despite all these conflicting results regarding the stability of hydriding materials in aqueous media, Bittner and Badcock ${ }^{\perp 5}$ ) concluded in their recent review article that $\mathrm{LaNi}_{s}$ appears to be the most promising material for electrochemical utilization studied to date.

We investigated $\mathrm{LaNi}_{5}$ and $\mathrm{LaNi}_{4}$ Cu electrodes with special emphasis on their behaviour during repeated cycling. The electrochemical performance of these electrodes is discussed in sec. 3.2. The observed capacity loss is analysed with the help of X-ray diffraction, surface arca measurements and electron microscopy, presented in secs $3.3,3.4$ and 3.5 , respectivcly. In sec. 3.6 the first conclusions are summarized.

\subsection{Galvanostatic charge/discharge cycling}

\subsubsection{Sample preparation and measuring equipment}

All intermetallic compounds used were prepared by melting a mixture of the composing elements in an arc furnace under an argon atmosphere (20 torr). To obtain better homogenization the samples were turned over and remelted several times. More details of the preparation procedure have been described by Var $\mathrm{Mal}^{4}$ ). All compounds were examincd by $\mathrm{X}$-ray powder diffraction in order to identify the structural parameters and to verify that no second phase was present.

Metal powder was obtained either by crushing and grinding mechanically or by repeated hydrogen gas absorption/desorption cycles. The specific surface area of this powder was determined by krypton gas adsorption measurements (BET), described in sec. 3.4. After pulverization only the fraction that passed through a $40 \mu \mathrm{m}$ sieve was used as active electrode material. Both the cast and the powder of intermetallic compounds were handled in ambient atmosphere without special precautions.

The electrodes were made by mixing active particles with fine copper powder (Merck p.a. electrolytic Cu) and cold-pressing this mixture to a porous pellet. 
The pellets were $8.0 \mathrm{~mm}$ in diancter (geometrical area $0.50 \mathrm{~cm}^{2}$ ) and about $0.5 \mathrm{~mm}$ thick, their total weight was approxinately $150 \mathrm{mg}$, so the void volume was about $30 \%$. Varying the weight ratio active matcrial/supporting copper powder between $1: 9$ and $1: 2$ and the applied pressure between 0.4 and $4.0 \times 10^{8} \mathrm{~Pa}$ did not inlfuence the electrode performance significantly. Only the heavily loaded samples weredeformed from flat to hemispherical after many charge/discharge cycles. Most pellets contained about $30 \mathrm{mg}$ active material and were pressed at a pressurc of $4.0 \times 10^{8} \mathrm{~Pa}$.

For the electrochcmical measurements a pellet was attached to a copper rod $(\omega=8.0 \mathrm{~mm})$ by a shrink-slecve and placed in a glass cell, as illustrated in fig. 10 .

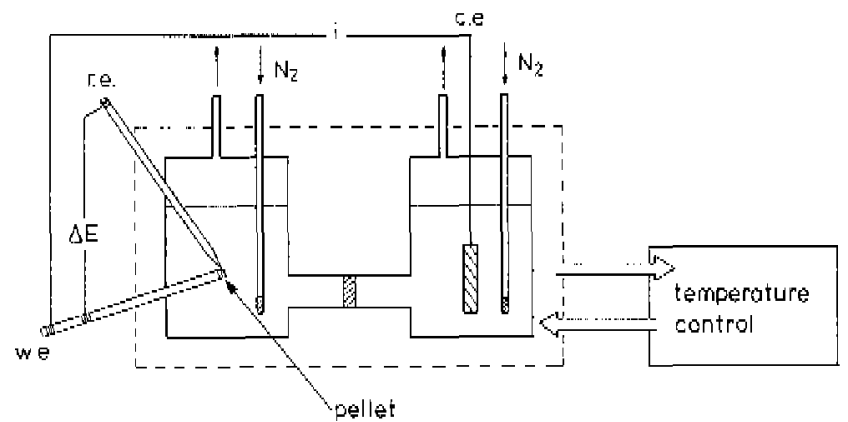

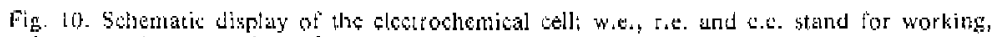

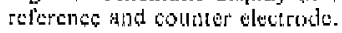

The cell comprised two compartments separated by porous glass ceramic and both were purged with nitrogen. The cell was surrounded by a water jacket to control the temperature mostly at $25^{\circ} \mathrm{C}$. As counter and reference electrode wo used, respectivcly, a platinum plate $\left(\mathrm{ca} .6 \mathrm{~cm}^{2}\right)$ and a $\mathrm{Hg} / \mathrm{HgO} / 6 \mathrm{M} \mathrm{KOH}$ electrode. All electrode potentials are given with respect to this reference elcctrode whose formal potential is $930 \mathrm{mV}$ more positive than the reversible hydrogen electrode. The electrolyte was a $6 \mathrm{M} \mathrm{KOH}$ solution (Merek, p.a. $\mathrm{KOH}$ pellets; deionized water). In order to start with a completely weted internal surface the electrode was vacuum-impregnated with electrolyte before cycling.

Fig. [ 1 shows a block diagram of the automated galvanostatic charge/discharge cycling apparalus to which the glass cell was connected. The ricrocomputer controlled the charge- and discharge-current, the charging period and the final discharge potential and calculated the storage capacity via the measured discharging period. In another mode the discharging period could be adjusted. The 4 cells galvunostat/volmeter umil, designed and built in our laboratory, 


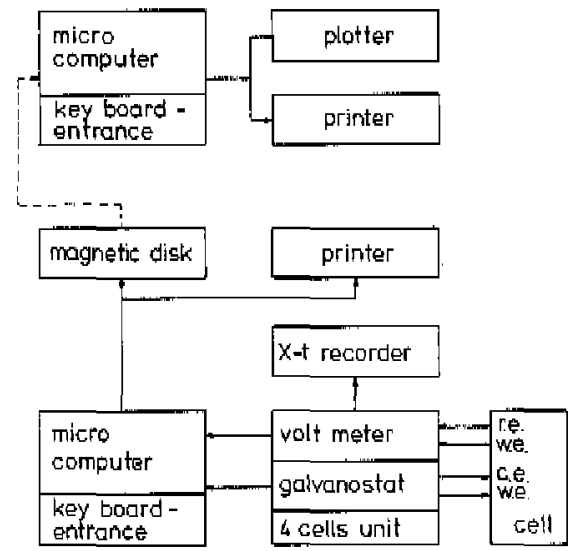

Fig. 11. Elock diagram of the automated galvanostutic charge/discharge cycling apparatus.

imposed the currents on four cells and measured the potential variations for controlling and recording purposes. With two of these units we were able to execute simultaneously eight independent experiments. The accuracy of the galvanostats was better than $0.1 \%$ for currents between $4 \mu \mathrm{A}$ and $65 \mathrm{~mA}$. All measuring data were both directly printed and stored on magnetic disks for printing and plotting afterwards.

\subsubsection{Results}

\subsubsection{A single galvanostatic charge/discharge cycle}

The electrochemical absorption and release of hydrogen by the compound $\mathrm{AB}_{5}$ can be represented by the redox equation

$$
\mathrm{AB}_{\bar{p}}+x \mathrm{H}_{2} \mathrm{O}+x \mathrm{e}^{-} \rightleftharpoons \mathrm{AB}_{5} \mathrm{H}_{x}+x \mathrm{OH}^{-} .
$$

This equation shows that each absorbed hydrogen atom corresponds to the storage of one electron. This results in a simple relation which allows us to calculate the theoretical capacity per unit weight

$$
C_{\mathrm{th}}=\frac{x F}{3,6 M_{\mathrm{AB}_{6}}} \mathrm{mAh} \cdot \mathrm{g}^{-1}
$$

where $\mathrm{F}$ and $M_{\mathrm{AB}_{6}}$ are the Faraday constant and the molecular weight of the $\mathrm{AB}_{5}$ compound, respectively, and $x$ stands for the number of hydrogen atoms per $A B_{5}$ unit as defined by eq. (14). The maximum value of $x$ being 6 , as determined 
by hydrogen gas desorption measurements ${ }^{16}$ ), the storage capacity of LaNis $\mathrm{Ni}_{5}$ is calculated to be $372 \mathrm{mAh} \cdot \mathrm{g}^{-1}$.

The main purpose of a galvanostatic charge/discharge cycle is to establish the experimental capacity value. Moreover, the potential variations during a cycle provide important information on the processes occurring. A single cycle consists of four successive periods:

a. charging with a constant cathodic current; moving to the right-hand side of ec. (14),

b. resting for a short period,

c. discharging with a constant anodic current; returning to the left-hand side of eq. (14), and finally

d. resting.

In battery terminology the rates of charge and discharge are usually expressed in terms of $C$, where $C$ is the numerical value of the electrode capacity in mAh. This value may be related to the theoretical capacity, $C_{\text {th }}$, eq. (15), or to a rated capacity as for instance $C_{5}$, which is defined as the capacity measured when the electrode is completely discharged in five hours ${ }^{17}$ ). A y C rate, i.e. a y C current, $i_{y c}$, equals the value of the current which forces the electrode to be charged or discharged completely within $y^{-1}$ hours, assuming no kinetic limitation.

Fig. 12 depicts a complete third cycle of a typical $\mathrm{LaNi}_{6}$ electrode, charged during one hour and discharged, both at a $1.25 \mathrm{Crate}$ (about $14 \mathrm{~mA}$ ). Starting at the rest potential, $-852 \mathrm{mV}$, the potential decreased rapidly to about $-1015 \mathrm{mV}$. At this level the potential stayed virtually constant for about $35 \mathrm{~min}$, and then gradually changed to a more negative, constant value, $-1030 \mathrm{mV}$. This potential will be referred to as the hydrogen evolution potential, $E_{\text {he }}$. Ideally, after 48 min. charging with a $1.25 \mathrm{C}$ current the electrode must be completely loaded

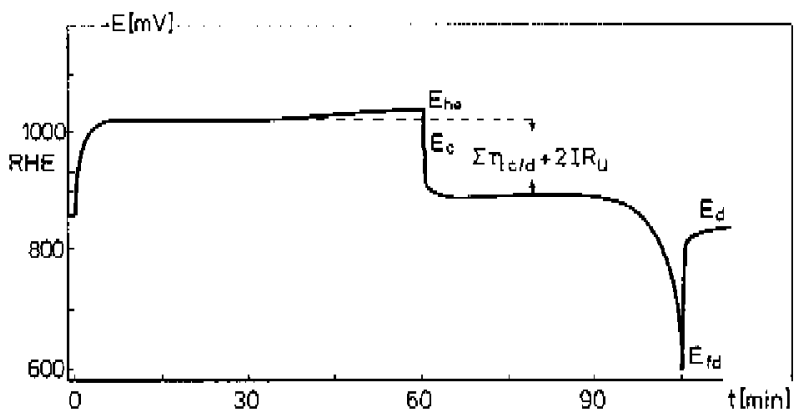

Fig. 12. The potential variation during the third galvanostatic charge/discharge cycle of a typical Lavi electrode. Both charging and discharging were carried out at $1,25 \mathrm{C}$ rate. 
and hydrogen gas evolution should start. However, especially in the case of a new electrode there is no sharp transition from one reaction to the other. After charging was completed, the current was interrupted for $30 \mathrm{~s}$ to measure the open circuit potential of the charged electrode; $E_{c}=-960 \mathrm{mV}$.

Subsequently, discharging started and lasted for $44.5 \mathrm{~min} ; 93 \%$ of the theoretical capacity was recovered at this high ratc. The potential difference between the charging and discharging curves, uncompensated for the ohmic resistance ( $=\Sigma \eta_{\mathrm{s} / \mathrm{d}}+2 I R_{\mathrm{U}}$ ), antounted to approximately $130 \mathrm{mV}$. The electrolyte resistance, $R_{u}$, was measured by the interruption method at a fully charged electrode evolving hydrogen gas. The $R_{\mathrm{u}}$ value between a new storage electrode and a well positioned reference electrode was less than $0.1 \Omega$. During repeated charging/discharging $R_{\mathrm{u}}$ increased to $0.2 \Omega$, due to changes in the porous structure. When the reference electrode was placed at a relatively large distance from the working electrode (about $2-3 \mathrm{~cm}$ ), the $R_{\mathrm{u}}$ value reached only $0.8 \Omega$ as a result of the high conductivity of a $6 \mathrm{M} \mathrm{KOH}$ solution. Discharging was terminated at the moment the potential exceeded a certain previously chosen potential level, called the final discharge potential, $E_{\mathrm{fd}}$. In this experiment $E_{\mathrm{ta}}$ was chosen to be $-600 \mathrm{mV}$, but because of the steep rise of the potential near the end of discharge any potential more positive than $-800 \mathrm{~m} V$ would be adequate, provided that the copper matrix did not oxidize $\left(E\left(\mathrm{Cu} / \mathrm{Cu}_{2} \mathrm{O}\right)=-460 \mathrm{~m} V\right)$. The steep rise did not result from a fast-growing hydrogen concentration gradient in the solid phase, but was caused by a general hydrogen depletion. Wher the current was stopped, the hydrogen concentration levelled off, producing a strong decrease in electrode potential. It is in fact the bydrogen concentration at the interface, together with the $\mathrm{pH}$, that determines the potential. The value measured after a $15 \mathrm{~min}$. relaxation period will be denoted as the discharged electrode potential: $E_{\mathrm{d}}=-333 \mathrm{mV}$.

Finally, it should be noted that the whole process took place in the immediate region of the reversible hydrogen electrode potential. For rechargeable negative electrodes in aqueous electrolytes this region is the most favourable potential range.

\subsubsection{Repeated galvanostatic charge/discharge cycles}

a. LaNis ELECTRODE

The previous section presented data on the electrode capacity and potentials. An even more important propety of a rechargeable battery electrode is its endurance. We therefore measured the changes in the performance of the electrode during repeated galvanostatic charge/discharge cycling. Fig. 13 depicts the decay of the storage capacity of a $\mathrm{LaNi}_{5}$ electrode as a function of the cycle number, $n$. Each dot in this graph represents the capacity of a cycle, discharged at the 


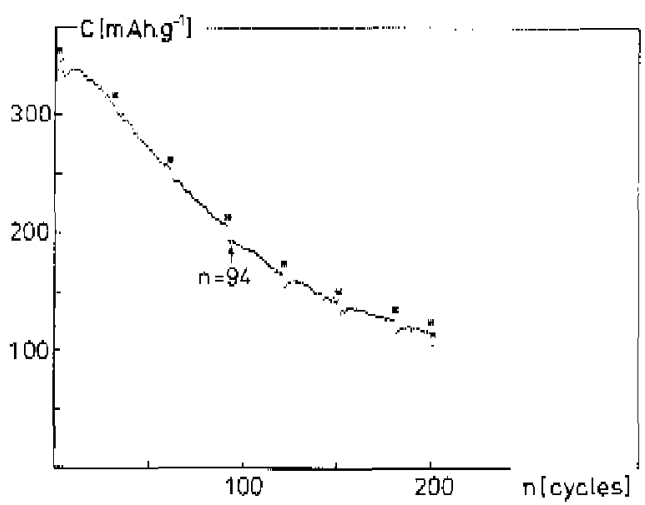

Fig. 13. The capacity declint of a typical 1 ani $\mathrm{Ni}_{5}$ elcotrode, discharged at $1.25 \mathrm{C}$ rate (dos) and $1.25+0.125$ C rate (asterisks), and charyed for 1 hour at $1.25 C$ ratc if $n \in 94$ and for' $\frac{1}{2}$ hour at 2.5 C rate if $n: 94$.

$1.25 \mathrm{C}$ ratc. To complete the hydrogen desorption the electrode was additionalfy discharged at the relatively low $0.125 \mathrm{C}$ current every thirty eycles. The curnulative capacity values are denoted by asterisks.

During the first cycles the electrode was charged at the $1.25 \mathrm{C}$ rate; after the $94^{\text {th }}$ cycle charging was carried out at the $2.5 \mathrm{C}$ rate. This change did not affect the course of the capacity curve, $C(n)$. Both this observation and the small contribution to the total capacity of the low rate-discharge illustrates again the suitability of LaNis electrodes for application in high power cells.

Plots of each of the potentials $E_{n e}, E_{a}$ and $E_{q}$, defined in sec. $3.2 .2,1$, are given in fig. 14. Besides, the electrode potentials after additional, low rate discharging, $E_{a}$, are indicated by crosses. The cumulative capacity measurements resulted in discontinuities in both $C(n)$ and $E_{\mathrm{d}}(n)$. The first cycles immediately afterwards showed a slightly reduced storage capacity caused by incomplete hydrogen desorption, as shown by the less positive $E_{d}$ values. Doubling of the charge current

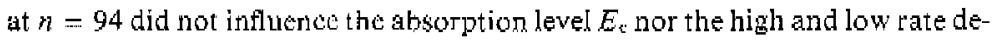
sorption levels, $E_{\mathrm{d}}$ and $E_{\mathrm{d}}{ }^{\prime}$. The hydrogen evolution overpotential, $\eta_{\mathrm{hc}}$, increased but not by more than $10 \mathrm{mV}$.

Another noteworthy phenomenon was the strong decline of $\eta_{\mathrm{h}}$ during the first cycles. The $\eta_{\mathrm{hu}}$-decrease of five similar $\mathrm{LaNi}_{5}$ electrodes was $105 \pm 20 \mathrm{~m} \mathrm{~V}$. Simultancously, the hydrogen content after discharge diminished rapidly, so the value of $E_{d}$ varicd from about -900 to $-750 \mathrm{mV}$, and the annount of absorbed hydrogen increased, as is expressed by the final $E_{\text {s }}$ value of about $-970 \mathrm{mV}$. These observations are due to an activation process, which took place during the 


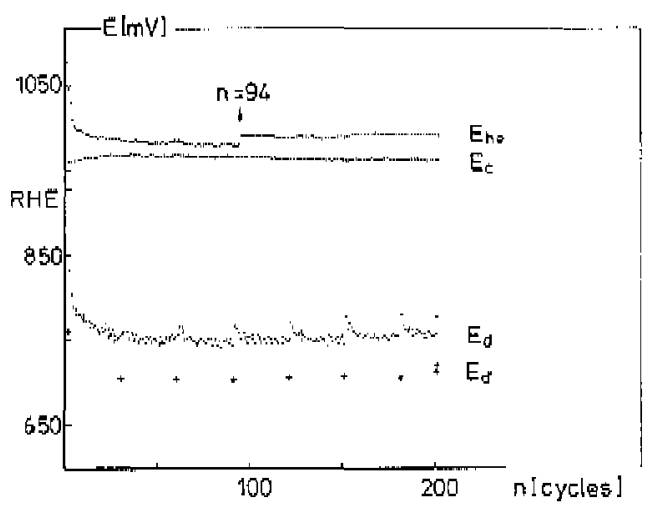

Fig. 14. The course of the potentials $E_{b e}, E_{i,}, E_{a}$ and $E_{d}$ ' during concimusus cycling of at LaNi clectrode.

first 25 cycles. The consequences of this activation are summarized in table III and are illustrated in fig. 15. This figure shows the charge and discharge curves of the cycles 1,38 and 51 , all at a $1.25 \mathrm{C}$ rate. The dashed line $a^{\prime \prime}$ represents the additional discharge at the $0.125 \mathrm{C}$ ratc of the first cycle; the additional capacity was $15 \mathrm{mAh} \cdot \mathrm{g}^{-1}$. The abscissa quantity is the amount of stored hydrogen expressed in terms of $Q$, i.e. the electrical charge passed during toading or the electrical charge needed for complete discharging. This facilitated the comparison of the corresponding charge and discharge potentials with respect to the representation in fig. 12. Clearly, the behaviour of the $\mathrm{LaNi}_{5}$ electrode was enormously improved by the activation process, resulting in a final $\sum_{\mathrm{c}} \eta_{\mathrm{c}}$ value of approximately $25 \mathrm{mV}$, and a larger discrepancy between charging and hydrogen evolution. The flatness of the charge and discharge curves should also be noted.

\section{TABLE III}

The changes in performance of a typical LaNi ${ }_{5}$ electrode during the activation process.

\begin{tabular}{c|c|c|c|c|c}
\hline $\begin{array}{c}n \\
\text { (cycles) }\end{array}$ & $\begin{array}{c}-E_{\mathrm{he}} \\
(\mathrm{mV})\end{array}$ & $\begin{array}{c}-E_{\mathrm{c}} \\
(\mathrm{mV})\end{array}$ & $\begin{array}{c}-E_{\mathrm{a}} \\
(\mathrm{mV})\end{array}$ & $\begin{array}{c}\sum_{\mathrm{c}_{\mathrm{d}}+2} 2 I R_{\mathrm{u}} \\
(\mathrm{mV})\end{array}$ & $\begin{array}{c}\left.C_{1.25}{ }^{*}\right) \\
\left(\mathrm{mAh}^{*} \mathrm{~g}^{-1}\right)\end{array}$ \\
\hline 1 & 1077 & 957 & 883 & 245 & 337 \\
3 & 1030 & 960 & 833 & 130 & 345 \\
38 & 985 & 968 & 752 & 28 & 295 \\
51 & 982 & 967 & 746 & 27 & 269 \\
\hline
\end{tabular}

*) $C_{1.25}$ is the storagc capacity calçwated from $1.25 \mathrm{C}$ rate discharte. 


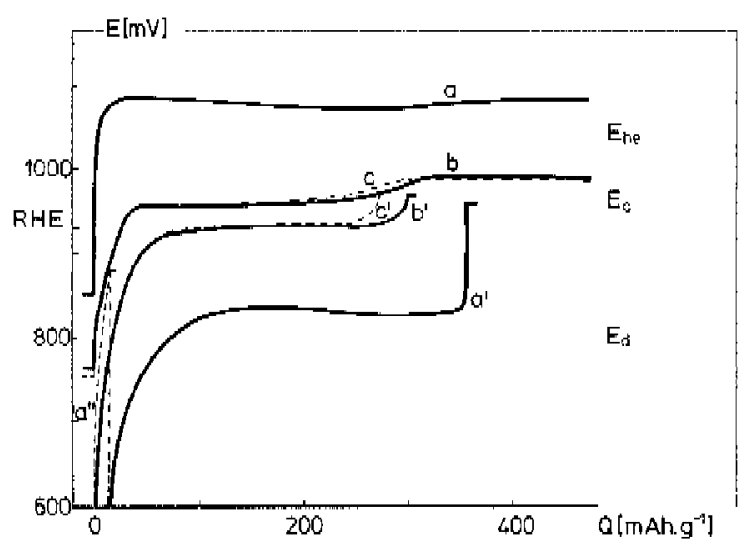

Fig. 15. The charge and diwharge curwes of a 1 .aNis clectrodc: $a$ and $a^{\prime}:$ cycic $1, b$ and $b^{\prime}$ : cycls $38, c$ and $c^{\prime}$ : cycle 51 , all at $1.25 \mathrm{C}$ cate. The datshed line $a^{\prime \prime}$ represents the ddditional discharge at $0.125 \mathrm{C}$ rate of the lirst oycle.

The decay of the storage capacity of a LaNi 5 electrode has already been shown in fig. 13. In order to establish the precise capacity decline during continuous charge/discharge cycling, both at $1.25 \mathrm{C}$ rate, several $\mathrm{LaNi}_{6}$ electrodes were tested. The intermetallic compound was pulverized by one hundred hydrogen

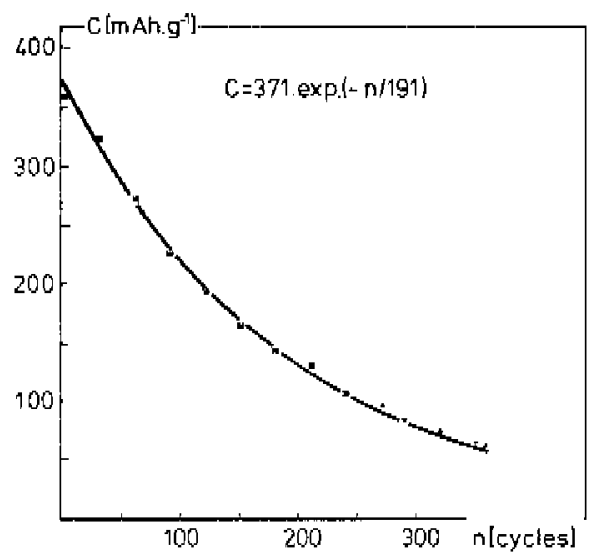

Fig. 16. The capacity decline of LaNio, averaged over several electrodes, all charged and discharged at $1.25 \mathrm{C}$ rate 
gas absorption/desorption cycles, as described in sec. 3.4. Prior to cycling, each electrode was polarized at $-850 \mathrm{mV}$ for 16 hours while the electrolyte was purged with nitrogen. Then the oxygen reduction current had decreased to $50 \mu \mathrm{A}$ or less. The final discharge potential amounted to $-600 \mathrm{~m} \mathrm{~V}$. The sum of the $1.25 \mathrm{C}$ and the $0.125 \mathrm{C}$ rate capacities is considered to be the total storage capacity, $C_{t}$. The average $C_{\mathrm{t}}$ values of several $\mathrm{LaNi}_{5}$ electrodes as a function of the cycle number, $n$, are represented by asterisks in fig. 16 . If the $C_{t}$ value of the first cycle is disregarded because of the activation process, the remaining $C$, points give a very satisfactory fit to the relation

$$
C_{\mathrm{t}}=C_{0} \exp \left(-\frac{n}{n^{*}}\right)
$$

with $C_{0}=371 \mathrm{mAh} \cdot \mathrm{g}^{-1}$ and $n^{*}=191$ cycles. $C_{0}$ stands for the starting capacity and almost equals the theoretical value as calculated from eq. (15). The parameter $n^{*}$ reflects the decay ratc and can be regarded as a stability constant. The fitting curve is also drawn in fig. 16. The cumulative capacity values of a single electrode which had been charged and discharged up to 360 times are displayed as dots. Obviously, there is a good agreement with the extrapolated curve.

\section{b. LaNi 4 Cu ELECTRODE}

By the same method of average $C_{\mathrm{t}}$ values the capacity decline of $\mathrm{LaNi}_{4} \mathrm{Cu}$ electrodes was aceurately determined. There were some differences in the experimental conditions. The electrode pellet now contained $300 \mathrm{mg}$ active powder,

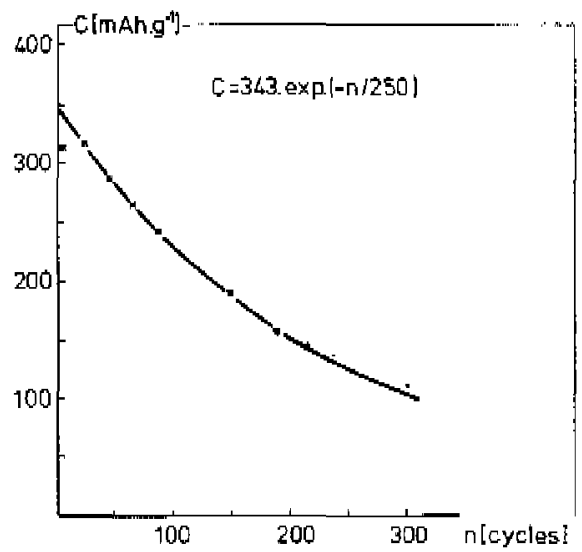

Fig, 17. The capacity decline of LaNi, Cu, averaged over several electrades, all charged and discharged at $2.0 \mathrm{C}$ rate. 
encapsulated in a matrix of $600 \mathrm{mg}$ copper and its geometrical area was $3.0 \mathrm{~cm}^{2}$. The electrodes were cycled against a rechargeable $\mathrm{Ni}(\mathrm{OH})_{2} / \mathrm{NiOOH}$ electrode without purging of the electrolyte by nitrogen ${ }^{8}$ ). Both charging and discharging of the electrodes were carried out at a 2.0 Crate, and the final discharge potential was $-700 \mathrm{mV}$. The total storage capacity was determined as the cumulative value of a five-steps-discharging at different rates in the sequence: $2.0 \mathrm{C} ; 1.0 \mathrm{C}$; $0.5 C ; 0.25 \mathrm{C}$ and $0.125 \mathrm{C}$ rate.

However, the result was again an exponential decay function but in this case with $C_{0}=343 \mathrm{mAh} \cdot \mathrm{g}^{-1}$ and $n^{*}=250$ cycles. Fig. 17 displays the average $C_{t}$ values (asterisks), the single electrode $C_{\text {. }}$ values after more than $200 \mathrm{cycles}$ (dots) and the fitting curve. The maximum hydrogen content calculated from this $C_{\text {o }}$ value, $5.6 \mathrm{H} / \mathrm{LaNi}_{*} \mathrm{Cu}$, corresponds very well with hydrogen gas desorption data $\left.{ }^{12}\right)$. The relation of eq. (16) proved to be valid for deseribing the capacity loss of the intermetallic compound electrodes.

\subsubsection{Discussion}

\subsubsection{High cycle rate}

The high rate of the electrochemical absorption and release of hydrogen by LaNi ${ }_{a}$ and $\mathrm{LaNi}_{4} \mathrm{Cu}$ clectrodes is due to the fast hydrogen diffusion in the metal(-hydride) and the small particle size. The hydrogen diffusion coefficient $D$ at $300 \mathrm{~K}$, in $\mathrm{LaNi}_{6} \mathrm{H}_{6}$ and in $\beta-\mathrm{TiFeH}_{1.03}$, as derived from NMR or quasi-elastic neutron scattering experiments ${ }^{19}$ ), is $2 \times 10^{-38}$ and $2 \times 10^{-12} \mathrm{~cm}^{2}{ }^{2} \mathrm{~s}^{-1}$, respectively. It has been suggested that the relatively fast hydrogen diffusion in $\mathrm{LaNi}_{b} \mathrm{H}_{6}$ is caused by a high degree of disorder in the occupation of the interstitial sites.

Van $\mathrm{Mal}^{4}$ ) examined microscopically the size distribution of $\mathrm{I}_{4} \mathrm{ANi}_{6}$ powder after one, twenly and one hundred gas absorption/desorption cycles. He found that after twenly cycles no appreciable changes oceured and that the particle diameters were distributed around $4 \mu \mathrm{m}$. The specific surface area of a sample after twenty cycles, as determined by the BET gas absorption method, was found to be $0.25 \mathrm{~m}^{2} \cdot \mathrm{g}^{-1}$. Assuming spherical particles of identical size (see sec. 3.4) a diameter of $3 \mu \mathrm{m}$ is deduced.

These data enable us to estimate the time scale of the hydrogen transport process via the root-mean-square displacement equation

$$
\delta=\sqrt{2 D t}
$$

Here $\delta$ stands for the diffusion layer thickness. For $\delta=2 \mu \mathrm{m}$, the LaNi 5 particle radius, the period $t$ is calculated to be $1 \mathrm{~s}$. Even during charging and discharging at a $2.5 \mathrm{C}$ rate, which takes 24 min each, limitations due to hydrogen atom diffusion in the metal latice can be disregarded. Transport limitation at the liquid side of the interface is also not expected in $6 \mathrm{M} \mathrm{KOH}$ with 
$D_{\mathrm{K}^{+}}=1.96 \times 10^{-5} \mathrm{~cm}^{2} \cdot \mathrm{s}^{-1}$ and $D_{\mathrm{OH}^{-}}=5.26 \times 10^{-6} \mathrm{~cm}^{2} \mathrm{~s}^{-1}$, both values at infinite dilution at $\left.25^{\circ} \mathrm{C}^{20}\right)$. This explains the flatness of the charge and discharge curves and indicates that the surface kinetics are rate-determining.

The high specific surface arca leads to a relatively low current density $j$ according to

$$
j=\frac{i}{m \cdot S A},
$$

where $m$ and $S A$ are the mass $(g)$ and the specific area $\left(\mathrm{cm}^{2} \cdot \mathrm{g}^{-1}\right)$ of the active electrode material. For charging or discharging of spherical particles of diameter $d$ at a $y C$ rate eq. (18) can be rewritter as

$$
j_{y C}=y C_{\mathrm{th}} \frac{e d}{6},
$$

where $\varrho$ is the density of the intermetallic conpound; $\varrho_{\mathrm{LaNi}}=8.28 \mathrm{~g} \cdot \mathrm{cm}^{-3}$. This equation shows that the current density is proportional to the particle size. The current density at $\mathbf{4}$ um LaNis powder during charging at the I $C$ rate amounts to only $0.2 \mathrm{~mA} \cdot \mathrm{cm}^{-2}$.

\subsubsection{Activation process}

The activation results in a considerable reduction of the overpotentials for charging, discharging and hydrogen evolution. For the measured hydrogen evolution overpotential, declining from approximately -160 to $-55 \mathrm{mV}$, the relation between the current density $j$ and the overpotential can be described by the Tafel equation ${ }^{21}$ )

$$
\eta=a+b \log j
$$

with the Tafel constants $a$ and $b$ defined as follows:

$$
\begin{aligned}
& a=\frac{2.3 R T}{\alpha n_{e} F} \log j_{\circ}, \\
& b=-\frac{2.3 R T}{\alpha n_{u} F} .
\end{aligned}
$$

In eq. (21a) $j_{\mathrm{n}}$ stands for the exchange current density, which is proportional to the standard heterogeneous rate constant, $k^{\circ}$. If $j o$ is constant, the $-10 \mathrm{mV}$ increase of the hydrogen overpotential after doubling the charge current at $n=94$ enables us to calculate to a first approximation the apparent Tafel slope; $b=$ $-33 \mathrm{mV}$. However, in three experiments the charge rate of a $\mathrm{LaNi} 5$ electrode was changed from 1.25 to $2.5 \mathrm{Crate}$ at the $15^{\text {th }}$ cycle, resulting in an averagc overpotential increase of $35 \mathrm{mV}$. From this value a slope of $-116 \mathrm{mV}$ is calculated. The value of the derivative $\mathrm{d} n / d \log /$ depends on the rate-determining step in 
the reaction sequence ${ }^{2 z}$ ). For a slow proton discharge (Volmer reaction) the characteristic valuc is $-120 \mathrm{mV}$. If the combination of the hydrogen atoms (Tafel reaction) is rate-determining a slope of $-30 \mathrm{~m} V$ is found. Apparently the mechanism of the hydrogen evolution rcaction changes duritig cycling.

At a constant charge rate and with the assumption that $b$ does not vary between the $n^{\text {th }}$ and the $k^{\text {th }}$ cycle, the egs (19) to (2I) can bo combined to

$$
\eta_{n}-\eta_{k}=b \log \frac{\left(k^{*} / d\right)_{n}}{\left(k^{\circ} / d\right)_{k}}
$$

Applying this equation to the activation process with $b=-116 \mathrm{mV}$ shows that the quotient $k^{\circ} / d$ after activation is 8 times the starting value. The activation process is therefore due to further disintegration of the metal powder (decrease of $d$ ), even after onc hundred hydrogen gas absorption/desorption cycles, and/or an improvement of the electrocatalytic properties of the electrode surface (increase of $k^{\circ}$ ).

The fact that all overpotentials, i.e. for changing, discharging and hydrogen evolution, were equally reduced by aboul $105 \mathrm{mV}$ can also be explained in two ways. The current density was desceased by further cracking or these three roactions possessed an identical rate-determining step, which was accelerated. This common step must be the Volmer reaction

$$
\mathrm{H}_{2} \mathrm{O}+\mathrm{e}^{-} \rightleftarrows \mathrm{H}_{\mathrm{ad}}+\mathrm{OH}^{-} \text {. }
$$

This is consistent with both the steep Tafel slope during the activation and the increasing absorbed hydrogen level. The distinction between a variation in par. ticle size or rate constant cannot be made on the basis of this observation.

\subsubsection{Capacity decay}

Figs 16 and 17 show the drastic capacity loss of $\mathrm{LaNi}_{5}$ and $\mathrm{LaNi}_{4} \mathrm{Cu}$ electrodes. If we define the cycle life of a rechargeable electrode as the number of cycles during which the storage capacity has declined to $60 \%$ of the starting value, the cycle life of these electrodes is restricted to about one hundred cycles. To theet the required endurance of one thousand cycles, the stability must be improved by a factor of teri.

Van Rijswick ${ }^{8}$ ) has alrcady pointed out that the 'demonstruted' suitability of a hydrogen-storing $\mathrm{LaNi}_{5}$ electrode was rather surprising because lanthanum is a metal that readily reacts with water. The equilibrium potential of the reaction

$$
\mathrm{La}+3 \mathrm{H}_{2} \mathrm{O} \rightleftarrows \mathrm{La}(\mathrm{OH})_{3}+3 \mathrm{H}^{+}+3 \mathrm{c}^{-} \text {, }
$$

is $-2.07 \mathrm{~V}$ with respect to the reversible hydrogen electrode ${ }^{23}$ ). The increase in nobility due to the formation of the intermetallic compound cannol possibly bridge 2.0 volts. As a more important effect of the formation of a compound, it 
might be expected that in a regular packed structure of several kinds of atoms the selective oxidation of the least noble metal would leave a surface layer of the more noble metal, which would then determine the corrosion properties, In this way, Van Rijswick suggested that compounds rich in cobalt, nickel or copper would be protected against corrosion by a thermodynamically stable surface layer.

Obviously, the protection is insufficient. The surface layer may possess an open structure, still allowing lanthanum to reach the electrode/electrolyte interface. Alternatively cracking of the metallic powder may continue, progressively yielding fresh surface. If the latter explanation holds, as partly suggested by the activation process, coating of the fine metal particles with a protective layer of for instance palladium or a passive oxide ${ }^{24,28}$ ) will not provide a solution for the severe deterioration. To characterize the degradation both the oxidation reaction and the disintegration of the intermetallic compound need further examination.

\subsection{X-ray diffraction analysis}

\subsubsection{Resuits}

$X$-ray diffraction analyses were carried out to identify the structural parameters of the pure and the hydrided intermetallic compounds and to determine the compositional changes in electrode samples after galvanostatic cycling. The $\mathrm{X}-\mathrm{ray}$ diffraction diagrams were obtained on powdered specimens, using $\mathrm{Cu}(\mathrm{K} \alpha)$ radiation in combination with a graphite monochromator. The diffractometer used was a Philips PW 1130/90, equipped with a vertical goniometer PW 1050. Hydriding of the ground intermetallics was implernented by exposure to hydrogen gas of 150 atm for 24 hours. To prevent desorption during recording, the hydrided powders were coated with glue.

Fig. 18 displays the $\mathrm{X}$-ray diagrams of $\mathrm{LaNi}_{5}, \mathrm{LaNi}_{4} \mathrm{Cu}$ and their hydrides, The diagrams $(a)$ and $(d)$ show that the intermetallic compounds consist merely of one phase which was identified as the hexagonal $\mathrm{CaCu}_{5}$ type of structure ${ }^{26}$ ); this crystal structure is described in space group $\mathrm{P} 6 /$ mmm. The broadened peaks of fig. $18(b)$ indicate the deformation of the solid phase after one hundred hydrogen gas absorption/desorption cycles at ambient temperature. Besides. lattice deformation, the line broadening may partially be attributed to the small size of some crystallite fragments. However, no additional lines, due to a second phase, appeared. The $\mathrm{X}$-ray diagram of $\mathrm{LaNi}_{5} \mathrm{H}_{6}(c)$ and that of $\mathrm{LaNi}_{4} \mathrm{CuH}_{5 . \mathrm{i}}(e)$ are similar to $(a)$ and $(d)$, respectively, but with all peraks shifted to smaller diffaction angles, indicating the same hexagonal structure but with larger lattice parameters. Despite the glue coating some hydrogen gas had desorbed from $\mathrm{LaNi}_{5} \mathrm{H}_{6}$ and thus a small amount of $\mathrm{LaNi}_{6} \mathrm{H}_{0.3}$ had been 


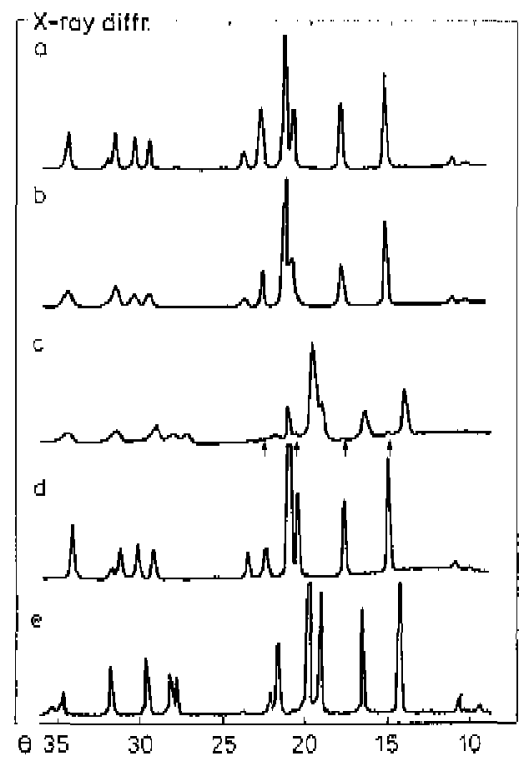

Fig. I8. X-ray diffaction diagrams of pure and hydrided LaNi, and LaNj $\mathrm{Cu}$ : $a$. LaNio, ground

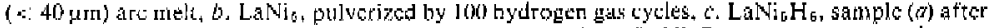
exposure to $\mathrm{H}_{2}, d, \mathrm{LaNi}_{4} \mathrm{Cu}$, ground $(\therefore 40 \mu \mathrm{m})$ ure melt, $e$. LaNi $\mathrm{CuH}_{6}$, sample $(d)$ after exposure to $\mathrm{H}_{2}$.

formed. The arrows in lig. 18(c) mark the diffraction peaks of the latter compound. Table IV shows the crystallographic data evaluated from fig. 18 together with some additional data. It is notewothy that the cell volumes of both compounds increase by twenty percent or mote during hydriding.

In order to relate the capacity decay of $\mathrm{LaNi}_{5}$ and $\mathrm{LaNi}_{4} \mathrm{Cu}$ electrodes to compositional changes, we recorded $X$-ray diagrams as a function of the cycle number. The samples examined were obtained from the galvanostatic cycling experiments diseussed in the previous section. The diagrams of a LaNi, electrode after 63,176 and 359 cycles are plotted in fig. $19(a-c)$. The diffraction angles of pure $\mathrm{La}(\mathrm{OH})_{3}$ with the corresponding relative intensities arc indicated by vertical bars (d). Although the $\mathrm{LaNi}_{5}$ and the $\mathrm{La}(\mathrm{OH})_{3}$ reflections are not well resolved against the copper background, fig. 19 shows clearly an increasitng amount of $\mathrm{La}(\mathrm{OH})$, with the cycle number. Moreover, at the tail of the copper reflection a shoulder appears, which is attributed to free nickel with a face-centered cubic structure, 
TABLE IV

Crystallographic data of $\mathrm{LaNi}_{6}, \mathrm{LaNi}_{4} \mathrm{Cu}$ and their hydrides.

\begin{tabular}{l|c|c|r|c|c}
\hline compound & $a(\dot{A})$ & $c(\AA)$ & $V\left(\AA^{3}\right)$ & $\Delta V / V(\%)$ & renarks \\
\hline $\mathrm{LaNi}_{5}$ & 5.003 & 3.971 & 86.06 & & (a) \\
$\mathrm{LaNi}_{5}$ & 4.999 & 3.988 & 86.31 & & (b) \\
$\mathrm{LaNi}_{5} \mathrm{H}_{6}$ & 5.395 & 4.244 & 106.97 & 24.3 & (c) \\
$\mathrm{LaNi}_{5}$ & 5.017 & 3.982 & 86.80 & & (i) \\
$\mathrm{LaNi}_{5} \mathrm{H}_{6}$ & 5.388 & 4.250 & 106.83 & 23.1 & (i) \\
$\mathrm{LaNi}_{4} \mathrm{Cu}$ & 5.034 & 4.002 & 87.82 & & (d) \\
$\mathrm{LaNi}_{4} \mathrm{CuH}$ & $\mathrm{Cu}$ & & & \\
$\mathrm{LaNi}_{4} \mathrm{Cu}$ & 5.403 & 4.162 & 105.21 & 19.8 & (c) \\
$\mathrm{LaNi}_{4} \mathrm{CuH}$ & 5.032 & 4.004 & 87.80 & & (ii) \\
\hline
\end{tabular}

(a) (e) corregpond to the $X$-ray diagrams of fig. 18 ; (i) data from re $\int .3$; (ii) data of a duplicate sample, which was placed in apecial pressure holder; during the determination of the lattice parameters of the hydride $p_{H_{2}}$ was $10 \mathrm{~atm}$, which resulted in an $x$-value somewhat larger than 5.6 .

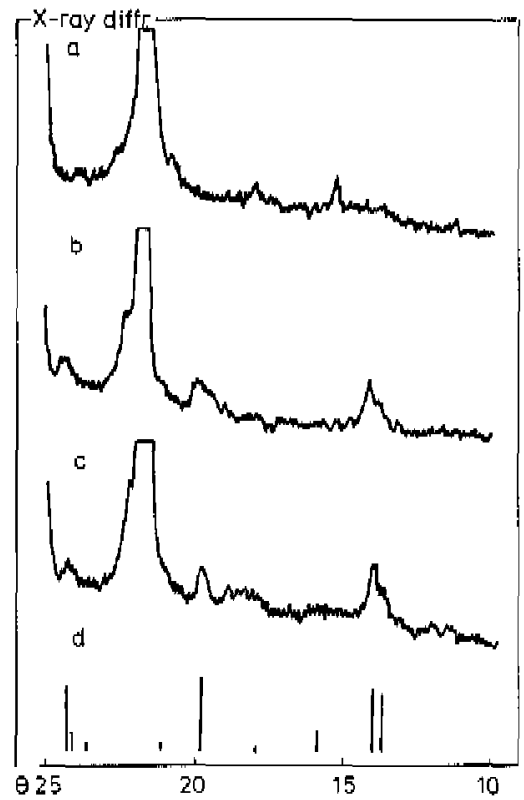

Fig. 19. X-ray diagrams of LaWis electrodes after $63(a), 176(b)$ and $359(c)$ cycles. The diffraction diagram of La(OH) s is schematically represented by vertical bass $(d)$; the large reflection peak at $\theta=21,76^{\circ}$ is dus to the copper matrix. 
The $\mathrm{X}$-ray diagrans of the $\mathrm{LaNi}_{4} \mathrm{Cu}$ electrodes exhibit a much better peakheight/background ratio, as shown in fig. 20. With increasing cycle number the $\mathrm{LaNi}_{4} \mathrm{Cu}$ peaks (unshaded) diminish and the $\mathrm{La}(\mathrm{OH})_{3}$ peaks (shaded) grow. Again tickel shoulders (dotted) appear at the tails of the copper reflection peaks. These diagrams prove explicitly that during galvanostatic charge/discharge cycling $\mathrm{LaNi}_{6}$ and $\mathrm{LaNi}_{4} \mathrm{Cu}$ electrodes are converted according to

and

$$
\mathrm{LaNi}+3 \mathrm{H}_{2} \mathrm{O} \rightarrow \mathrm{La}(\mathrm{OH})_{3}+5 \mathrm{Ni}+\frac{9}{2} \mathrm{H}_{2}
$$

$$
\mathrm{LaNi}_{4} \mathrm{Cu}+3 \mathrm{H}_{2} \mathrm{O} \rightarrow \mathrm{La}(\mathrm{OH})_{3}+5 \mathrm{Ni}_{.8} \mathrm{Cu}_{, 2}+\frac{1}{2} \mathrm{H}_{2,}
$$

respectively.

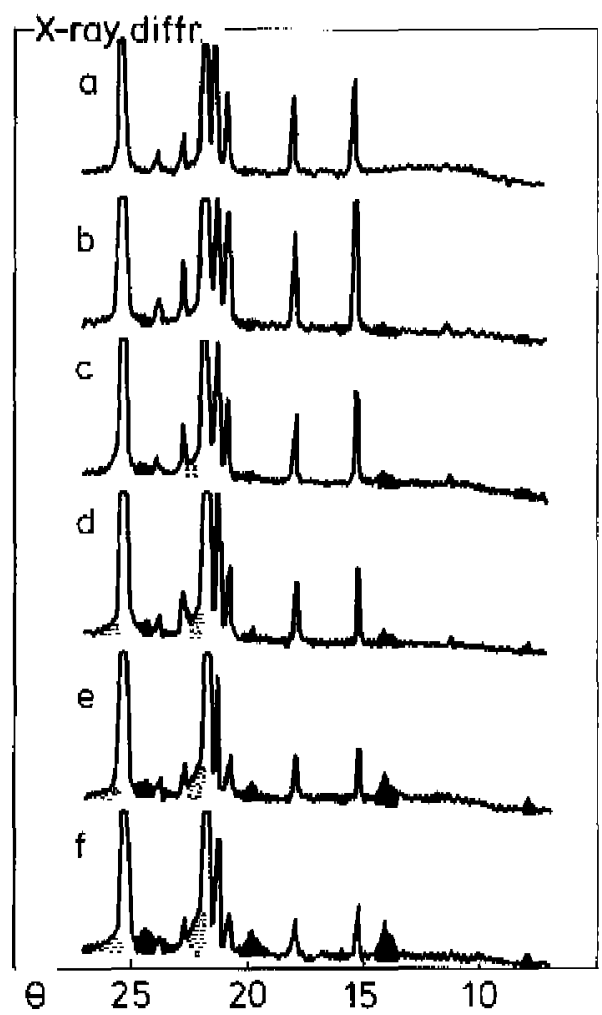

Tig. 20. X-ray diffraction aralysits of LaWj, Cu clcetrodes as a function of the eycle number:

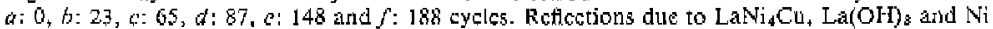
(or $\mathrm{Ni}_{8} \mathrm{Cu} .2$ ) are indicated by wishaded, shaded and dottcd, respectively. The difraction peak: of the copper matrix appear at $\theta-21.76^{\circ}$ and $\theta=25.35^{\circ}$. 


\subsubsection{Discussion}

The large lattice expansion of twenty percent or more during hydriding together with the brittleness of these intermetallic compounds causes the pulverization into fine powder. This will be illustrated with the help of the pressurecomposition isotherms depicted in fig. 21. Whenever the elcetrode is not com-

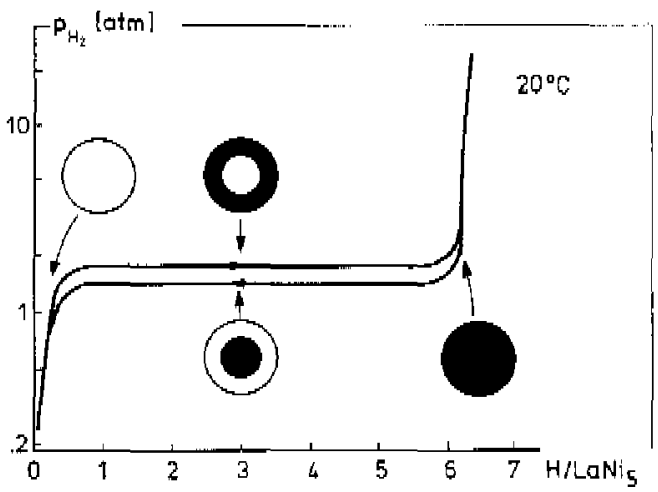

Fig. 2l. The absorption $(\rightarrow)$ and desorption $(-)$ isotherms of LaNi ${ }_{6}$ at $20^{\circ} \mathrm{C}$ (dala from ref, 3 ). The inserts indieate schematically the phase distribution in each particle; unshaded and shaded represent the $\alpha$ - and the $\beta$-phase, respectively.

pletely charged or discharged, each intermetallic compound particle contains two phases: a hydrogen-poor $\alpha$-phase and a hydrogen-rich $\beta$-phase. The outside layer always consists of the newly formed phase, which can be $\alpha$ or $\beta$ depending on the direction of the previous process, desorption or absorption, respectively. Because of the different volumes of the $\alpha$ and $\beta$ unit cells, enormous mechanical stresses are concentrated at the phase bouncary and lead inevitably to disintegration of the particles into smaller fragments.

Measurements of changes in the magnetic properties of LaNis during hydrogen gas-cycles by Schlapbach et al. ${ }^{27,28}$ ) showed that besides the non-magnetic $\mathrm{LaNi}_{5}$ ferromagnetic nickel prccipitates were found. In their study of the surface composition of poly- and monocrystalline $\mathrm{LaNi}_{5}$ they also found that the lanthanum concentration at the surface is considerably higher than that in the bilk, not only after exposure to air but even after cleavage in high vacuum. $\left(5.10^{-10}\right.$ torr). The free encrgy of intermetallic compounds is minimized if the surface concentration of the element with the smaller surface energy is increased. The suxfaco energies of lanthanum and nickel at $300 \mathrm{~K}$ are 0.87 and $2.39 \mathrm{~J} \cdot \mathrm{M}^{-2}$, respectively, and therefore the LaNi $i_{5}$ surface layers will segregate 
into lanthanum and nickel ${ }^{29}$ ). Schiapbach et al. suggested that the continuing scgregation during cycling is not due to the hydrogen gas itself. They suggested that if is due instead either to the temperature rise (increase of mobility), caused by the heat of hydriding, or to the oxygen or water impuritics in the hydrogen gas, which oxidize the lanthanum at the surface.

The formation of $\mathrm{LaNi}_{5} \mathrm{H}_{8}$ from $\mathrm{LaNi}_{1}$ by the absorption of hydroger gas is an exothermic reaction with $\Delta H_{\alpha / 6}^{\circ}=-30.4 \mathrm{~kJ} \cdot\left(\mathrm{mole}_{2}\right)^{-1}$. The heat capacity $C_{0}^{\circ}(298.15 \mathrm{~K})$ of $\mathrm{LaNi}_{5}$ and $\mathrm{LaNi}_{5} \mathrm{H}_{6}$ is $\mathrm{I} 52$ and $236 \mathrm{JK}^{-1} \mathrm{~mole}^{-\mathrm{t}}$, respectively ${ }^{30}$ ). Hence, in a adiabatic system or locally in a large storage container the temperature may increase considerably ( $\Delta T: 400$ to $500 \mathrm{~K}$ ) upon hydriding. In an electrochemical coll, the heat due to this hydride formation enthalpy will not be dissipated. In such a cell, heat is oniy generated due to the overpotentials during current flow. However, the heat effect of $\mathrm{LaNi}_{5}$ electrodes is negligible as a result of the low overpotentials, even at high cur'tents.

The free energy change of the $\mathrm{LaNi}_{6}$ oxidation according to ec. (25a) equals the $\Delta O^{\circ}$ of the reaction of lanthanum with water (ea. 24) minus the $\Delta G^{\circ}$ of the formation of the compound $\mathrm{LaNi}_{5}$. Thus, neglecting the entropy change of the LaNis formation from lanthanum and nicket.

$$
\Delta G^{\cup}\left(\mathrm{LaNi}_{\overline{6}} \text { oxidation }\right)--n_{\mathrm{q}} F E^{\mathrm{O}}-\Delta H^{\circ}\left(\mathrm{LaNi}_{5}\right) \text {. }
$$

This leads to $\Delta G^{\circ}\left(\mathrm{La}_{\mathrm{a}} \mathrm{Ni}_{5}\right.$ oxidation $)=-472 \mathrm{~kJ} \cdot\left(\text { mole } \mathrm{LaNi}_{5}\right)^{-1}$, which is almost four times $\Delta / r_{r}{ }^{\circ}\left(\mathrm{LaNi}_{5}\right)--127 \mathrm{~kJ} \cdot\left(\text { mole } \mathrm{LaNi}_{5}\right)^{-1}$. So, in aqeuous environments the driving force for the segregation of $\mathrm{LaNi}_{6}$ is not the difference in the surface encrgy of the constituents but the strong affinity of $\mathrm{LaNi}_{6}$ for water. This explains the observed discrepancy in capacity loss after electrochemically ( $6 \mathrm{M} \mathrm{KOH}$ ) and volumetrically (pure $\mathrm{H}_{2}$ gas) cycling.

Thus, the intermetallic compound electrodes decompose into oxidation produets which are inactive for the storage of hydrogen. Because the charge transfer reactions of the corrosion process, i.e. the reduction of water and the oxidation of lanthanum, occur readily, the segregation of LaNis must be the rate-deterrnining step. It can therefore be expected that the specific surface area would play an important role in the rate of the capacity decay.

\subsection{Specific surface area measurements}

\subsubsection{The BET method}

The specific surface area of pure intermetallic compound powders and clectrode pellets was determined from gas adsorption measurenents, applying the BET method ${ }^{81}$ ). In 1938 Brunauer, Emmet and Tellex derived an equation to describe a multilayer adsorption isotherm, which is now generally known as the $\mathrm{BE} \Gamma$ cquation 


$$
\frac{V}{V_{\mathrm{m}}}=\frac{c p}{\left(p_{\mathrm{o}}-p\right)\left[1+(c-1) \frac{p}{p_{\mathrm{\alpha}}}\right]},
$$

where $p$ and $p_{0}$ are the pressure and the saturation pressure of the adsorbate, and $V$ and $V_{m}$ are the total volume of gas adsorbed and the volume adsorbed at monolayer coverage. The parameter $c$ is defined as

$$
c=\exp \left(\frac{\left|E_{\text {adx }}\right|-\left|E_{\text {vap }}\right|}{R T}\right) .
$$

and indicates the relative preference of an adsorbate molecule for attaching itself to the adsorbent or to a layer already covered by the adsorbate. $E_{\text {adr }}$ and $E_{\text {vap }}$ refer to the adsorption and the vaporization free energies. Thus, the BET equation describes the volume of gas adsorbed at different values of $p / p_{0}$ in terms of two parameters $V_{\mathrm{m}}$ and $c$. It should be noted that $V_{\mathrm{m}}$ equals the volume of gas which would be adsorbed if a monolayer was formed; it is not assumed that the monolayer is completely filled. Theretore, the surface area $A$ may be evaluated from $V_{m}$ if the area occupied per absorbate molecule $\sigma^{\circ}$ is known

$$
A=\frac{V_{\mathrm{m}}}{V_{\mathrm{mol}}}, N_{\mathrm{A}} \sigma^{\circ},
$$

where $V_{\text {mol }}$ is the molar volume of the adsorbate at the same $p$ and $T$ as $V_{m}$; $N_{\mathrm{A}}$ is Avogadro's number. To evaluate $V_{\mathrm{m}}$, eq. (27) can be rearranged into the following linear form

$$
\frac{1}{V} \cdot \frac{p}{p_{o}-p}=\frac{c-1}{c V_{\mathrm{m}}} \cdot \frac{p}{p_{o}}+\frac{1}{c \breve{V}_{m}} .
$$

This form suggests that a plot of $p /\left(V \cdot\left(p_{0}-p\right)\right)$ versus $p / p_{0}$ should yield a straight line with slope $m=(c-1) /\left(c V_{m}\right)$ and intercept $b=\left(c V_{m}\right)^{-1}$. Now it is easily seen that $V_{\mathrm{m}}=(m+b)^{-1}$. In the range $0.05 \leqslant p / p_{0}<0.30$ the linear form of the BET equation fits the experimental data very well for a variety of gases and adsorbents. This feature has made the $\mathrm{BET}$ method a standard technique for surface area determination.

Many of our samples were electrode pellets, consisting of approximately $120 \mathrm{mg}$ copper powder and only $30 \mathrm{mg}$ active material. To determine the specific surface area of the active material with an accuracy of at least $0.2 \mathrm{mg}^{2} \cdot \mathrm{g}^{-1}$, the deviation from the average of the measured areas should not exceed $6.10^{-4} \mathrm{~m}^{2}$. The determination of such small areas with the required accuracy was achieved by means of a special experimental approach. We used krypton as adsorbate and a turboumolecular high vacuum pump for thoroughly removing adsorbed contaminants from both the apparatus and the samples. The BET apparatus was 
designed and built in our laboratory. After exposure of the interior to the ambient environment the apparatus was degassed by heating at $100^{\circ} \mathrm{C}$ and pumping until a pressure of $10^{-10}$ torr was reached. Prior to the adsorption measurement each sample was degassed by heating at $200^{\circ} \mathrm{C}$ and pumping for 14 hours. The pressure was then about $5 \times 10^{-7}$ torr.

Krypton differs from the more commonly used adsorbate, nitrogen, in two ways. The cross-sectional area $\sigma^{\circ}$ of an adsorbed krypton atom is slightly larger than that of a nitrogen molecule. The $a^{\circ}$ values recommended for krypton and nitrogen at $77 \mathrm{~K}$ are $20.2 \AA^{2}$ and $16.2 \AA^{2}$, respectively ${ }^{32}$ ). However, the much lower value of the saturation pressurc of krypton at the bolling point of nitrogen $(=77 \mathrm{~K}), p_{0}=2.1 \mathrm{torr}$, is more important. If the adsorbate is added with successive increments of $\Delta\left(p / p_{\circ}\right)$, about the same amount of gas will be adsorbed (actually: $16.2 / 20.2$ ), but krypton adsorption takes place in a much lower pressurc range. A larger volume of krypton gas is thus needed to accomplish the same increment $\Delta\left(p / p_{0}\right)$. Because the gas volume per $\Delta\left(p / p_{0}\right)$ step is inversely proportional to the saturation pressure, the sensitivity is improved by a factor of 300 . Besides krypton behaves more like an ideal gas than nitrogen at the liquid nitrogen temperature.

The surface area of all samples was evaluated from at least two isotherms. The aver age difference between the duplicate measurements on electrode pellets was found to be $0.01 \mathrm{~m}^{2}$ or $2.6 \%$.

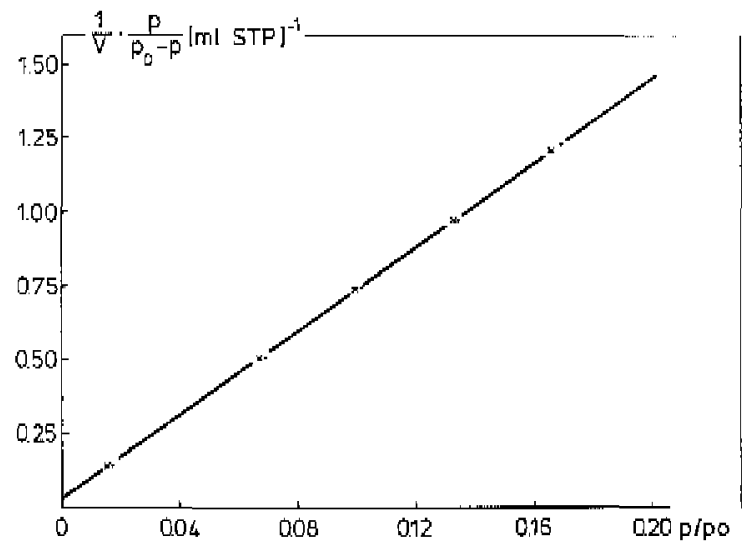

Fig. 22. The BET isotherm at $77 \mathrm{~K}$ of a LaNis elcetrode after 103 tharge/discharge cycles. The sample consisted of $102.6 \mathrm{mg}$ copper powder and $28.5 \mathrm{mg}$ remaining LaNis plus oxidation products; * and $x$ are data points of duplicate measurements, 
Concluding this scction, a practical example of the method will be given. The two isotherns of a LaNi pellet after 103 charge/discharge cycles, plotted in fig. 22, coincide. Obviously, the linear form of the BET equation fits well. The results, evaluated from the data of fig. 22 and summarized in table $\mathrm{V}$, show the excellent agreenent betwecn the two measurements. The surface area of the pellet, $A$, is $0.7586 \mathrm{~m}^{2}$. From the electrochemical experiments it is known that after 103 charge/discharge cycles only $58 \%$ of the LaNis is still present and $42 \%$ of the initial material has been converted to oxidation products. The specific area of the remaining $\mathrm{LaNi}_{5}$ plus the formed oxidation pro-

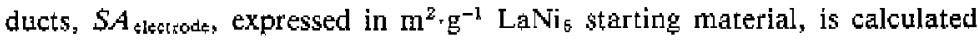
from $A$ according to

$$
S A_{\text {eiectrods }}=\frac{A}{m_{\mathrm{LaNi}_{\mathrm{b}}}}-\left(\frac{m_{\mathrm{Cu}}}{m_{\mathrm{LaNi}}}\right) \cdot S A_{\mathrm{Cu}}
$$

where $m_{\mathrm{LNN}_{5}}$ is the mass of $\mathrm{LaN}_{5}$ assuming no oxidation took place; $m_{\mathrm{Cu}}$ and $S A c_{u}$ are the mass and the specific surface area of the copper powder in the pellet.

The $S A$ cu of a pressed, dry pellet amounts to $0.216 \mathrm{~m}^{2} \cdot \mathrm{g}^{-1}$. After 37 cycles, carried out by potentiodynamic scanning in the potential range of a real electrode, we measured a specific surface area of $0.292 \mathrm{~m}^{2} \cdot \mathrm{g}^{-1}$. The electrode potential of a LaNi ${ }_{5}$ electrode acted as the 'function generator' for the potentiostat, which controlled the copper pellet potential. The increase is due to oxidation of the copper surface, wetted by $6 \mathrm{M} \mathrm{KOH}$. Because the electrode potential was always negative with respect to the $\mathrm{Cu} / \mathrm{Cu}_{2} \mathrm{O}$ reversible potential $(-460 \mathrm{mV})$, this oxidation was caused by oxygen after the clectrode was removed from the cell, despite thorough rinsing in water and methanol immediately and further storing in a desiccator for 24 hours. Therefore, we assumed the value of $0.292 \mathrm{~m}^{2} \cdot \mathrm{g}^{-1}$ to be independent of the number of cycles. The $S A$ electrode value of the sample in fig. 22 is $26.8 \mathrm{~m}^{2} \cdot \mathrm{g}^{-1}$.

\section{TABLE $\mathrm{V}$}

Results evaluated from the data points of fig. 22 .

\begin{tabular}{|c|c|c|c|}
\hline parameter & -points & $x$-points & average \\
\hline$b \quad(\mathrm{ml} \mathrm{STP})^{-1}$ & 0,0263 & 0.0314 & \\
\hline$m(\mathrm{ml} \mathrm{STP})^{-1}$ & 7.1191 & 7.1315 & \\
\hline$V_{m}(\mathrm{mI}$ STP $)$ & 0.1400 & 0.1396 & 0.1398 \\
\hline$A \quad\left(\mathrm{~m}^{2}\right)$ & 0.7595 & 0.7577 & 0.7586 \\
\hline
\end{tabular}




\subsubsection{Results and discussion}

In scc. 3,2,3 it was suggested that the activation process of the powder and the capacity loss are related to further disintegration. We therefore measured the specific surface arca of LaNis powder after repeated hydrogen gas absorption and desorption, and of $\mathrm{LaNi}_{5}$ and $\mathrm{LaNi}_{1} \mathrm{Cu}$ electrodes as a function of the number of galvanostatic charge/discharge cycles.

Pulverization by continuous gas cycling was carried out in an automated, volumetric absorption/desorption apparatus between 20 and $10^{-d}$ atm at ambient temperature. To prevent oxidation or poisoning of the powder surface by oxygen or water vapour ${ }^{14,38}$ ), special precautions were taken. The inlet hydrogen gas $\left(\mathrm{H}_{2} \geqslant 99.99 \% ; \mathrm{O}_{2}<10 \mathrm{ppm} ; \mathrm{H}_{2} \mathrm{O}<10 \mathrm{ppm}\right)$ was additionally purified by molecular sieves (oxysorb), which reduced the oxygen and water content to less than 0.1 and $0.5 \mathrm{ppm}$, respectively. Desorption took place in two stcps via a low-pressure, buffer vessel. This vessel was also preceded by oxysorb adsorbents. The apparatus was constructed of stainless steel and proved to be $100 \%$ leak-tight as checked by the helium test. The cycle time was 45 min; absorption took 20 , desorption $25 \mathrm{~min}$.

Fig. 23 shows the specific surface area of $L a N i$, powder as a function of the number of gas cycles. Several samples were taken from different are melts; all gave similar results. Cracking mainly occurred during the first fifty cycles, lcading to a specific surface area of $0.22 \mathrm{~m}^{2} \cdot \mathrm{g}^{-1}$, which is in agreement with the findings of $\left.\mathrm{Van} \mathrm{Mal}^{4}\right)$. The $S A$ value aiter one thousand absorption/desorption cycles increased to only $0.28 \mathrm{~m}^{2} \cdot \mathrm{g}^{-1}$. The latter sample was measured again after one year of storage in a desiccator and within $2 \%$ the same value was found!

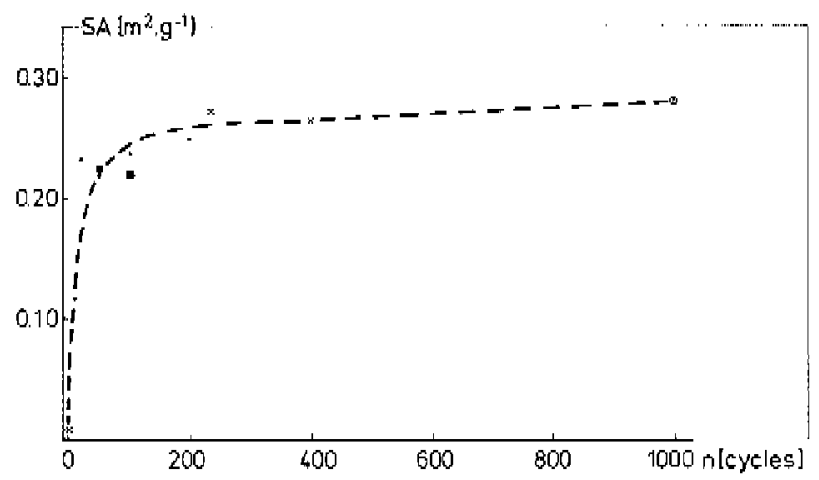

Fig. 23. The specific surface area of LaN $j_{n}$ powder from several arc melts as a function of the ulriber of thydrogen gus ahsorption/desorption cyeles. 
Assuming the powder consists of spherical particles, all with diameter $d$, we can casily evaluate this typical length from the specific surface area

$$
d=\frac{6}{\varrho \cdot S A} \text {. }
$$

The final size of LaNis particles, conresponding to $S A=0.28 \mathrm{~m}^{2} \cdot \mathrm{g}^{-1}$, is $2.6 \mu \mathrm{m}$. The 'diameter' of the crystallites in these arc melt samples varied from 100 to $200 \mu \mathrm{m}$, as determined microscopically. Thus, not only the crystallites are separated from each other, but also transcrystalline fractures occur as a result of cycling.

The specific surface area of $\mathrm{LaNi}_{4} \mathrm{Cu}$ after several gas-cycles was found to be $0.24 \mathrm{~m}^{2} \cdot \mathrm{g}^{-1}$. We also determincd the specific surface area, obtained after grinding LaNi ${ }_{5}$ powder by mechanical means and passing it through a $40 \mu \mathrm{m}$ sieve. The result was remarkable: $0.25 \mathrm{~m}^{2} \cdot \mathrm{g}^{-1}$. Apparently, there is a characteristic limiting value for the specific sur face area of this type of intermetallic compound under mechanical stress.

The determination of the specific surface area of a LaNi ${ }_{5}$ electrode after repeated electrochemical cycling was described in the previous sec. (3.4.1). Fig. 24(a)
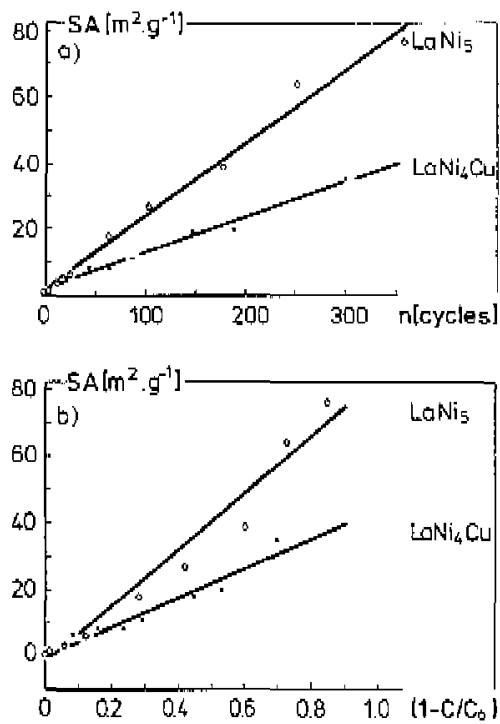

Fig. 24. The specific surface area of $1,2 \mathrm{Nis}(0)$ and $\mathrm{LaNi} \mathrm{Cu}_{d}(\varphi)$ electrodes, expressed in $\mathrm{m}^{2} \cdot \mathrm{g}^{-2}$ (g refers to initial active material). The chargedischarge rates of the LaNis and the LaNis Cu clsetrodes were 1.25 and 2.06 , respectively. $(c)$ and $(b)$ display the dependence on the cycle number and on the fraction of oxidation products, respectively. 
displays the data for $\mathrm{LaNi}_{5}$ and $\mathrm{LaNi}_{4} \mathrm{Cu}$ electrodes as a function of the cyclenumber. The specific surface area of the remaining active material plus the oxidation products is very large compared to the final value of the gas-cycled powder and increases approximately in proportion to the cycle number. It is therefore probable that these high values are largely due to the oxidation products. However, during the activation process eracking of the active material might have contributed to the sur face area enlargement. Therefore, we have to consider the specific surface area of the electrode to be due to two terms

$$
S A_{\text {electrode }}=S A_{\text {active }} \cdot \frac{C}{C_{o}}+S A_{\text {sxidprod }} \cdot\left(1-\frac{C}{C_{0}}\right),
$$

If $C$ and $C_{0}$ represent the actual and the initial storage capacity, then the factors $C / C_{o}$ and $\left(1-C / C_{0}\right)$ express the fraction of the remaining active material and that of the oxidation products, respectively, both per unit mass initial active material. Atomic emission spectroscopy has shown that the anounts of lanthanum and nickel in the dectrode peltet do not change during cycling. The parameter $S A_{\text {oxidprod }}$ is given by

$$
S A_{\text {oxidprod }}-\frac{M_{\mathrm{Ln}(\mathrm{OH})_{3}}}{M_{\mathrm{LuNi}_{\mathrm{H}}}} \cdot S A_{\mathrm{La}(\mathrm{OH})_{\mathrm{A}}}+\frac{5 M_{\mathrm{N} 1}}{M_{\mathrm{LaNi}_{\mathrm{g}}}} \cdot S A_{\mathrm{Ni}}
$$

where $M_{i}$ and $S A_{i}$ are the molecular weight and the specific surface arca of compound $i$.

Considering that for large cycle numbers the first term of eq. (33) is substantially smaller than the second and assuming that the parameter $S A$ oxisprod is constant, a plot of $S A_{\text {clctrods }}$ versus $\left(1-C / C_{0}\right)$ should result in a straight line which, when extrapolated passes through the origin. The value of $S A_{\text {oxidyrod }}$ can be evaluated from the slope of this line. From the difference between the (larger) measured walues and the extrapolated line, information can be obtained concerning changes in the specific surface area of the active material.

In fig. 24(b) the specife surface area values of $\mathrm{LaNi}_{6}$ and $\mathrm{LaNi}$, Cu electrodes are plotled as a function of $\left(1-C / C_{0}\right)$. It should be noted that the abscissa is not a time axis, but $\left(1-C / C_{0}\right)$ merely represents the fraction of oxidation products formed. It is therefore surprising that the value of the $\mathrm{LaNi}_{4} \mathrm{Cu}$ slopc is about half that of the $\mathrm{L}_{\$} \mathrm{Ni}_{5}$ slope: 45 and $85 \mathrm{~m}^{2}-\mathrm{g}^{-1}$, respectively. The specific surface area of $\mathrm{La}(\mathrm{OH})_{3}$ is possibly influenced by the initial active material density in the pellet; $\mathrm{LaNi}_{5} ; 20 \mathrm{wt} \%$ and $\mathrm{L}_{4} \mathrm{Ni}_{4} \mathrm{Cu}: 33 \mathrm{wt} \%$. The stability of the inter metallic compound electrodes cannot therefore be directly deduced fron the specific surlace area increase.

The in formation on changes in the specifie surface area of the active material, as obtained from fig. $24(b)$, is very limited. The differences between the measwred and the extrapolated values are of the same order of nagnitude as the ac- 
curacy of the fitted lines. It is curious that the linear relationship between $\$ A$ and $n$ describes the measured data better than that between $S A$ and $\left(1-C / C_{0}\right)$, in spite of the exponential capacity decay. Apparently, the $S A$ values measured at high cycle numbers are too large. If the assumed constancy of $S A A_{\text {oxidprod }}$ would be incorreet, its value is expected to decrease with $n$ because of processes such as crystal growth or conglomeration of particles. This would make the description according to eq. (33) even worse.

The results of the BET measurements do not indicate to what extent further disintegration occurs. However, after only three galvanostatic cycles, we determined specific area values of 1.4 and $1.3 \mathrm{~m}^{2} \cdot \mathrm{g}^{-1}$ for $\mathrm{LaNi}_{5}$ and $\mathrm{LaNi} \mathrm{i}_{4} \mathrm{Cu}$ electrodes, respectively, which are more than five times greater than the values obtained from the gas-cycled powders. This suggests that additional cracking takes place in the electrolyte.

\section{5. Ëlectron microscopy; results and discussion}

The changes in the morphology of the intermetallic compound and the formation of new phases were studied by both transmission and scanning electron microscopy (TEM and SEM). The TEM and SEM mierographs were made with a Philips PSEM 500 and a Philips EM 301, respectively.

Fig. 25 depicts several TEM photographs of material from cleaved $\mathrm{LaNi}_{4} \mathrm{Cu}$ electrode pellets after galvanostatic cycling. Two kinds of particle are found: jagged pieces, which disintegrated from approximately $10-15 \mu \mathrm{m}$ to $1-2 \mu \mathrm{m}$ 'diameter' during the first fifty cycles, and needles which only appeared after twenty cycles or more. These needles are monoerystals, slightly bent and with a hexagonal structure (the $c$-axis coincides with the needle axis), as determined by electron diffraction. We therefore concluded that these needles consist of $\mathrm{La}(\mathrm{OH})_{3}$ precipitated from the solution in the immediate viscinity of the intermetallic compound. The needle dimensions did not change constderably with the cycle number. Characteristic values are: length between 0.1 and $0.4 \mu \mathrm{m}$, width between 0.01 and $0.02 \mu \mathrm{m}$ and thickness about half the width. The specific surface area of $\mathrm{La}(\mathrm{OH})_{8}$, calculated from these valucs, varies from 60 to $140 \mathrm{~m}^{2} \cdot \mathrm{g}^{-1}$. This order of magnitude is consistent with the high surface area values cetermined from the BET measurements.

Figs 26 and 27 are compilations of SEM photographs, which give an illustrative overview of the degradation of $\mathrm{LaNi}_{\mathrm{t}}$ electrodes. The corresponding photographs are made of the same spot at the cleaved pellet surface, but the magnification of each photograph in fig. 27 is four times that of its counterpart in fig. 26 . Fig. $26(a)$ depicts $\mathrm{LaNi}_{5}$ powder pulverized by one hundred hydrogen gas absorption/desorption cycles and embedded in copper particles. LaNi ${ }_{5}$ is present as conglomerates of small fragments, which are generated by transcrystaline 

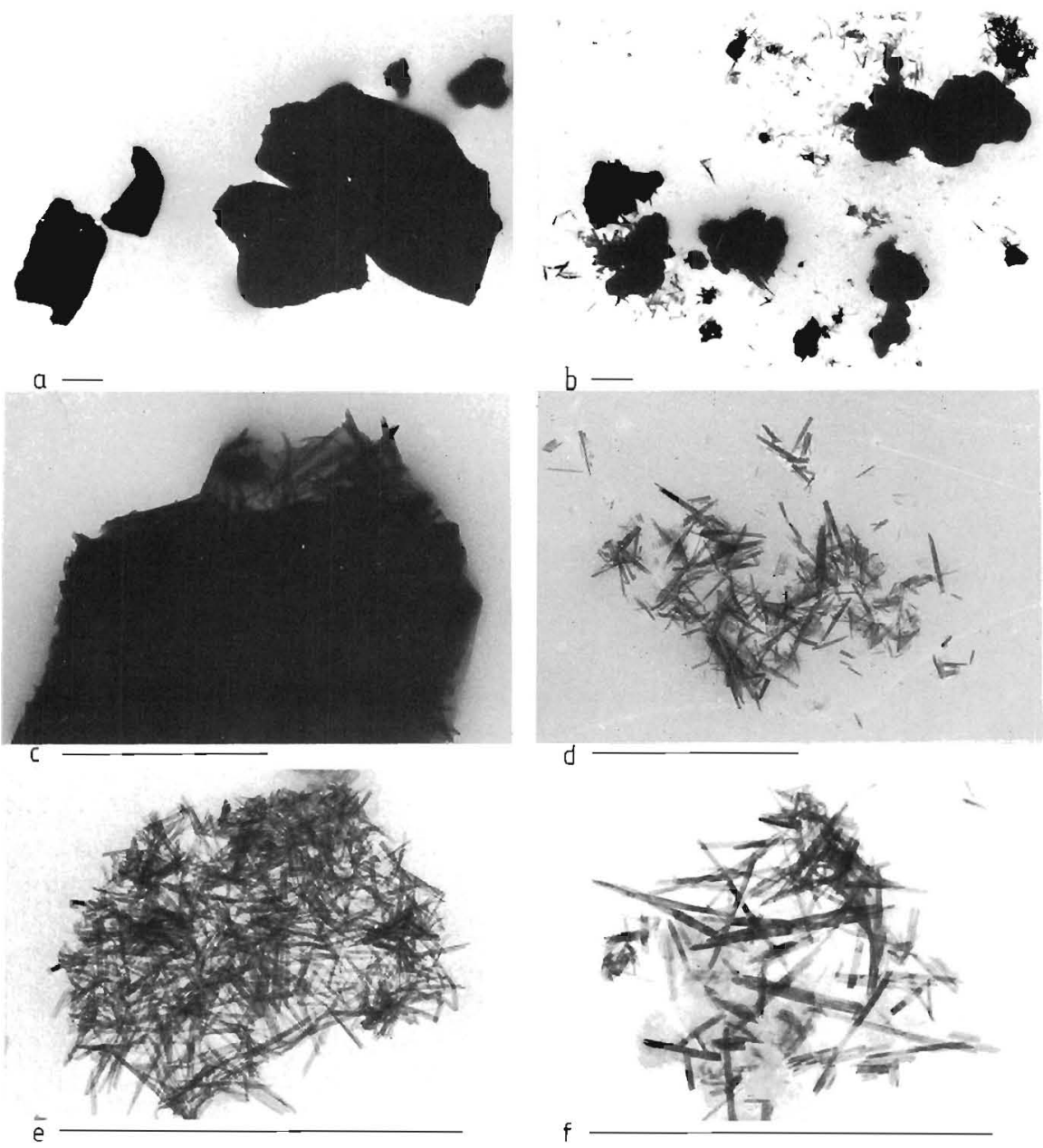

Fig. 25. TEM photographs of material from cleaved $\mathrm{LaNi}_{4} \mathrm{Cu}$ electrode pellets after galvanostatic cycling: $a$ : 3 cycles, $b: 300$ cycles, $c: 43$ cycles, $d: 23$ cycles, $e: 63$ cycles, $f: 300$ cycles. The bar represents $1.0 \mu \mathrm{m}$.

cracks. Such conglomerates are revealed as the large jagged pieces in TEM photographs. The size of the fragments decreased upon further cracking from approximately $7 \mu \mathrm{m}$ in the starting material to $2.5-3 \mu \mathrm{m}$. The latter value was found between the 25 th and the 63 th galvanostatic cycle.

However, additional electrochemical charging and discharging resulted in further size reduction, now caused by the decomposition of the intermetallic compound. This is indicated by the development of rounded edges of the frag- 

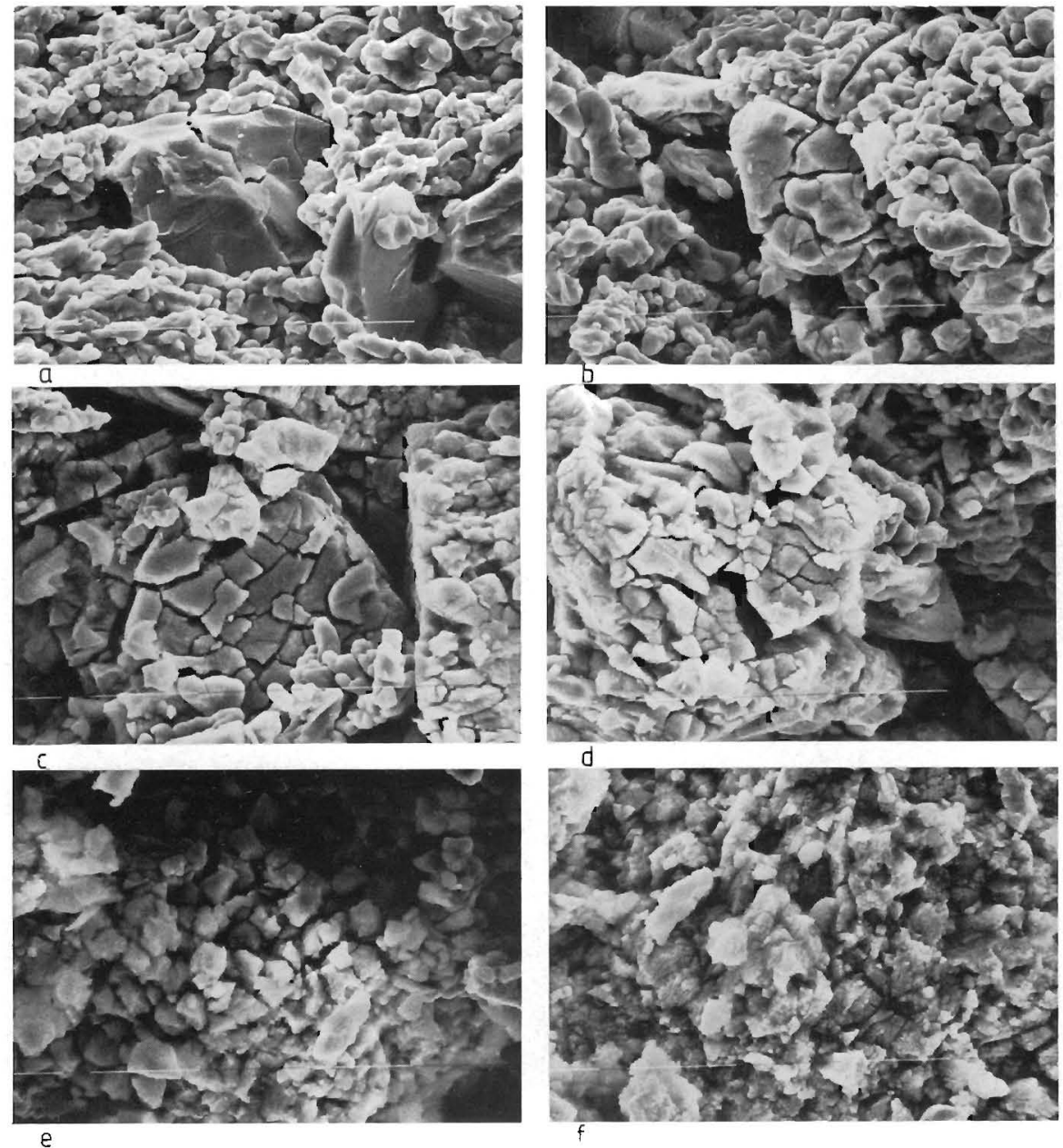

Fig. 26. SEM photographs of $\mathrm{LaNi}_{5}$ electrode pellets at several cycle numbers: a-e corresponds to $0,12,25,63,176,359$ cycles, respectively. One bar represents $10 \mu \mathrm{m}$.

ments and larger gaps between them; neighbouring chunks no longer fit in with each other. After 12 cycles $\mathrm{La}(\mathrm{OH})_{3}$ needles already appear and after 176 cycles small domains (ca. $0.3 \mu \mathrm{m}$ ) become vaguely recognizable. The latter may be attributed to nickel precipitates, which have also been detected by X-ray diffraction. Finally, the electrode surface is completely covered by a thick layer of porous $\mathrm{La}(\mathrm{OH})_{3}$.

Considering the irregularity and the roughness of the chunk surfaces, the characteristic length of $7 \mu \mathrm{m}$ after gas cycling agrees well with the $3 \mu \mathrm{m}$ evaluated 

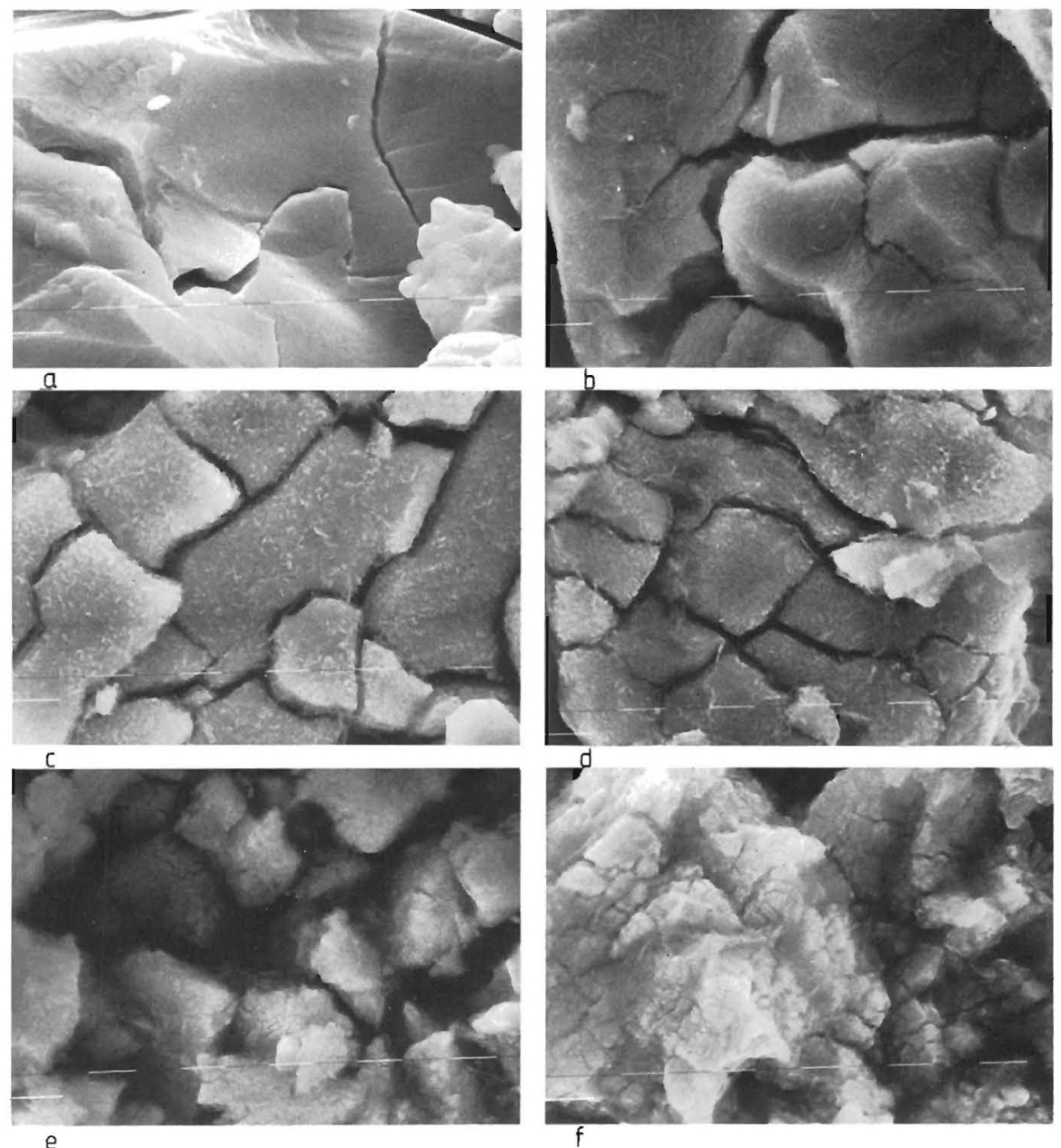

e

Fig. 27. SEM photographs of $\mathrm{LaNi}_{5}$ electrode pellets; identical to fig. 26 but at a larger magnification: one bar represents $1.0 \mu \mathrm{m}$.

on the assumption of smooth, spherical particles from the BET result of $0.25 \mathrm{~m}^{2} \cdot \mathrm{g}^{-1}$. The size reduction of these fragments as a result of additional cracking is less than a factor of 3 , which accounts only partly for the decreasing overpotential during the activation process. Consequently, the heterogeneous rate constant of the charge transfer reaction has increased during the activation process.

The thickness of the electrode pellets was accurately determined by means of low-magnification SEM photographs. The thickness of $\mathrm{LaNi}_{5}$ electrodes, con- 
taining about 80 wt $\%$ copper, gradually increased with growing $\mathrm{La}(\mathrm{OH})_{s}$ concentration from 0.45 to $0.69 \mathrm{~mm}(>50 \%$ !) without the electrodes falling apart. The mechanical strength of the copper matrix ensured the maintenance of electrical contact.

\subsection{Conclusions}

The large amount of hydrogen stored and released electrochemically in $\mathrm{LaNi}_{5}$ and $\mathrm{LaNi}_{4} \mathrm{Cu}$ is practically the same as that determined from gas absorption/desorption experiments on these materials. The rechargeable electrodes made from these intermetallic compounds allow high rate charging and discharging of the full capacity at low overpotentials in the vicinity of the reversible hydrogen electrode potential.

During repeated cycling the storge capacity declines drastically as a result of the conversion of the intermetallic compounds into $\mathrm{La}(\mathrm{OH})_{9}$ and $3 d$ transition metal precipitates. This conversion process can be described by the exponential decay function

$$
C(n)=C_{0} \exp \left(-\frac{n}{n^{*}}\right)
$$

The $n^{*}$ value for these compounds is about 200 cycles. To meet the requirements of practical rechargeable battery electrodes, it should be increased by a factor of 10 .

The rate-determining step in the deterioration process is the segregation of the intermetallic compound. Because of the heterogeneous character of this reaction, its rate can be expected to change proportionally with the specific surface area. The final sutface area value of hydrogen-gasncycled $\mathrm{LaNi}_{6}$ and $\mathrm{LaNi}_{4} \mathrm{Cu}$ powder amounts to $0.25 \mathrm{~m}^{2} \cdot \mathrm{g}^{-1}$. However, during the first 25 to 50 galvanostatic cycles, i.e. during the activation process, the sur face area of the active material is increased by a factor of 2 to 3 as a result of further disintegration. This increase did not progressively affect the capacity degradation rate. On the contrary, for all 350 cycles the rate of the degradation process continuously decteased with the cycle number

$$
v=-\frac{\mathrm{d}}{\mathrm{d} n} C(n)=\frac{1}{n^{*}} C(n) .
$$

This observation may be interpreted in tertms of a gradual improvement of the surface layer protection, because this layer becomes more and more enriched by precipitates of the more noble element(s). But even after a considerable fraction of the intermetallic compound has been converted, the protection remains completely insufficient. 
Another explanation for the diminishing conversion rate follows from the fact that eq. (36) is a first order rate equation. The degradation rate is proportional to the actual capacity, i.e. to the amount of remaining active material. This is a rather unexpected relationship for a heterogeneous reaction. However, it suggests that the capacity decay is related to the storage process. This means that the rate-determining step, i.c. the segregation of the intermetallic compounds, depends on the absorption and release of hydrogen by this compound. The thermodynamical, driving force for segregation is the large decrease of the Gibbs frece energy duc to the formation of $\mathrm{La}(\mathrm{OH})_{3}$. However, the mobility of the constituent elements at room temperature is very low. Because of the negligible heat effects of $\mathrm{LaNi}_{5}$ electrodes, the rate of the segregation reaction is not increased by a tempcrature rise. Therefore the kinetics of the segregation reaction should be affected by the repeated expansion and shrinkage of the particles during cycling. The mechanical stress accompanying this 'respiration' process can be regarded as the 'driving' force for the 'peristaltic' transport of lanthasum to the surface.

As a consequence of this latter explanation, we fornulated the hypothesis that a reduction of the lattice expansion during hydriding should lead to more stable metal hydride electrodes.

\section{REFERENCES}

9) II Zijlstra and F, F. Westomdorp, Solid Stale Comm. 7. 857 (1969).

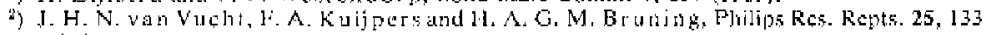
$1,70)$.

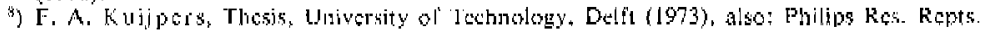
Sippl., No. 2 (1973)

1) H. M. van Mal, Thesix, University of Testuology, Deltt (1976), alko: Philips Res. Repts. Sippl., No. 1 (1976).

5) H. Ewe, E. W. Jati and K, Stephan, Encrgy Conversion 13, 109 (1973).

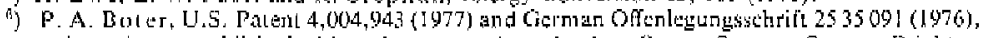
and rewhts. unpublished aluowsh presented at the Int. Power Sources Syrmp. Brigliton (1974).

य) G. Bronod, J, Sartadin, M, Bonnemey, A. Percheron, I. C. Acbatd and l..

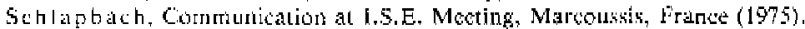

) M. I. J. van Rijswick, Proe. lot, Symp. Hydrides for Energy Storage, Geilo, Norway, 261 (197\%)

9) G. Bronoel, 5. Sartacin, M. Bonnemay, A. Fercheron, J, C. Achard and l.. Schlapbach, lot. I, of Hydrogen Finergy 1, 251 (1976).

10) A, Pereheron-Giuegen, I. C. Aehard, J. Sarradinand G. Bronö̈, Pros. Int. Symp. Hydrides for Lnergy Sisrage, Gélo, Norway, 485 (I977).

11) T. L. Markin, N. J, Hridger, R. Bennet and k. M. Dell. Proc, 28th Power Sources Symup., Nilanlic: Cily, $136(1978)$

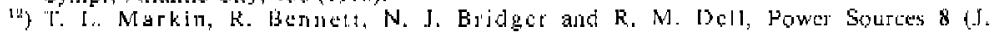
'hongson, ed.), Acaderuic Prest, absti, 29 (1981).

18) T. L. Markij and R. M. Del, I. E.jectroanal. Chenn. 118, 217 (1981).

14) G. L. Holleck, J. R, Dijscoll and B. E. Paul, J. Less-Cormon Met, 74, 379 (1960).

17) II, J", Billnel and C, C. Rad ouck, J. Electrochem. 5oc. 130, 193C. (1983),

18. K. H. J. Buschow and H. H. van Mal. I. Less-Common Mel. 29, 203 (1972). 
17) International Elettrotechnical Commission, Sub-Comnittee 21 A: Alkaline Accumulators, publication 285.

13) H. H. van Mal, K. H. J. Buschow and A. R. Miedema, J, L.c55-Common Met, 35, 65. (1974).

F) K. H. J. Buschow, P. C. P. Bouten snd A. R. Miedema, Rep. Prog. Phys, 45, 937 (1982).

20, .F. Newman, Electrochemiçal Systems, Prentice-Hail, Englewood Cliffs (1973).

${ }^{2}$ ) A. J. Bard and I.. R. Faulkner, Electrochemical Methods, John Wilcy \& Sons, New York (1980).

$\left.{ }^{27}\right)$ J, $Q^{\prime} M$. Bockris and D. Drazic, Electrocherrical Science, Taylor \& Francis, London (1972).

23) M. Pourbaix, Atlas of Electrochemical Equilibria in Aqucous Solution. NACE, Houston (1974).

24) N. Bocs and M. Züchner, Z. Naturforsch. Teil A. 31, 754 (1976).

ah B. Schroder, H. W. Schröecr and E. von Reusen, Patentschrift DE 323467 Cl.

ath J. H. Wernick and S. Geller, Acta Cryst, 12, 662 (1959).

${ }^{27}$ L. Schlapbach, A. Seiler, H. C. Siegmenn, T' van Waldki'ch, P, \%ijroher ard C. R. Brundle, Int. J. Hydrogeri Energy 4, 21 (1979).

54) L.Sehlapbach, A. Seiler, F. Stuchi and H. C. Siggnann, J. Less-Common Met, 73, 145 (1980).

29) A. R. Miedcma, 2. Metallkde, 69, 455 (1978).

36) D. Ohlendorf and II. E. Flotow, J. Chem. Phys. 73, 2937 (1980).

31) F. C. Hiemeria, Principles of Colboid and Surface Chemistry, Marcel Dekker', New York (197\%)

sx) A. L. MeGcllan and H. F. Hatrsberger, J, Coll. Int. Sci, 23, 577 (1967).

85) G. D. Sandrock and P. D. Goodoll, J. T.css-Common Mel. 73, 16l (1980). 


\section{MULTICOMPONENT ELECTRODES}

\subsection{Introduction}

We concluded the previous chapter with a hypothesis for improving the stability of metal hydride electrodes. Hydride electrodes made of a compound the lattice constants of which increase less than those of $\mathrm{LaNi}_{5}$ on hydriding would be more stable than $\mathrm{LaNi}_{5}$ electrodes. Hence, in order to examine this hypothesis experimentally, intermetallic compounds which expand less on hydriding, are required.

Van Mal, Buschow and Kuijpers ${ }^{1}$ ) investigated the hydrogen absorption of LaNi $\mathrm{Ni}_{6-} \mathrm{CO}_{2}$ compounds and the corresponding changes in lattice parameters as a function of the composition parameter $z$. They obtained the hydrogen pressure-concentration isotherms of the $\mathrm{LaNi}_{5-5} \mathrm{Co}_{5}$ series during desorption, see fig. 28. The largest hydrogen absorption capacity is observed for $\mathrm{LaNi}_{5}$ $(z=0): 6 \mathrm{H}$ atoms per formula unit at a constant pressure level, the plateau pressure. Whereas the isotherms of the compound with $z=0.5$ and $z \geqslant 3.5$ contain two well defined plateaus, the equilibrium pressure of compounds with intermediate $z$ values increases continuously with the hydrogen concentration after the first hydride phase has been formed. Replacement of nickel by cobalt lowers the equilibrium pressure of the first hydridc. Moreover, the maximum absorption capacity at moderate pressures ( $p_{\mathrm{H}_{2}} \leqslant 10 \mathrm{~atm}$ ) decreases gradually with increasing cobalt content.

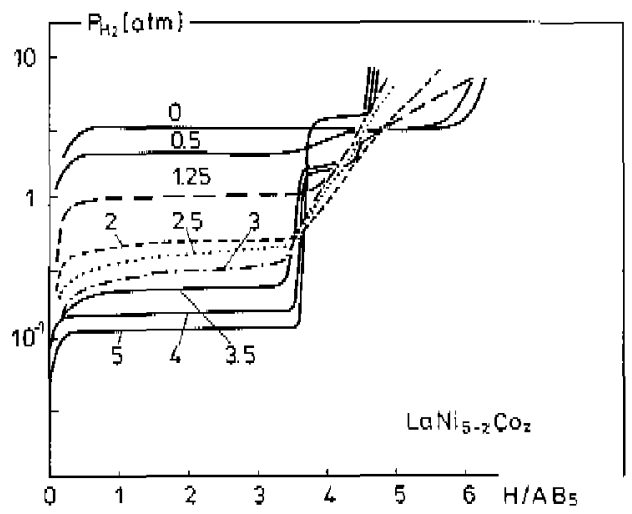

Fig. 28. Piessure-concent 7 tion isotherms of various $\mathrm{LaNi}_{5-2} \mathrm{Co}_{2}-\mathrm{H}_{2}$ systems obtained during desorplion at $40^{\circ} \mathrm{C}$; the $z$ valucs are indicated (data from ref. 1). 
All the hexagonal compounds of the $\mathrm{LaNi}_{s-z} \mathrm{Co}$ system possess a limited hydrogen solubility of a few tenths of a $\mathrm{H}$ atom per formula unit. This hydrogen-poor phase is denoted by $\alpha$. The changes in lattice dimensions of the various $\mathrm{LaNi}_{5-x} \mathrm{CO}_{x}$ compounds caused by hydrogen absorption lead to the formation of four distinguishable hydride phases, denoted by $\beta^{\mathrm{I}}, \gamma, \mathrm{H}^{1}$ and $\mathrm{H}^{\mathrm{H}}$. Both the $\beta^{\mathrm{I}}$ and the $\gamma$-structures are orthorhombic, because of an anisotropic expansion of the originally hexagonal basal plane of the $\mathrm{CaCu}_{5}$-type ${ }^{2}$ ). The $\mathrm{H}^{\mathrm{I}}$ and $\mathrm{H}^{\mathrm{II}}$ phases are indexed hexagonally, but are probably orthothombic with a lattice constant ratio $a / b=\sqrt{3}$. The occurrence of these crystallographically different phases is indicated schematically in fig. 29 as a func-

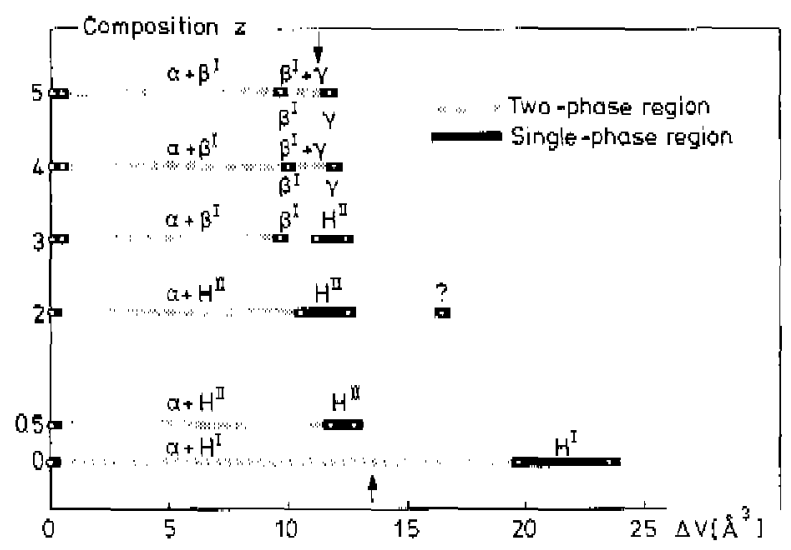

Fig. 29. Schematic representation of the changes in phase obeerved by X-tay diffraction in LaNi $i_{-2} \mathrm{Co}_{2}$ samples after increasing the hydrogen content; $\Delta V$ rcpresents the absolutc volume increase per formula unit. The two arrows indicate a hydroges eoneeritration of $4 \mathrm{H}$ atoms per formula unit (data from ref. l).

tion of the hydrogen-induced lattice expansion, $\Delta V$. This figure clearly shows that even a partial substitution of cobalt for nickel in $\mathrm{LaNi}_{5}$ results in a considerable reduction of the expansion of the unit cell.

We therefore studicd the relationship between the stability and the unit cell expansion of $\mathrm{LaNi}_{6}$-related compounds, modified by substitution. Electrodes made of such compounds are here referred to as multicomponent electrodes. Furthermore, the dependence of the stability on the specific surface area and on the cycle procedure was investigated. 


\subsection{I altice expansion and stability}

\subsubsection{Litectrochemical data}

The capacily curve of the multicomponent electrodes was determined from repeated galvanostatic charging and discharging over many cycles. The sample preparation and measuring equipnent were as described for LaNi in sec. 3.2,1. However, sone of the as-cast samples of the substituted intermetallic eompounds necded vacuum-annealing at high temperatures, i.c., $800 \approx T \approx 1100^{\circ} \mathrm{C}$, to obtain homogeneous compounds with the $\mathrm{CaCu}_{5}$ structure

The changes of the total storage capacity of the $\mathrm{LaNi}_{3-1} \mathrm{Co}_{2}$ and $\mathrm{LaNi}_{5-2} \mathrm{CO}_{2} \mathrm{Al}_{1}$ systerns with the cyule number are depicted in the figs 30 and 31 , respectively. As in the previous chapter, the total storage capacity $C_{1}$ is considered to be equal to the sum of a high-discharge-rate capacity and the additional $0.125 \mathrm{C}$ rate capacity. At first all electrodes were both charged (1 hour) and discharged at $1.25 \mathrm{C}$ rate. After approximately one hundred cycles the charging enditions were altered to $2.5 \mathrm{C}$ rate for half an hour while the discharge rate was kcpt unchanged. Between the $250 \mathrm{~h}$ and the 350 th cycle the discharge rate was also increased to $2.5 \mathrm{C}$. The doubling of the charge current did not generally affect the $C_{t}$ curve. However, for some compounds slightly diminished $C_{t}$ values were found, probably duc to somewhat less efficient hydrogen absorption. On the other hand, the positive step in the storage capacity values mcasured after increasing the discharge current is attributod to a smaller loss of stored hydrogen by spontaneous desorption in an open ecll.

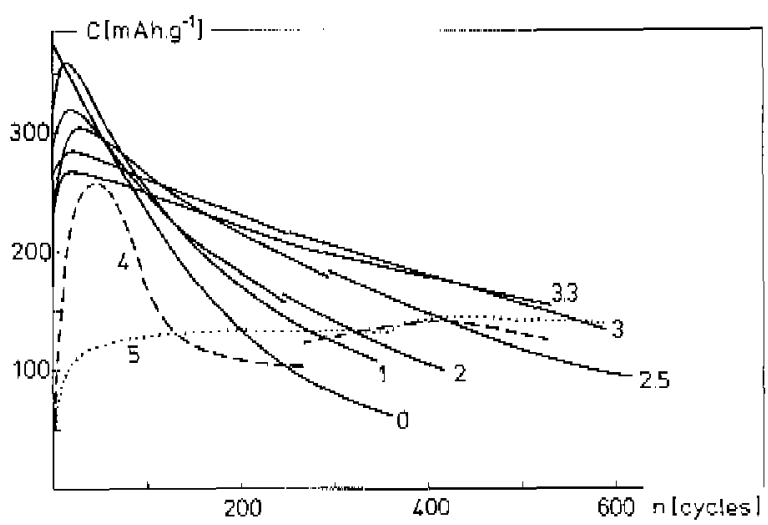

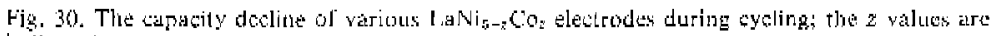
indigated. 


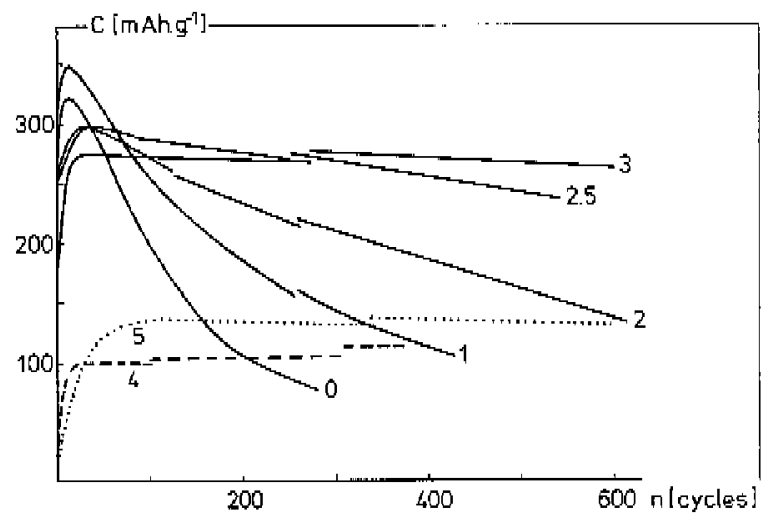

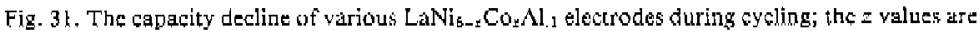
indiçated.

The measured capacity curves of the compounds with the highest cobalt content, i.e. $z=4$ or 5 , differ markedly from the others. The reason for this unexpected behaviour is not clear. On the contrary, the capacity curves of the compounds with $z \leqslant 3.3$ change gradually as a function of $z$. Both the initial capacity and the capacity decay rate decrease with increasing substitution of cobalt for nickel.

We also conducted investigations into the $\mathrm{LaNi}_{5-z} \mathrm{Co}_{2} \mathrm{Si}_{11}$ system, the results of which were nearly identical to those for the $\mathrm{LaNi}_{5-z} \mathrm{Co}_{z} \mathrm{Al}_{\text {. }}$ system. Furthermore, we measured the electrochemical behaviour of intermetallic compounds in which also the constituent lanthanum was partially replaced by other lanthanides and/or titanium. An essential feature of all these lanthanumreplacing elements is that each forms a stable binary hydride. An example of this type of material is $\mathrm{La}_{.5} \mathrm{Nd}_{2} \mathrm{Ni}_{2.8} \mathrm{Co}_{2.4} \mathrm{Si}_{1 .}$. The variation of both the $1.25 \mathrm{C}$ rate capacity and the total storage capacity of a $\mathrm{La}_{8} \mathrm{Nd}_{2} \mathrm{Ni}_{2,5} \mathrm{Co}_{2,4} \mathrm{Si}_{11}$ electrode is represented in fig. 32. Charging of this electrode was also carried out at the $1.25 \mathrm{C}$ rate. In this figure two important characteristics of this multicomponent electrode are shown. First, the excellent stability is demonstrated by the very small capacity loss after more than six hundred and fifty cycles. The average capacity decay rate is 0.35 times the initial capacity per thousand cycles. Moreover, the small contribution of the additional $0.125 \mathrm{C}$ rate cappacity illustrates the high-rate chargeability and dischargeability.

A survey of the initial storage capacity and the stability of nineteen multicomponent electrodes is given in table VI. Because the capacity decay could 


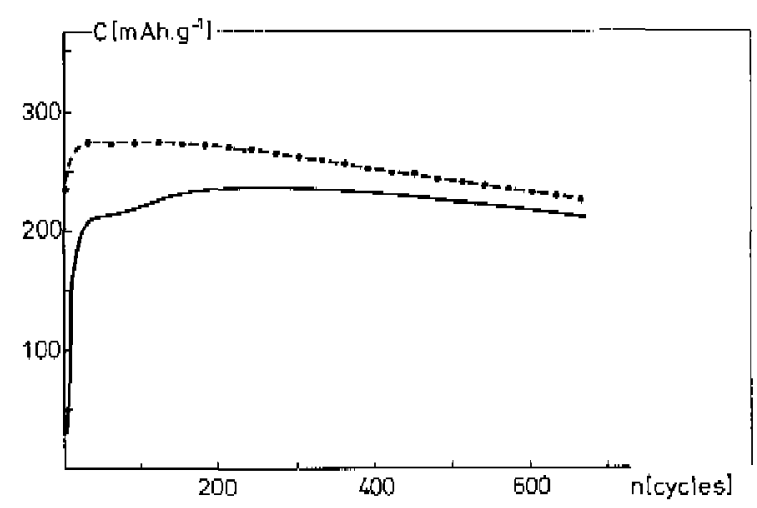

Fig. 32. The capacity curves of a $\mathrm{La}_{8} \mathrm{Nd}_{.2} \mathrm{Ni}_{2,5} \mathrm{Co}_{2,4} \mathrm{Si}_{1}$ clcctrode; upper: total storage capacity, lower: 1.25 C ratc capacity,

not generally be described by a simple linear or exponential function, the stability is expressed in terms of a capacity ratio

$$
S_{400}=\frac{C_{t}(400)}{C_{t}(0)} .
$$

Here, $C_{\mathrm{t}}(0)$ and $C_{\mathrm{t}}(400)$ represent respectively the initial total storage capacity, determined from extrapolation to the zeroth cycle, and the remaining total storage capacity after four hundred cycles. Although this stability parameter has been chosen rather arbitrarily, it facilitates comparison of the tested materials. Several compounds were found to lose less than twenty percent of their storage capacity after four hundred cycles $\left(S_{400} \geqslant 80\right)$, and therefore arc designated as stable electrode materials.

Table VI also gives the number of stored hydrogen atoms per formula unit, $x$, the value of which was calculated from $C_{1}(0)$ according to eq. (15). Within a group of materials, with or without aluminium or silicon, the stability is inversely related to the number of stored hydrogen atoms. H. Peis ${ }^{3}$ ) has reported that the absorption of hydrogen by metals increases the unit cell volume by $2.9 \AA^{3}$ per stored hydrogen atom independent of the material. This already suggests a relationship between the stability and the expansion of the lattice.

\subsubsection{Crystallographic data}

The crystallographic data for the substituted intermetallic compounds and their hydrides were determined by $\mathrm{X}$-ray diffraction analysis. The experimental approach was the same as that used for $\mathrm{LaNi}_{6}$ and $\mathrm{LaNi}_{4} \mathrm{Cu}$ samples. 


\section{TABLE VI}

The initial storage capacity, expressed in $C_{t}(0)$ and in the number of absorbed $\mathrm{H}$ atoms per formula unit compared with the stability of multicomponent electrodes, $S_{400}$.

\begin{tabular}{|c|c|c|c|c|}
\hline compound & & $\begin{array}{c}C_{1}(0) \\
\left(\mathrm{mAh} \cdot \mathrm{g}^{-1}\right)\end{array}$ & $\begin{array}{c}x \\
\left(\mathrm{H} / \mathrm{AB}_{6}\right) \\
\end{array}$ & $S_{400}$ \\
\hline $\mathrm{LaNi} 1_{6-\pi} \mathrm{Co}_{2}$ & $\begin{aligned} z= & 0 \\
1 & \\
& 2 \\
& 2.5 \\
& 3 \\
& 3.3\end{aligned}$ & $\begin{array}{l}372 \\
372 \\
342 \\
324 \\
292 \\
273\end{array}$ & $\begin{array}{l}6 \\
6 \\
5.5 \\
5.2 \\
4.7 \\
4.4 \\
\end{array}$ & $\begin{array}{l}.12 \\
.25 \\
.30 \\
.45 \\
.61 \\
.64\end{array}$ \\
\hline $\mathrm{LaNi} i_{5-\pi} \mathrm{Co}_{7} \mathrm{Al}_{.1}$ & $\begin{aligned} & z= 0 \\
& 1 \\
& 2 \\
& 2.5 \\
& 3 \\
&\end{aligned}$ & $\begin{array}{l}355 \\
365 \\
315 \\
313 \\
289 \\
\end{array}$ & $\begin{array}{l}5.8 \\
5.9 \\
5.1 \\
5.1 \\
4.7 \\
\end{array}$ & $\begin{array}{l}.16 \\
.30 \\
.59 \\
.82 \\
.94 \\
\end{array}$ \\
\hline $\mathrm{LaNi}_{4-x} \mathrm{Co}_{2} \mathrm{Si}_{.1}$ & $\begin{array}{c}z=1 \\
2 \\
2.5 \\
3\end{array}$ & $\begin{array}{l}350 \\
310 \\
296 \\
280 \\
\end{array}$ & $\begin{array}{l}5.7 \\
5.0 \\
4.8 \\
4.6\end{array}$ & $\begin{array}{l}.33 \\
.65 \\
.81 \\
.96 \\
\end{array}$ \\
\hline $\begin{array}{l}\mathrm{La}_{.8} \mathrm{Nd}_{, 4} \mathrm{Ni}_{3} \mathrm{Co}_{2} \\
\mathrm{La}{ }_{3} \mathrm{Nd}_{.3} \mathrm{Ni}_{2.5} \mathrm{Co}_{2,4} \\
\mathrm{La}_{.8} \mathrm{Nd}_{.8} \mathrm{Ni}_{2.5} \mathrm{Co}_{2.4} \\
\mathrm{La}_{.7} \mathrm{Nd}_{.2} \mathrm{Ti}_{.1} \mathrm{Ni}_{2.5} \mathrm{C}\end{array}$ & $\begin{array}{l}\mathrm{Al}_{.3} \\
\mathrm{Si}_{. \mathrm{I}} \\
\mathrm{O}_{2.0} \mathrm{Al}_{.5}\end{array}$ & $\begin{array}{l}302 \\
293 \\
293 \\
254\end{array}$ & $\begin{array}{l}4.9 \\
4.8 \\
4.7 \\
3.9\end{array}$ & $\begin{array}{l}.48 \\
.87 \\
.88 \\
.90\end{array}$ \\
\hline
\end{tabular}

Hydriding was achieved by exposure to hydrogen gas at 150 atm for at least 24 hours, and desorption during recording of the $X$-ray diagrams was prevented by coating the hydrided powders with glue.

The data on the expansision of the lattice constants and of the unit cell due to hydriding are summarized in tables VII A and VIIB. The hydride phase of the compounds with $z \leqslant 3.3$ has been indexed hexagonally, table VIIA, whereas the structure of the hydride phases richer in cobalt is orthorhombic, table VII B. Our results for the $\mathrm{LaNi}_{5-z} \mathrm{Co}_{z}$ system agree very well with the data reported previously ${ }^{1}$ ). The anisotropic expansion of the basal plane reşults in the formation of the orthorhombic structure. Furthermore, with increasing cobalt content the elongation of the $c$-axis $(\Delta c)$ decreases much faster than that of the $a-$ or $b$-axis ( $\Delta a$ or $\Delta b$ ). This is attributed to the re- 


\section{TABLE VIIA}

Lattice expansion due to the lormation of hexagonal hydrides.

$V$ is the unit cell volume of the intermetallic compounds; $V_{\mathrm{H}}=\Delta V / x$ : the unit cell expansion in $A^{*}$ per absorbed $\mathrm{H}$ atom.

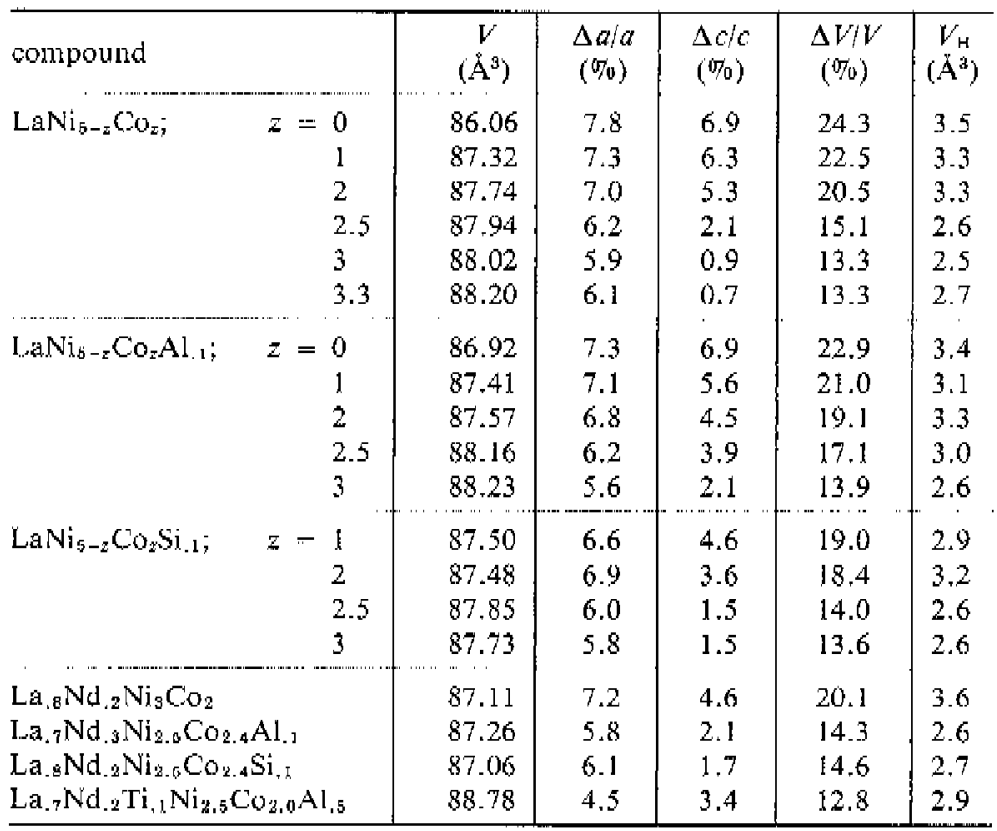

\section{TABLE VIIB}

Lattice expansion due to the formation of orthorhombic hydrides. $V$ is the unit cell volume of the hexagonally indexed intermetallic compound. The volume of the orthorhombic unit cell is twice as large.

\begin{tabular}{l|c|c|c|c|c}
\hline compound & $\begin{array}{c}V \\
\left(\AA^{3}\right)\end{array}$ & $\begin{array}{c}\Delta a / a \\
(\%)\end{array}$ & $\begin{array}{c}\Delta b / b \\
(\%)\end{array}$ & $\begin{array}{c}\Delta c / c \\
(\%)\end{array}$ & $\begin{array}{c}\Delta V / V \\
(\% / \%)\end{array}$ \\
\hline $\mathrm{LaCo}_{6}$ & 89.56 & 7.3 & 5.2 & 0.2 & 13.1 \\
$\mathrm{LaNiCO}_{4} \mathrm{Al}_{.1}$ & 89.44 & 5.9 & 6.4 & 1.1 & 13.9 \\
$\mathrm{LaCo}_{5} \mathrm{Al}_{.1}$ & 89.88 & 4.4 & 6.2 & 0.2 & 1.1 \\
$\mathrm{LaNiCO}_{4} \mathrm{Si} .2$ & 89.09 & 5.8 & 6.4 & 0.4 & 13.0 \\
\hline
\end{tabular}


duced number of absorbed hydrogen atoms; these hydrogen atoms preferentially occupy sites in the metal layers perpendicular to the $c$-axis ${ }^{2}$ ).

The volume expansion of the unit cell decreases from twenty four percent for compounds rich in nickel to about thirteen percent for compounds containing nickel and cobalt in the ratio 2:3. Further replacement of nickel by cobalt does not appreciably influence the volume expansion. Table VII A also gives the volume expansion of the unit cell per stored hydrogen atom. For the calculation of this quantity the elcetrochemically-determined $x$ value given in table VI was used. Although the average value of the 'hydrogen atom volume', $V_{\mathrm{H}}$, is $2.9 \hat{A}^{3}$ (the value reported by Peisl ${ }^{3}$ )) the intermetallic compounds can easily be divided into two groups: the nickel rich matcrials $(z=0$, 1 or 2) with $\overline{V_{H}}=3.3 \AA^{3}$ and the compounds with $\overline{V_{H}}=2.7 \AA^{3}$.

This observation may be aseribed to the loss of the original volume contraction which generally accompanies the formation of intermetallic compounds. The volume contraction upon formation of $\mathrm{AB}_{3}$ compounds is due to a redistribution of the electronic charge between the electropositive lanthanide atoms with a low electron density and the electronegative cobalt or nickel atoms with a high electron density ${ }^{*}$ ). If one calculates the volumes of the $\mathrm{LaNi}_{5}$ and the $\mathrm{LaCO}_{5}$ unit cell from the atomic volumes of the pure constituents 92.0 and $92.8 \AA^{3}$ are found, respectively. Comparison of these values with the unit cell volume presented in the tables VIIA and VII B shows that the volume contraction upon the formation of $\mathrm{AB}_{5}$ compounds is much larger for the nickel rich compounds than for the cobalt rich compounds. On the other hand, hydrogen absorption results in a partial reestablishment of the atomic volumes because the electron density of hydrogen is smaller than that of njckel or cobalt. A larger apparent hydrogen atom volume is therefore expected for the nickel rich intermetallic compounds. As an advantageous consequence, the storage capacity does not decline in proportion to the reduction of the volume expansion, but less rapidly.

The electrochemical and crystallographic data may only be related 10 one another if the corresponding hydride phases have the same composition. The composition of a hydride, i.c. the value of $x$ in $\Delta \mathrm{B}_{5} \mathrm{H}_{*}$, depends on the hydrogen equilibrium pressure. In electrochemical cxperiments in an open cell the maximum 'pseudo-equilibrium' hydrogen pressure is about 10 atm, as is indicated by the open circuit potential of fully charged electrodes, $E_{0}=-960 \mathrm{mV}$. The volume expansion of the intermetallic compound $\mathrm{La}{ }_{8} \mathrm{Nd}_{2} \mathrm{Ni}_{2.5} \mathrm{Co}_{2.4} \mathrm{Si} .1$ on hydriding was also detcrmined during exposure to hydrogen gas at different pressures. As sample holder for recording $X$-ray diagrams, we used a pressure vessel which comprised a beryllium window. The sample was a porous pellet consisting of an equal anount of $\mathrm{La}_{8} \mathrm{Nd}_{2} \mathrm{Ni}_{2.6} \mathrm{Co}_{2.4} \mathrm{Si}_{2 .}$ powder and nickel powder . 


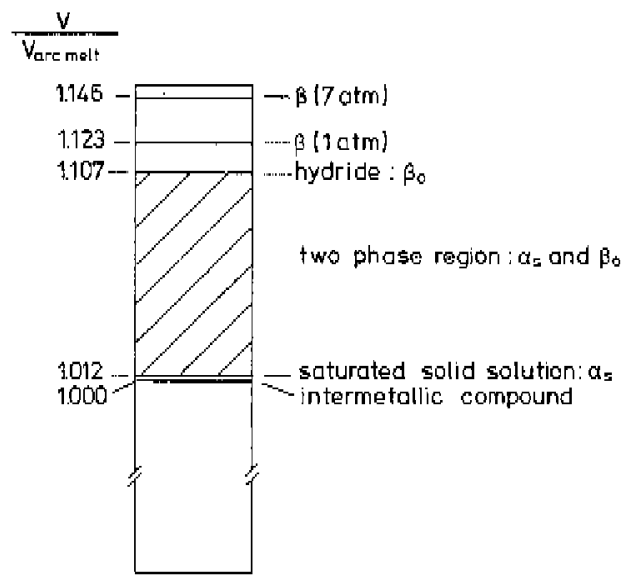

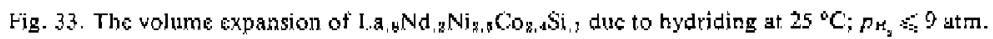

The relative volume change of this intermetalic compound at different stages of hydriding is illustrated in fig. 33. Whereas the lattice expansion of $\mathrm{LaNi}_{F}$, $24.3 \%$ is mainly due to the phase transition $\mathrm{LaNi}_{5} \mathrm{H}_{5} \rightarrow \mathrm{LaNi}_{5} \mathrm{H}_{6}$, only a volume increase of $9.5 \%$ is found for the saturated solid solution -- hydride transition $\left(\alpha_{5} \rightarrow \beta_{0}\right)$ of $\mathrm{La}, 8 \mathrm{Nd}_{.2} \mathrm{Ni}_{2.5} \mathrm{CO}_{4,4} \mathrm{Si}_{, 1}$. After this phase transition the volume gradually increases as more hydrogen atoms dissolve in the hydride phase. The volume expansion determined from the hydride phase which was prepared by exposure to $150 \mathrm{~atm}$ and glue coating is the same as that of the hydride which is in equilibrium with hydrogen gas of $7 \mathrm{~atm}$. Thus, the expansion data of table VII also describe the volume increase during electrochemical charging.

\subsubsection{Discussion}

The data on the stability of multicomponent electrodes during repeated charging and discharging and on the lattice expansion of the corresponding intermetallic compounds during hydriding have already been presented in the previous sections. In fig. 34 we have plotted the stability parameter $S_{400}$ as a function of the relative volume increase. Two classes of intermetallic compound can be discerned: compounds of the $\mathrm{LaNi}_{5-z} \mathrm{Co}_{*}$ system and materials containing a small amount of aluminium or silicon. For both classes the stability increases proportionally to the decreasing volume expansion. The increasing anisotropy of the lattice expansion with increasing cobalt content (table VIIA) is no obstacle for the growing stability, 


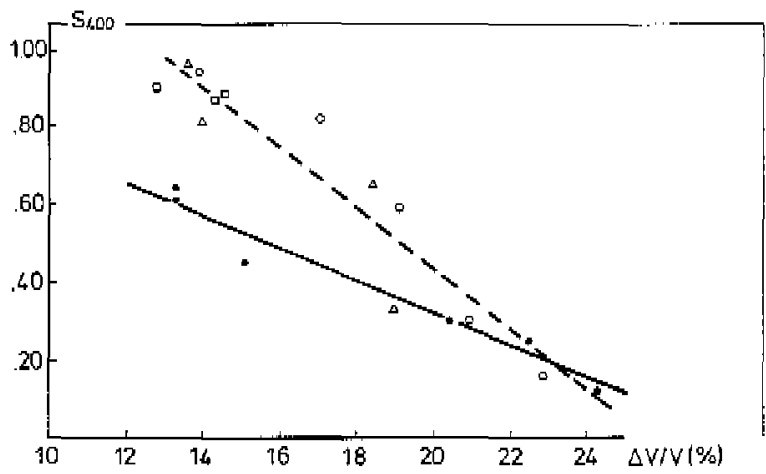

Fig. 34. The stability $S_{a y 0}$ of LaNis-related hydride electrodes as a function of the lattice ex-

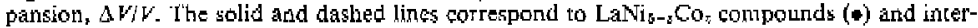

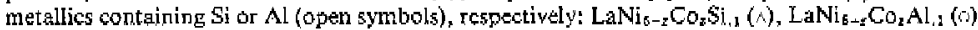
and others (ri).

Our hypothesis that a reduction of the lattice expansion during hydriding should lead to more stable metal hydride electrodes has thus beetr verified by the experimental results, presented in this section. The basis of the hypothesis was that mechanical stress çaused by the repeated absorption and release of hydrogen will enhance the local mobility, i.e. the local diffusion rate, of the constituent metal atoms enabling segregation to take place even at room temperature. The magnitude of the surface area is assumed to be the same for all compounds, at least after a certain number of cycles. However, a reduction of the volume expansion may also lead to less disintegration, leaving larger particles and therefore resulting in a diminished corrosion rate.

It is remarkable that two classes of intermetallic compound have been observed. The slope of the linear relationships of fig. 34 is a measure for the sensitivity to mechanical stress due to lattice expansion. The sensitivity of the compounds containing aluminium or silicon is twice that of the $\mathrm{LaNi}_{5-2} \mathrm{CO}_{7}$ compounds. The small additions of aluminium or silicon, only two atomic percent, may impede the transport of lanthanum or neodymium to the surface by the formation of an oxide layer. This sur face layer is only capable of maintaining its obstructing function if it is not damaged, i.e. eracked, by the volume changes of the particle. This interpretation is consistent with the high sensitivity to mechanical stress. Alternatively, the process of disintegration of the intermetallic compounds may be influenced by small additions of aluminium or silicon.

Clearly, the particle size of stable intermetallic compounds needs further examination. 


\subsection{Specific surface area: results and discussion}

The stability of several multicomponent electrodes is higher than that of $\mathrm{LaNi}_{n}$ by a factor of seven to eight. If it is assumed that the corrosion rate per unit surface area is indopendent of the material, the final particle size of these stable intertnetallic compounds should be seven to eight times larger than that of LaNi

The specific surface area of the stable compounds $\mathrm{La} .7 \mathrm{Nd} .2 \mathrm{Ti}_{.2} \mathrm{Ni}_{2.5} \mathrm{Co}_{2.0} \mathrm{Al}$.s and $\mathrm{La}_{4} \mathrm{Nd} .2 \mathrm{Ni}_{2.5} \mathrm{Co}_{2.4} \mathrm{Si}_{1}$ after pulverization by continuous gas cycling was determined by the BET mothod; sec sec. 3.4. After 25 to 50 hydrogen gas absorption/desorption cycles the 'final' particle size was obtained. The corresponding value of the specifie surface area was found to be $0.25 \mathrm{~m}^{2}+\mathrm{g}^{-1}$, as shown if table VIlI. The powder obtained by mechanical grinding had ap-

\section{TABLE VIII}

The specific surface area of $\mathrm{La}_{10} \mathrm{Nd}_{2} \mathrm{Ti}_{1,1} \mathrm{Ni}_{2,5} \mathrm{Co}_{2,0} \mathrm{Al}, 5$ and La.8Nd. $\mathrm{Ni}_{2.5} \mathrm{Co}_{2.4} \mathrm{Si}$. powder as a function of the number of hydrogen gas absorption/desorption cycles.

\begin{tabular}{|c|c|c|}
\hline compound & $n$ (cycles) & $S A\left(m^{2} \cdot g^{-1}\right)$ \\
\hline $\mathrm{Lad.7}_{7} \mathrm{Nd} .2 \mathrm{Ti}_{.2} \mathrm{Ni}_{2.5} \mathrm{Co}_{2.0} \mathrm{Al}_{.6}$ & $\begin{array}{r}25 \\
150 \\
300 \\
715\end{array}$ & $\begin{array}{l}0.26 \\
0.23 \\
0.23 \\
0.25\end{array}$ \\
\hline $\mathrm{I}_{\mathrm{A}_{-} 8} \mathrm{Nd}{ }_{2} \mathrm{Ni}_{2}{ }_{6} \mathrm{Co}_{2.4} \mathrm{Si}_{-1}$ & $\begin{array}{r}25 \\
75 \\
98 \\
750 \\
*)\end{array}$ & $\begin{array}{l}0.18 \\
0.25 \\
0.21 \\
0.19 \\
0.17\end{array}$ \\
\hline
\end{tabular}

") Pulverization was carried out by mechanical grtinding.

proximately the same specific surface area. Thus, as a result of repeated trydrogen gas absorption and desorption, these stabie compounds crack at the same rate and to the same extent as $\mathrm{LaNi}_{5}$ and $\mathrm{LaNi}_{4} \mathrm{Cu}$.

The increase of the BET surface area of $\mathrm{La}_{.8} \mathrm{Nd}_{.2} \mathrm{Ni}_{2.5} \mathrm{Co}_{2,4} \mathrm{Si}_{1}$ electrodes due to electrochemical cycling was also measured. These clectrodes were made from powder, pulverized by 75 hydrogen gas cycles. Both charging and discharging were carried out at $1.25 \mathrm{C}$ Jatc. At every thirtieth cycle the electrode was additionally discharged at $0.125 \mathrm{C}$ tate. The capacity curves of one of these elcctrode; have already been shown in fig. 32. During galvanostatic cycling the specific surface area, $S A$, increased in proportion to the cycle number, $n$, 
according to the relationship: $S A=2.13+0.035 n \mathrm{~m}^{2} \cdot \mathrm{g}^{-7}$. As with LaNis clectrodes, the possible increase in surface area caused by additional cracking was overshadowed by the high specific surface area of the oxidation products.

The improvement of the reaction kinetics due to the activation process of these $\mathrm{La}_{38} \mathrm{Nd}_{2} \mathrm{Ni}_{2.8} \mathrm{Co}_{2.4} \mathrm{Si}_{.1}$ electrodes is comparable to that of LaNis electrodes. Within 40 cycles the overpotential for hydrogen evolution measured at eight electrodes, decreased by $92 \pm 6 \mathrm{mV}$. Application of eq. (22) with the Tafel slope $b=-118 \mathrm{mV}$ indicates that the quotient $\left(k^{\circ} / d\right)$ after activation is 6 times the initial value. For $\mathrm{LaNi}_{5}$ electrodes we found a factor of 8 . However, scanning electron micrographs showed that the LaNis particle size was reduced less than 3 times.

The changes in the morphology of the multicomponent electrodes during electrochemical cycling were also investigated by scanning electron microscopy, The SEM photographs of $\mathrm{La}_{1} \mathrm{Nd}_{.2} \mathrm{Ni}_{y_{.} .} \mathrm{Co}_{4.4} \mathrm{Si}_{.3}$ electrodes are shown in fg. 35 . The selected micrographs, showing two magnifications of three cleaved electrode pellets, give a good illustration of the alterations due to cycling. The micrographs of an unused electrode in fig. 35( $a$ ) and $(b)$ display a conglomeratc of the disintegrated intermetallic compound embedded in a copper matrix. These photographs are indistinguishable from those for fresh $\mathrm{I}_{\mathrm{aNi}} \mathrm{aN}_{5}$ electrodes; for comparison sce figs $26(a)$ and $27(a)$. After approximately 40 cycles hydroxide needles have been precipitated and the average fragment size has diminished from 7 to $5 \mu \mathrm{m}$. During further cycling the electrode morphology does not change appreciably. The micrographs of fig. 35(e) and $(f)$ show the fragments after 666 cycles. The jagged structure with its sharp edges is still present.

Whereas during electrochemical charging and discharging the specific sur face area of $\mathrm{LaNi}_{6}$ powder increased from $0.25 \mathrm{to} 0.70 \mathrm{~m}^{2} \cdot \mathrm{g}^{-1}$, the specific surface area of stable intermetallic compounds only grew from 0.25 to $0.35 \mathrm{~m}^{2} \cdot \mathrm{g}^{21}$. This difference between $\mathrm{LaNi}_{5}$ electrodes and stable multicomponent elcctrodes can not account for the observed stability improvement. The corrosion rate is therefore mainly determined by factors other than the specific surface area. The relationship between the stability and the lattice expansion on hydriding must primarily be a conscquence of the enhanced segregation rate during cycling.

\subsection{Interrupted galvanostatic cycling; results and discussion}

All the capacity curves presented so far have been measured by continuous repetition of charge/discharge cyctes as described in sec. 3.2. This procedure for examining materials results in a capacity decay rate per cycle, which gives a lifetime expressed in a number of feasible cycles, i.e. the cycle life. Besides the cycle life, the time dependence of the storage capacity is also an essential aspect of the electrode stability. 

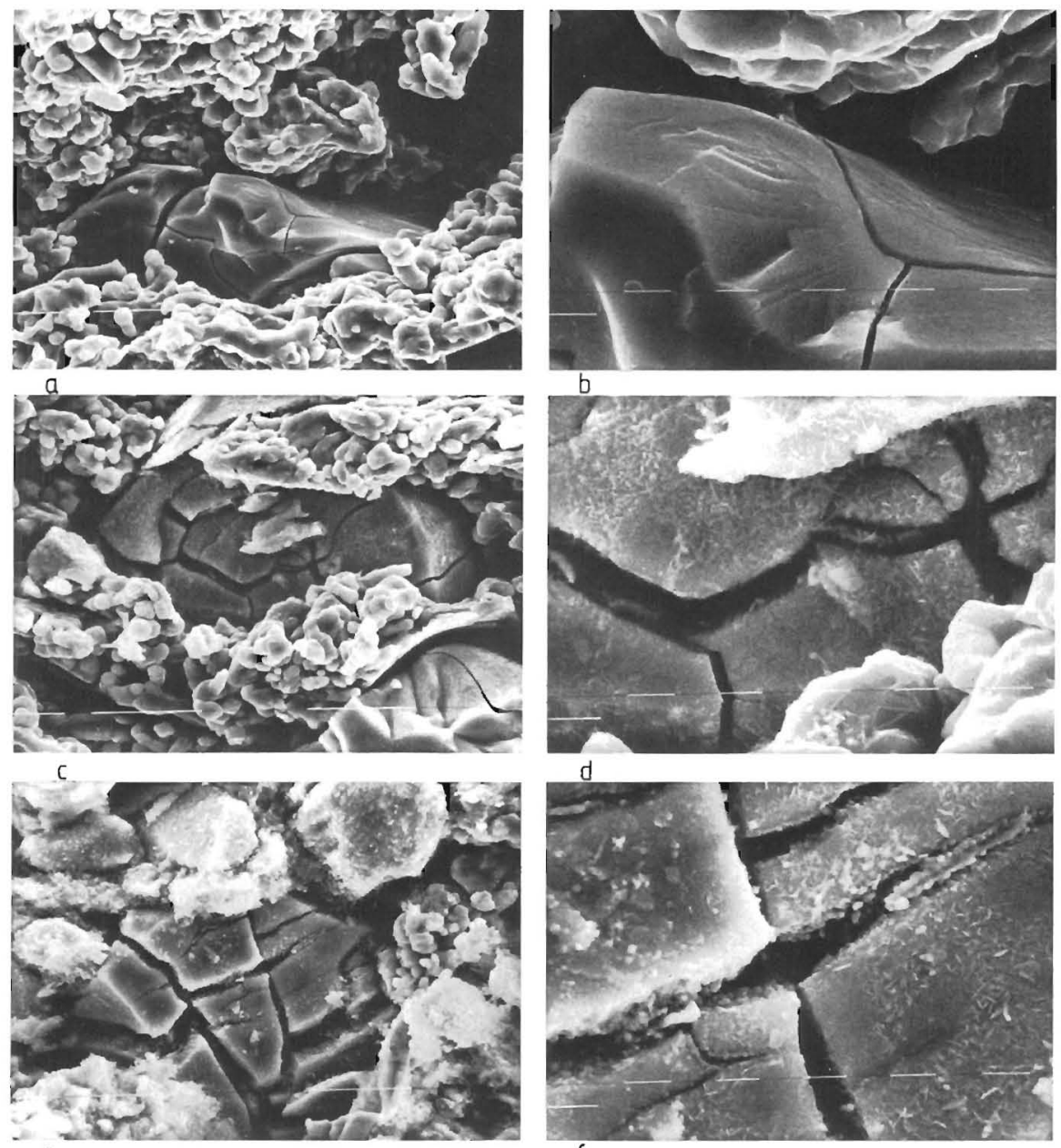

d

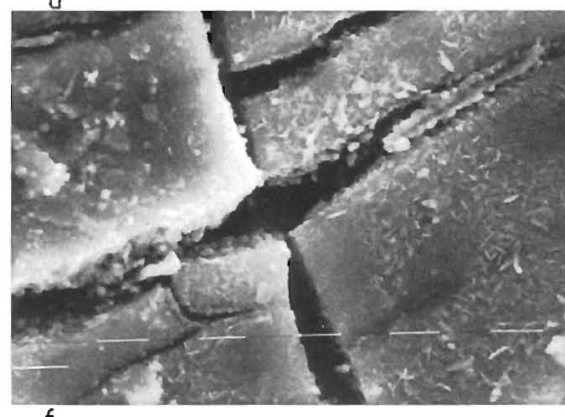

e

f

Fig. 35. SEM photographs of cleaved La.8 $\mathrm{Nd}_{2} \mathrm{Ni}_{2.5} \mathrm{CO}_{2.4} \mathrm{Si}_{11}$ electrodes after $0(a$ and $b), 41$ ( $c$ and $d$ ) and 666 cycles ( $e$ and $f$ ). One bar represents $10 \mu \mathrm{m}$ in $a, c$ and $e$, and $1 \mu \mathrm{m}$ in $b, d$ and $f$.

From repeated charge/discharge cycles at $1.25 C / 1.25 C$ rate the capacity decay rate of $\mathrm{La}_{.8} \mathrm{Nd}_{.2} \mathrm{Ni}_{2.5} \mathrm{Co}_{2.4} \mathrm{Si}_{.1}$ electrodes was found to be 0.35 times the initial capacity per thousand cycles. Cycling of the same electrode material at $2.5 C / 2.5 C$ rate resulted in a capacity loss of $25 \%$ after one thousand cycles. Halving the cycle period from two hours to one seems to lower the decay ratc. Alternatively, these data can be interpreted as a capacity decay rate of $0.30 \times 10^{-3} C_{o}$ per cycle, determined with an accuracy of $0.05 \times 10^{-3} C_{\text {o }}$ per cycle. 
Hence, we tried to gain insight into the time dependence of the storage capacity by interrupting the galvanostatic cycles for long waiting periods. By imposing fixed electrode potentials during these waiting periods the electrodes were maintained in the charged or discharged state at $-990 \mathrm{mV}$ or $-850 \mathrm{mV}$, respectively. These experiments were conducted on $\mathrm{LaNi}_{5}$ and $\mathrm{La}_{8} \mathrm{Nd}_{.8} \mathrm{Ni}_{2.6} \mathrm{CO}_{2.4} \mathrm{Si}_{1}$ electrodes, both charged and discharged at $1.25 \mathrm{C}$ rate. The resulting capacity curves of these clectrodes are shown in the figs $36(a)-(b)$ and $37(a)-(b) ;(a)$ and
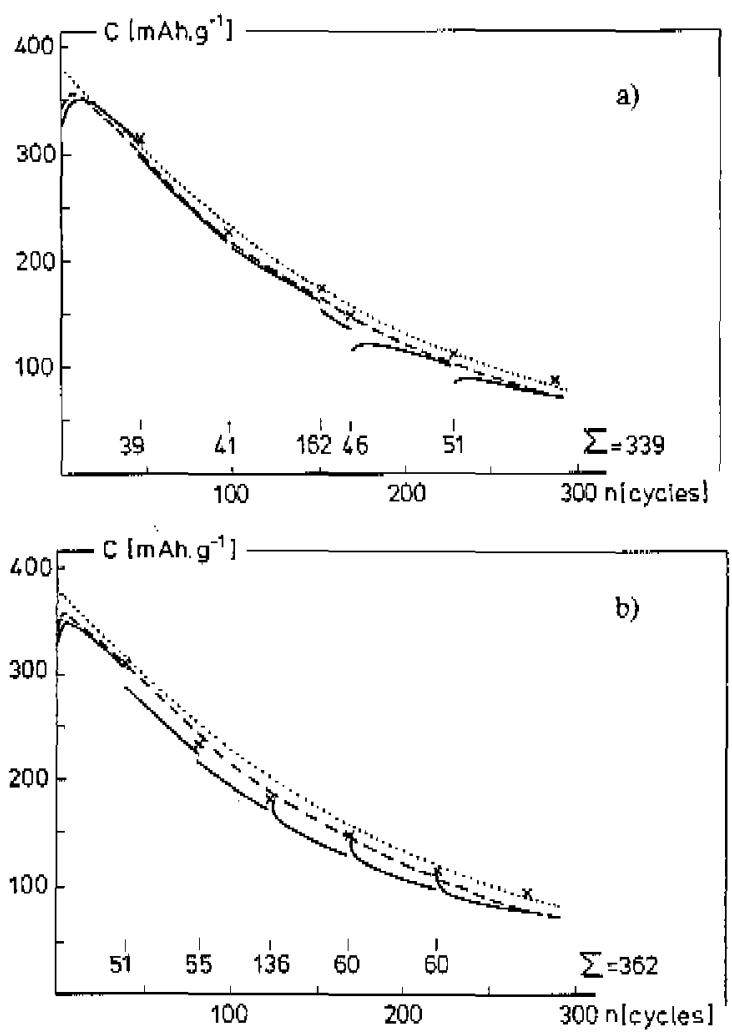

Fig. 36. Capacity curves of LaNi, electrodes during interruptad cycling, compared with thosc during continuous cycling, both at $1.25 \mathrm{Cl} 1.25 \mathrm{C}$ rate. During the interruptions the electrodes were kept in the discharged $(a)$ or in the charged $(b)$ state. The periods of interruption and their duration, expressed in number of cycle-periods, are indicated. — interrupted cycling: high-ratc capacity; $x$ interrupted cycling: eurnulative capacity; --- continuous cycling: high-rate capacity; .... continuous cycling: cumulalive capacity. 

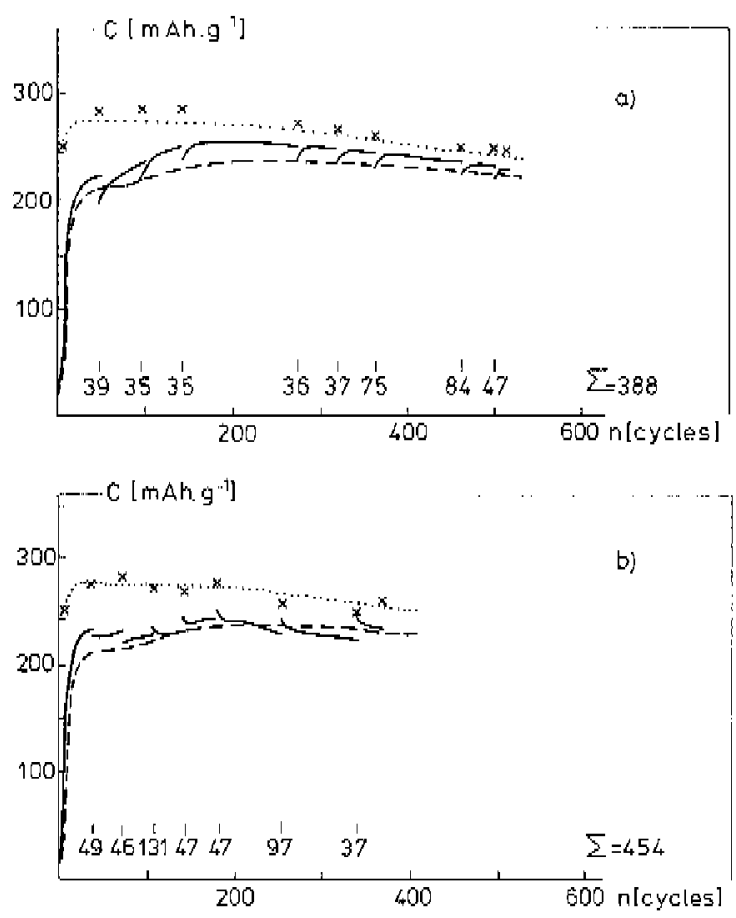

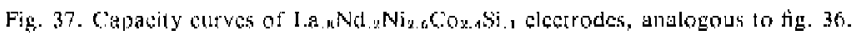

(b) refer to the exposure to the $6 \mathrm{M} \mathrm{KOH}$ solution in the discharged and the charged state, respectively. The last cycle before each waiting period was followed by discharging at $0.125 \mathrm{C}$ rate; the eumulative capacity values are denoted by crosses. The vertical bars and the figures below then indicate the points of interruption and the duration of the waiting periods, expressed in the number of $1.25 \mathrm{C} / 1.25 \mathrm{C}$ rate cycles for eomparison, the high-rate capacity and the cumulative capacity curves of continuously cycled elcotrodes are also displayed in the figs $36(a)-(b)$ and $37(a)-(b)$.

Bccause of the waiting periods discontinuities are found in the capacity curves. These are ascribed to various causes. The LaNin electrodes lost 3 to $6 \%$ of their storage capacity during the first waiting period. The discharge efficiency of $\mathrm{L}_{4} \mathrm{Ni}_{5}$ and $\mathrm{I} . \mathrm{a}_{8} \mathrm{Nd}_{2 .} \mathrm{Ni}_{2.5} \mathrm{Co}_{2.1} \mathrm{Si}_{2}$ electrodes was reduced temporarily after maintaining these elcetrodes in the discharged state (figs 36(a) and 37(a)); this 
was shown by the less positive values of the open circuit potential after discharge. On the other hand, the discharge kinetics were improved by the storage of these electrodes in the charged state (figs $36(b)$ and $37(b)$ ). The oxidation of the stored hydrogen atoms takes place at nickel andior cobalt sires. It is possible that the number and/or the activity of these sites were increased and decreased by the imposed potentials: $-990 \mathrm{mV}$ and $-850 \mathrm{mV}$, respectively. If this is the case, then the change in active sites should occur evcr at $-850 \mathrm{mV}$, notwithstanding the more positive oxidation potentials of nickel and cobalt: $E\left(\mathrm{Ni} / \mathrm{Ni}(\mathrm{OH})_{2}\right)=-820 \mathrm{mV}$ and $E\left(\mathrm{Co} / \mathrm{Co}(\mathrm{OH})_{2}\right)=-825 \mathrm{mV}$.

Despite the observed discontinuities, the interrupted capacity curves of both materials very closely resemble the corresponding capacity curves determined from continuous charging and discharging. Disregarding the slight capacity loss of LaNi $\mathrm{L}_{5}$, exposute of both charged and discharged electrodes to the electrolyte has no detrimental effect on the storage capacity. Corrosion of the intermetallic compounds only oceurs during cycling. Consequently, corrosion must be related to the process of expansion and shrinkage of the intermetallic compound particles and not to the completely expanded state. During both charging and discharging a large hydrogen concentration jump, located at the phasc boundary, moves through the particles. Hence, the large mechanical stress induced by the distorted lattices at the phase boundary also travels through the particles and evidently vanishes when the 'new' crystal structure has been formed.

\subsection{Conclusions}

The volume expansion of a series of pscudo-binary $A B_{5}$ compounds upon hydriding varies between thirtcen and twenty-four percent, depending on the chosen composition of the substituted compound. Because of the different values of the 'hydrogen atom volune' the initial storage capacity declines less rapidly than in proportion to the reduction of the lattice expansion from 372 to about $280 \mathrm{mAh} \cdot \mathrm{g}^{-1}$.

The enormous improvement in stability due to the reduction of the lattice expansion is not caused by reduced disintegration of the intermetallic compounds. After a certain number of electrochemical cycles the specific surface arca of the intermetallic compounds only varies from 0.35 to $0.70 \mathrm{~m}^{2} \cdot \mathrm{g}^{-1}$.

The capacity loss of both $\mathrm{LaNi}_{\mathrm{t}}$ and multicomponent electrodes is directly related to the charging and the discharging process. The degradation of the intermetallic compounds proceeds only during cycling and provided that an oxidizing agent, e.g. water or oxygen, is present. Bccausc of the low mobility of the constituent elements at room temperature, the rate-determining step of the conrosion reaction is the segregation of the intermetallic compounds into 
lanthanides and $3 d$ transition metals. The $3 d$ metals form small metallic erystallites. Lanthanum and neodymium are immediately oxidized by water and subsequently precipitate as hydroxide needles. As a result, the chemical poteritial of lanthanum and neodymium at the solid-liquid interface is maintained at a very low value. Nevertheless, diffusion only occurs simultaneously with the process of expansion and shrirkage of the intermetallic compound particles. Heat effects are not involved. The activation energy for diffusion should therefore be diminished by the mechanical stress, which results from the lattice expansion upon hydriding. This increased mobility is located near the phase boundary. As a consequence, during charging and discharging a zone of enhanced mobility travels through the intermetallic congound particles, enabling the transport of lanthanum and neodymium to the surface. This mechanism for the degradation process is strongly supported by the linear relationship established between the stability of metal hydride electrodes and the decreasing lat tice expansion. In this way, the hypothesis formulated in chap. 3 has been verified.

There is no such a travelling zone of enthanced mobility in materials in which a separate hydride phase will not be formed upon hydrogen absorption. In terms of pressure-concentration isotherms this means that the hydrogen equilibriurn pressurc of such a material should gradually increase with increasing hydrogen content (sloping plateau). The degradation mechanism discussed above therefore implics that electrodes made from amorphous alloys should be more stable than those made from the corresponding crystalline intermetallic compounds.

Two classes of intermetallie compounds can be discerned: compounds of the LaNi $i_{-z} \mathrm{Co}_{z}$ system and materials containing a small amount of aluminium or silicon. Electrodes made from one of the materials of the latter class are exceptionally stable provided that its lattice expansion is minimal. Only thirty percent of the initial storage capacity of $\mathrm{La}_{.4} \mathrm{Nd}_{, 2} \mathrm{Ni}_{2,0} \mathrm{Co}_{2,4} \mathrm{Si}_{, 2}$ is lost after onc thousand cycles. Besides the particular influence of the small volume expansion, this high stability is attributed to the formation of oxide layers containing aluminium or silicon. These surface layers function as an additional hindrance for the transport of the lanthanide elements to the solid-liquid interface.

\section{REFERENCES}

1) H. H. van Mal, K. H. J, Buschow and F. A. Kuijpcrs, J. Lcss-Comnon Mat. 32, 289 (1973).

2) F. A. Kuijpers, Thesis, University of Technology, Deift (1973), also: Fhilips Reis. Reptis. Suppl., No. 2 (1973).

v) H, Peisl, Hydrogen in metats $I$, Topics in Applicd Physics, in G. Alefeld and J, Volk] (eds), Springer-Verlag, Berlin (1978).

5) K. H. J. Buschow, F. C. P. Boulen and A. R. Miedema, Rep. Prog. Phys. 45, 937 (1982). 


\section{SEALED NICKEL-HYDRIDE BATTERIES}

\subsection{Cell concept}

The combination of the rechargeable nickel electrode and one of the metal hydride electrodes provides a new galvanic cell: the nickel-hydride battery. Such a battery has several inherent advantages over the lead-acid and the nickel-cadmium sealed storage cells.

The reactions at both electrodes of the nickel-hydride cell have already beeth described in detail in chap. 2 . In a simplified form, the charge $(\rightarrow)$ and the discharge ( $\leftarrow$ ) reaction of the nickel electrode can be represented as

$$
\mathrm{Ni}(\mathrm{OH})_{2}+\mathrm{OH}^{-} \rightleftharpoons \mathrm{NiOOH}+\mathrm{H}_{2} \mathrm{O}+\mathrm{e}^{-},
$$

and at the hydride electrode as

$$
\mathrm{M}+x \mathrm{H}_{2} \mathrm{O}+x \mathrm{e}^{-} \rightleftarrows \mathrm{MH}_{x}+x \mathrm{OH}^{-},
$$

where $\mathrm{M}$ and $\mathrm{MH}_{x}$ stand for the hydride forming compound and the metal hydride. So, the overall cell reaction for charging and discharging is

$$
x \mathrm{Ni}(\mathrm{OH})_{2}+\mathrm{M} \neq x \mathrm{NiOOH}+\mathrm{MH}_{x} .
$$

For both electrodes, the charge/discharge mechanism does not involve the internediate formation of dissolved metal ion species. Instead, charging and discharging occurs via a solid state transition mechanism, which results in a high structural stability of both electrodes. During operation of the cell, there is neither a net generation nor a net consumption of elcetrolyte species, such as $\mathrm{OH}^{-}$and $\mathrm{H}_{2} \mathrm{O}$. This permits a simple and compact construction. The theoretical energy density of a nickel-hydride cell with $\mathrm{La}_{8} \mathrm{Nd}_{{ }_{2}} \mathrm{Ni}_{2.5} \mathrm{CO}_{2.4} \mathrm{Si}_{.1}$ as negative electrode material anounts to $202 \mathrm{Wh}-\mathrm{kg}^{-1}(\mathrm{Emf}=1.35 \mathrm{~V}$; $\left.x=5 \mathrm{H} / \mathrm{AB}_{5}\right)$. This value is almost the same as that of the nickel-cadmium cell, i.e. $210 \mathrm{Wh} \cdot \mathrm{kg}^{-1}$. However, due to the reasons mentioned above, the actual energy density of the nickel-hydride battery is expected to be larger than the usual $20 \%$ of the theoretical value.

As is illustrated by eq. (40), charging and discharging of a nickel-hydride battery can be viewed as a mere pumping of protons from one electrode to the other. As discussed in chap. 2 , this itrplies that such a cell is capable of being charged and discharged at high rates and with a high degree of utilization of active material. The power density is therefore expected to be considerably larger than that of nickel-cadmium cells.

Moreover, in sealed nicke-hydride cells, both overcharging and overdischarging are allowed provided that the storage capacity of the hydride electrode 
exceeds that of the nickel electrode $\left.{ }^{1}\right)$. Oxygen, evolved at the nickel electrode during overcharging. will be redueed at the hydride electrode. This oxygen evolurion/reduction cycle is identical to the oxyen recombination process in sealed rickel-cadmium cells, as discussed in sec. 2.1.5. But, in contrast with the situation in a nickel-cadmium cell, hydrogen gas cvolved at the nickel electrode during overdischarging, has no megative effect on the cell performance either. The hydrogen formed will be absorbed by and oxiclized at the bydride electrode. As a consequence, a hazardous gas pressure is not built up during overcharging or overdischarging.

Furthermore, nickel-hydride cells do not contain the poisonous heavy metals cadmium and mercury. This is partieularly important for the widespread use of small batteries, where recycling would involve complicated procedures.

\subsection{Electrode materials}

\subsubsection{Introduction}

Up to now, the insufficicnt durability of $\mathrm{LaNi}_{5}$ and $\mathrm{LaNi}_{f} \mathrm{Cu}$ electrodes hindered the development of the nickel-hydride cell. Sines several stable multicomponent electrodes have now been found, the nickcl-hycride battery appears feasible. Table $V I$ contains seven intermetallic compounds with a stability factor $S_{400}$ of morc than $80 \%$. The capacily loss of these electrode materials was detertmined from half-cell measurements. For these measurements smali amounts of active material were tested in contact with a large volume of electrolyte solution, continuously purged with nitrogen to remove oxygen and with the counter electrode placed in a separate compartment (sec. 3.2).

It is therefore necessary to establish the endurance of these stable intermetallic compounds also in the even more corrosive environment of complete cells. Moreover, the examination of the behaviour of the hydride electrode during overcharging and overdischarging is only possible in sealed cells.

\subsubsection{Negarive electroder}

Obviously, in the selection of an appropriate intermetallic compound the stability is a very important factor. However, besides stability the high rate chargeability and dischargeability may become deccisive. This holds in particular when high power density batteries are required. The dependence of the capacity on the charge and discharge rate is compared for three stable multicomponent clectrodes in fig. 38. The total storage capacity is considered to be equal to the sum of a high-discharge-rate capacity and the additional $0.125 \mathrm{C}$ 
rate capacity. The total storage capaçity was deterrmined every thirtieth cycle and the resulting curves are similar to those of the figs 30 and 31 . Successively, three different cycle regimes were applied:

(i) cycling was started with both charging and discharging at $1.25 \mathrm{C}$ rate,

(ii) after about one hundred cycles the charge rate was doubled to $2.5 \mathrm{C}$, and

(iii) at approximately the three hundredth cycle the discharge rate was also increased to $2.5 \mathrm{C}$.

In all cases, the final discharge potential remained $-550 \mathrm{~m} V$.

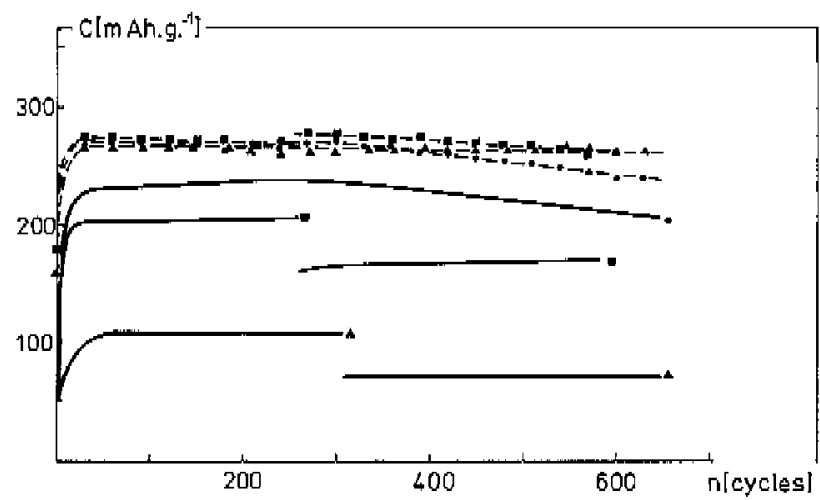

Fig. 38. The total stotage capacity (dashed curvcs) and the high-ratc cupacity (solid lines) of several multicomponent electrodes as a function of the cycle number and for various rates; charge rate: $1.25 \mathrm{C}$ if $n:=100$ and $2.5 C$ if $n>=100$; discharge rate: $1.25 \mathrm{C}$ if $n \Rightarrow 300$ and $2.5 \mathrm{C}$ if

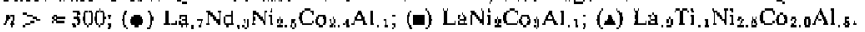

The total storage capacities, measured for the three multicomponent electrodes of fig. 38 , only differ slightly, but the amounts of charge recovered at high discharge rates vary considerably for the various compounds. For La.7 $\mathrm{Nd}_{.9} \mathrm{Ni}_{2.5} \mathrm{Co}_{2,4} \mathrm{Al}_{.1}$ electrodes the fraction of the high-discharge-rate capacity lies between 85 and $90 \%$ and is almost independent of the applied cycle regime. On the other hand, the $1.25 \mathrm{C}$ rate capacity of electrodes made from $\mathrm{LaNi}_{2} \mathrm{Co}_{3} \mathrm{Al}_{.1}$ and La.8 $\mathrm{Ti}_{.1} \mathrm{Ni}_{2.5} \mathrm{Co}_{2} \mathrm{Al}_{5}$ is about 75 and $40 \%$ of the total capacity value, respectively. Moreover, for these electrodes doubling of the discharge current to $2.5 \mathrm{C}$ additionally results in substantially reduced capacities.

For the three electrodes, neither the $1.25 C$ rate capacities, nor the total storage capacitics are affected when only the charge current is increased. Evidently, the charge kinetics of these electrodes proceed more casity, than the kinetics of the discharge reactions. This is also clearly demonstrated by the first 
chargc/discharge cycle. While a new clectrode is capable of accepting charge at $1.25 \mathrm{C}$ rate, less than $10 \%$ is generally recovered during discharge at the same rate. Possibly, the electrochemical oxidation of stored hydrogen is the ratelimiting step. This assumption is supported by the observation that self-discharge of fully charged electrodes in open cells takes place via the spontaneous escape of hydrogen gas. However, different hydrogen diffusion tates in the $\alpha$ and $\beta$-phase may also play a role.

$\mathrm{As}$ is seen from fig. 38, the intermetallic compound $\mathrm{La} .7 \mathrm{Nd} .9 \times \mathrm{Ni}_{2.5} \mathrm{CO}_{2.4} \mathrm{Al} .1$ is more favourable than $\mathrm{LaNi}_{2} \mathrm{Co}_{3} \mathrm{Al}_{1}$ and $\mathrm{La}_{29} \mathrm{Ti}_{1} \mathrm{Ni}_{2.6} \mathrm{Co}_{2} \mathrm{Al}_{5}$ for application in high power density batteries, despite its slightly lower stability. The behaviour of $\mathrm{La}_{8} \mathrm{Nd}_{2} \mathrm{Ni}_{2,5} \mathrm{Co}_{2,4} \mathrm{Si}_{12}$ clectrodes is almost identical to that of $\mathrm{La}_{.7} \mathrm{Nd}_{.2} \mathrm{Ni}_{2.5} \mathrm{CO}_{2.4} \mathrm{Al}_{.1}$, as is shown by table $\mathrm{VI}$ and comparison of the figs 32 and 38 . Because the compound containing silicon had been characterized more extensively (chap. 4), this intermetallic compound was selected for the first experiments in sealed cells.

The potential variations of a $\mathrm{La}, 8 \mathrm{Nd}_{8} \mathrm{Ni}_{2,8} \mathrm{CO}_{2,4} \mathrm{Si}_{1}$ electrode in $6 \mathrm{M} \mathrm{KOH}$ at $25^{\circ} \mathrm{C}$ are depicted as a function of the state of charge $Q$ in fig. 39 . Similar to the determination of the $\mathrm{LaNi}_{5}$ isotherms, shown in tig. 9 , we approached the equilibrium state by imposing $100 \mathrm{~ms}$ current puIses and mesas uring the induced potential transients. With the amount of charge passed during cach pulse corresponding to $1.25 \times 10^{-4} \mathrm{H} / \mathrm{AB}_{\mathrm{s}}$, the relaxation process took about $500 \mathrm{~ms}$. We measured the equilibrium potential after $700 \mathrm{~ms}$.

Both the charge and the discharge isotherm shows a plateau between $Q=30$ and $Q=210 \mathrm{mAh}-\mathrm{g}^{-1}$, which is a consequence of the $\alpha / \beta$-transition. The bound-

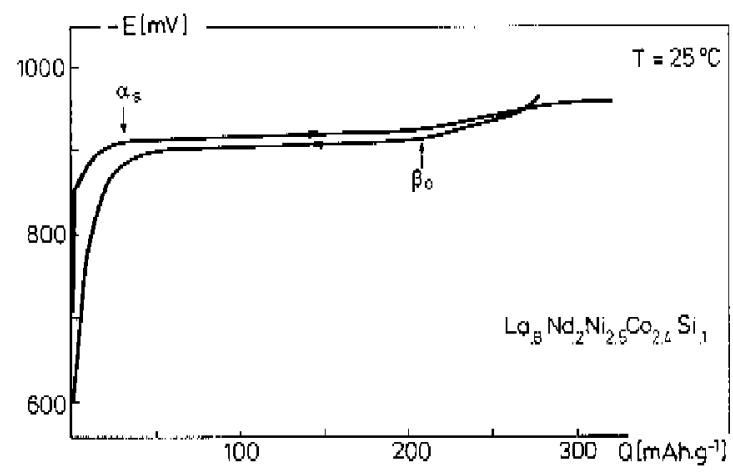

Fig. 39. Charge $(\rightarrow)$ and discharge $(-)$ isolkerri tor a $\mathrm{La}_{.8} \mathrm{Nd}_{.2} \mathrm{Ni}_{2.8} \mathrm{Co}_{7,4} \mathrm{bi}_{1}$, clectrode at $25^{\circ} \mathrm{C}$ in $6 \mathrm{M}$ KOI measured $\mathrm{vs}$. $\mathrm{Hg} / \mathrm{HgO}$ reference electrode. The lower and the upper boundary of the two phase region, $\alpha_{k}$ and $\beta_{\omega}$, are indicated by arrows. 
aries of the two-phase region, calculated from 30 and $210 \mathrm{mAh} \cdot \mathrm{g}^{-2}$, are: $\alpha_{\mathrm{s}}=0.5$ and $\beta_{0}=3.4 \mathrm{H}_{1} / \mathrm{AB}_{5}$. Due to inhomogeneities in the sample, which was not annealed at high temperature, the plateau is slightly sloping $\left(5 \mathrm{mV} /\left(\mathrm{H} / \mathrm{AB}_{5}\right)\right)$. At $x=2.1 \mathrm{H} / \mathrm{AB}_{6}$, i.e. $Q=130 \mathrm{mAh} \cdot \mathrm{g}^{-1}$, the desorption pressure amounts to $0.2 \mathrm{~atm}$ $(E=-907.6 \mathrm{mV})$ and the potential difference between the charge and the discharge isotherm is only $6.3 \mathrm{mV}$. When the equilibrium potential reaches $-956 \mathrm{mV}$ during charging in an open cell, which corresponds to $7.4 \mathrm{~atm}$, further storage becomes impossible owing to the evolution of hydrogen gas. The escape of hydrogen gas is also obser ved during the first stage of the discharge isotherm. This explains the inter section of the charge and the discharge isotherm at $Q=270 \mathrm{mAh} \cdot \mathrm{g}^{-1}$.

The electrochemical data of fig. 39 agree very well with the $X$-ray diffraction results, discussed in sec. 4.2.2 and illustrated in fig. 33. Moreover, the electrochemical isotherms for $\mathrm{La}_{8} \mathrm{Nd}_{28} \mathrm{Ni}_{2,6} \mathrm{CO}_{2,4} \mathrm{Si}_{1,1}$ resemble closely the pressurecomposition isotherm for the $\mathrm{LaNi}_{2,5} \mathrm{CO}_{2.5}-\mathrm{H}_{2}$ system of fig. 28 .

\subsubsection{Positive electrode}

The active material of the positive electrode is nickel hydroxide, which is present as a micro-crystalline precipitate in the pores of a sintered nickel plate. The oxidation of $\mathrm{Ni}(\mathrm{OH})_{2}$ to form $\mathrm{NiOOH}$ corresponds to a storage capacity of $289 \mathrm{~mA} \cdot \mathrm{g}^{-1}+$ Actually, the oxidation state of nickel changes between +2.3 and +3.0 to +3.7 , depending on which $\mathrm{NiOOH}$ modification $(\beta$ or $\gamma)$ is formed during charging, as is discussed in sec. 2.1.4. So, the storage capacity may vary from 200 to $400 \mathrm{mAh} \cdot \mathrm{g}^{-1}$, depending on method of charging.

From measurements in open cells, we determined total capacity yalues as high as $360 \mathrm{mAh} \cdot \mathrm{g}^{-1}$ after high rate charging ( $360 \mathrm{~mA} \cdot \mathrm{g}^{-1}$ for 1 hour). However, for these bigh oxidation states the rate of self-discharge is very high and the rickel electrode degrades. A typical value for the capacity of the nickel electrode is therefore $250 \mathrm{mAh} \cdot \mathrm{g}^{-1}$. During charge/discharge cycles the open circuit potential of the nickel electrode varies between 1.20 and $1.50 \mathrm{~V}$ vs. RHE.

\subsection{Electrode and cell construction}

\subsubsection{Electrode preparanion}

Two types of hydride electrode have been made: pressed plate and paste electrodes. $\mathrm{La}_{18} \mathrm{Nd}_{22} \mathrm{Ni}_{2,5} \mathrm{CO}_{2,4} \mathrm{Si}_{2,}$ powder, pulverized by repeated hydrogen gas absorption/desorption cycles, was used as active material. The pressed plates were shaped by mixing active particles with fine copper powder in the mass ratio $1: 4$ and subsequently cold-pressing this mixture on a grid of expanded nickel. The applied pressure was $4 \times 10^{8} \mathrm{~Pa}$. Each plate contained about $1.5 \mathrm{~g}$ active mass and its dimensions were $4.0 \times 3.5 \times 0.1 \mathrm{~cm}^{3}$. The structure of these plate electrodes was similar to that of the electrode pellets used in the half-cell measurements (sec. 3.2). 
The preparation of a paste electrode is illustrated in fig. 40. The paste was made by adding a methyl cellulose solution to a mixture of pulverized $\mathrm{La} .8 \mathrm{Nd}_{.2} \mathrm{Ni}_{2.5} \mathrm{CO}_{2.4} \mathrm{Si}_{1 .}$ and carbonyl nickel powder $\left(m_{\mathrm{act}} / m_{\mathrm{Ni}}=5\right)$. The hydride electrode was completed by coating a strip of expanded nickel, which served as current collector, with the paste. The width of the paste electrodes was always $3 \mathrm{~cm}$ and the length was chosen between 12 and $20 \mathrm{~cm}$, depending on the cell requirements. As a consequence of the experimental set-up the electrode thickness was not constant. However, the thickness remained below $0.9 \mathrm{~mm}$. So, the average density of active material varied from 0.11 to $0.14 \mathrm{~g} \cdot \mathrm{cm}^{-2}$.

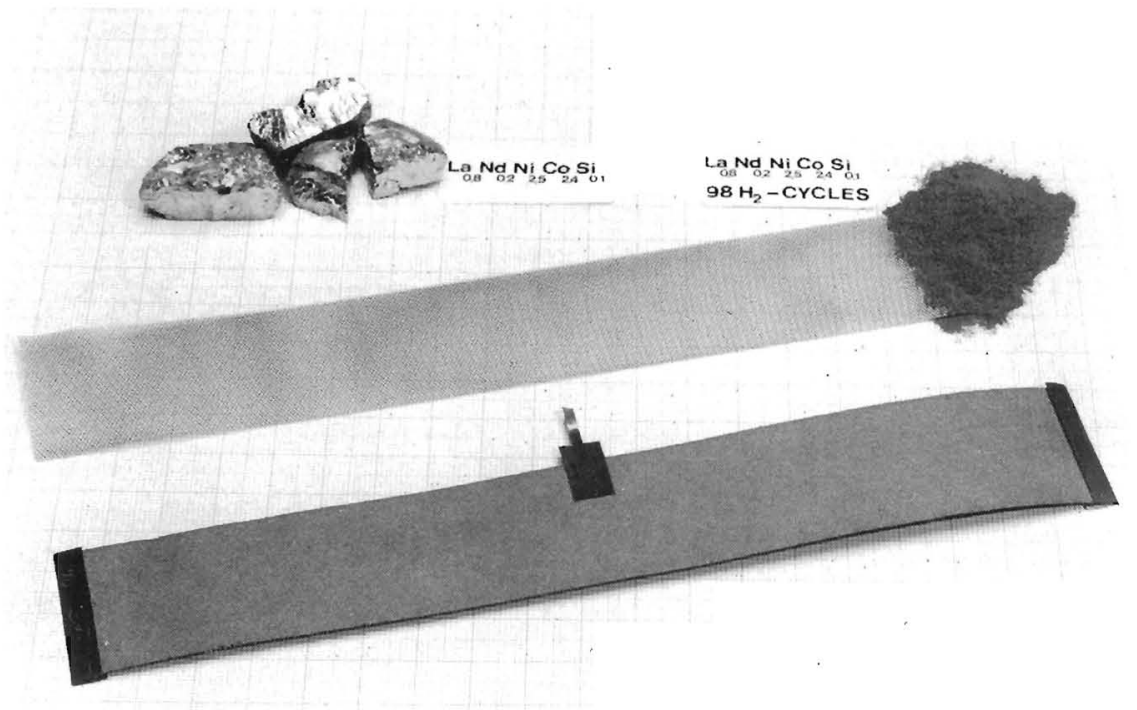

Fig. 40. Preparation of a paste metal hydride electrode from the intermetallic compound La.8 $\mathrm{Nd}_{.2} \mathrm{Ni}_{2.5} \mathrm{CO}_{2.4} \mathrm{Si}_{1 .}$.

The positive electrodes were sintered nickel electrodes. The active material $\mathrm{Ni}(\mathrm{OH})_{2}$ was precipitated in the pores of sintered nickel plates by alternately impregnating the base plates with concentrated solutions of $\mathrm{Ni}\left(\mathrm{NO}_{3}\right)_{2}$ and $\mathrm{NaOH}$. The active mass density depended on the number of impregnation cycles. We prepared electrodes with an average density of 0.084 and $0.10 \mathrm{~g} \cdot \mathrm{cm}^{-2}$ after four and five cycles, respectively. The nickel electrodes with the lower density were applied in our cells. The electrode thickness was $0.8 \mathrm{~mm}$ and the geometric area varied with the cell design. 


\subsubsection{Cell design}

In order to allow overcharging of a sealed nickel-hydride cell the storage capacity of the hydride electrode must exceed that of the nickel electrode. When this is the case, oxygen evolution starts at the nickepl elcctrode at the end of charging, while the negative clectrode is still storing hydrogen. As the oxygen, which is formed subsequently reacts at the hydride electrode, the state of charge of both electrodes remains constant.

Moreover, it is preferable to have the hydride electrode already partially charged prior to cycling of a new cell. This spare charge of the hydride electrode prevents the evolution of oxygen at this electrode during overdischarging. Instead, hydrogen gas is formed at the nickel electrodc. A capacity-determining nickel electrode is therefore essential for the functioning of a sealed nickel-hydride cell.

Howerver, as we have seen, the excess storage capacity of the hydride electrode will decrease during cycling owing to the cortosion of the intcrmetallic compound. Failure of the sealed cell is expected when the storage capacities of both elcetrodes become equal. If eycling is still continued, the pressure in the cell gradually increases and ultimately exceeds the level at which the safety valve opens (about $20 \mathrm{~atm}$ ). Thus, the durability is primarily determined by the excess of active mass and the corrosion rate of the hydride electrode. The calculated cycle life of nickel-hydride cells is given in fig. 41 as a function of these parameters.

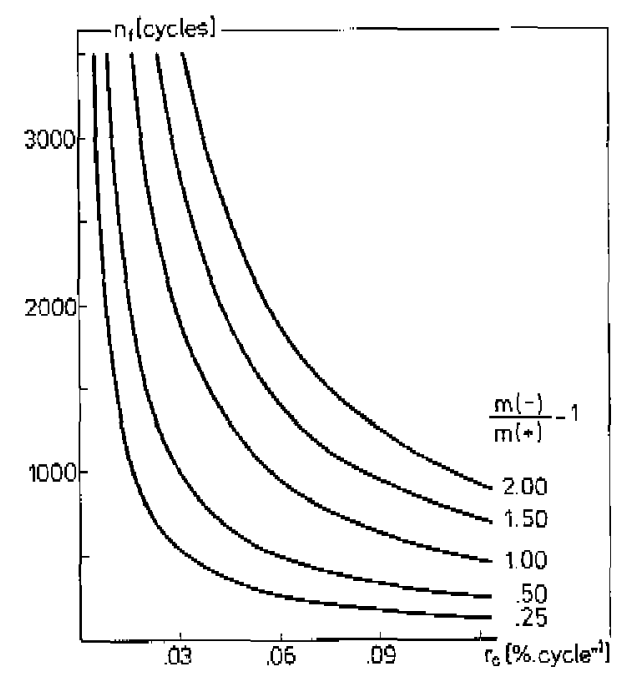

Fig. 41. Calculated cycle life of nickel-hydride cells as a function of the corrosion rate of the hydtide electrode matcrial at various ratios for the excess nesative active mass $(=m(-) / m(+)-1)$. 
The assumptions made for the calculation, are:

a. at $n \geqslant n_{\mathrm{f}}$ failure occurs because the actual storage capacities of both electrodes have become equal,

b. the storage capacity of the nickel electrode remains $250 \mathrm{mAh} \cdot \mathrm{g}^{-1}$,

c. the initial storage capacity of the hydride electrode is $290 \mathrm{mAh} \cdot \mathrm{g}^{-1}$; however, $10 \%$ of this value is utilized as spare charge,

d. only the fraction of the intermetallic compound which participates in the cycling process corrodes; this is a consequence of the results discussed in chap. 4,

e. the hydrogen formed by the oxidation of lanthanum and neodymium will also be absorbed by the hydride electrode, which leads to a substantial increase of the apparent corrosion rate $(1.64 \times)$.

The plots of fig. 41 enable us to select an appropriate intermetallic compound, for instance from table VI, and to tailor the relative size of the electrodes to the required cycle life. On the other hand, if the corrosion rate in batteries differs from that in half-cells, the correct value can be estimated from the cycle life of the battery with the aid of fig. 41 .

\subsubsection{Cell construction}

Both prismatic and cylindrical cells have been constructed. The prismatic cells contained two pressed plate hydride electrodes and between them one sintered

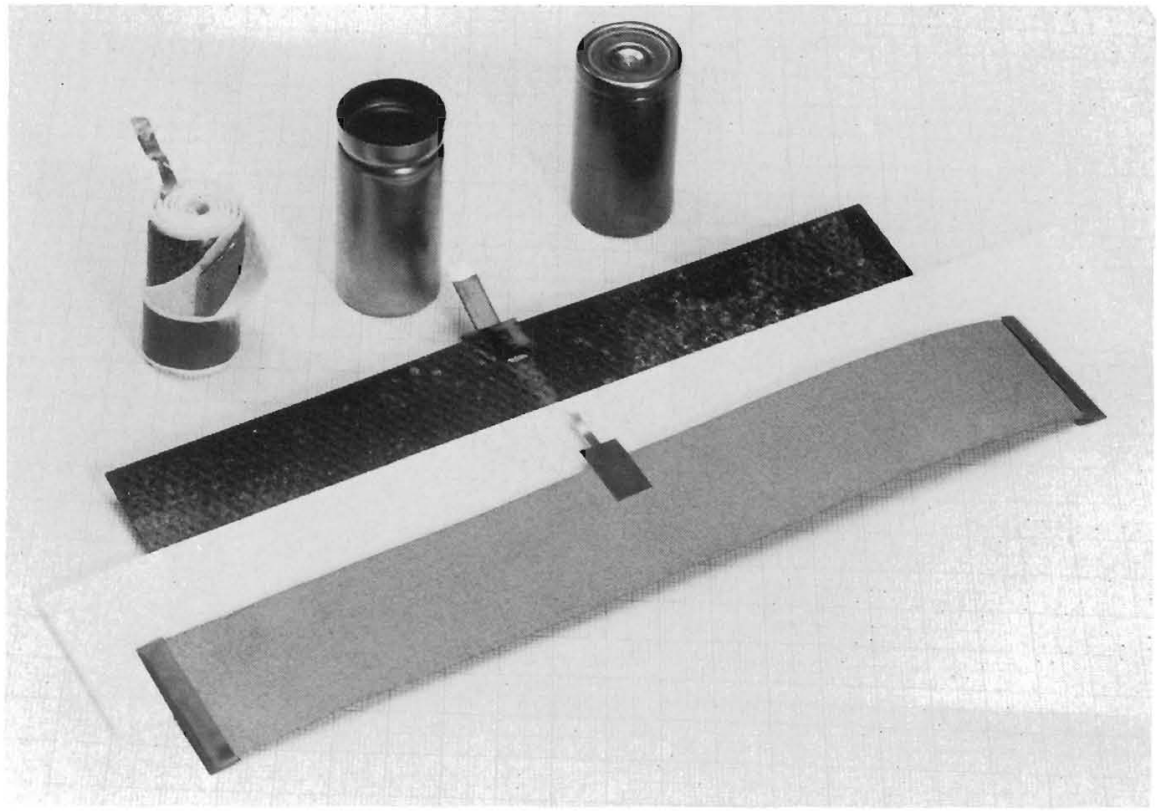

Fig. 42. Assembling of a cylindrical nickel-hydride battery. 
nickel electrode, which is enveloped by a separator (polyamide; $0.2 \mathrm{~mm}$ thick). For the cylindrical cells, a paste hydride electrode, completely enclosed in separator cloth and a nickel electrode strip were rolled together and placed in a battery can (sub $C$ size; $\varnothing_{\mathrm{i}}=21 \mathrm{~mm}$ ), as illustrated in fig. 42 . A solution of $5 \mathrm{M} \mathrm{KOH}$ and $1 \mathrm{M}$ $\mathrm{LiOH}$ was used as electrolyte. After the electrodes plus separator were thoroughly wetted by means of vacuum impregnation, the surplus electrolyte was removed.

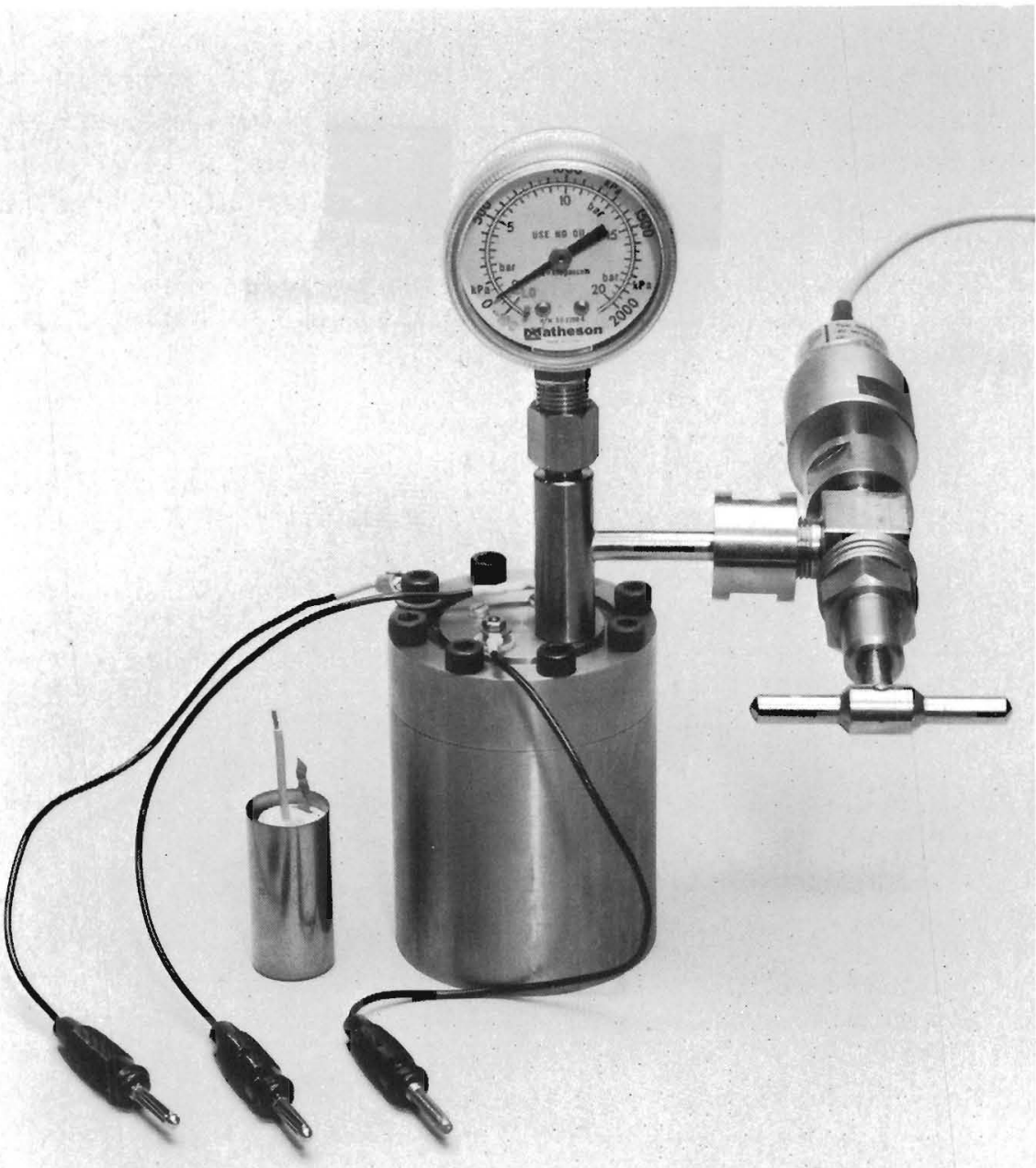

Fig. 43. Cylindrical nickel-hydride test cell and pressure vessel. 
Both the parallel-sided cell stacks and the wound electrode packages were mounted in a stainless-steel container. The void volume, i.e. the volume of the gas space, was 26 and $3 \mathrm{ml}$ for the prismatic and the cylindrical cells, respectively. Each of the sted containers was equipped with a pressure gauge and a transduçer, as shown in fig. 43, One of the cylindrical cells (cell $D$ ) was also provided with a $\mathrm{Hg} / \mathrm{HgO}$ reference electrode.

\subsection{Results and discussion}

In this section the data obtained from four different nickel-hydride cells will be presented and discussed. The distinguishable features of these four cells are summarized in táble IX.

\section{TABLE IX}

Features of the various nickel-hydride cells tested.

\begin{tabular}{l|c|c|c|c|c|c|c}
\hline cell & lypc & $\begin{array}{c}C_{\text {yad }} \\
(\mathrm{mAh})\end{array}$ & $\left.\frac{m(-)}{m(+)}{ }^{2}\right)$ & $\begin{array}{c}\text { spare } \\
\text { charge }\end{array}$ & $\begin{array}{c}\text { cycle } \\
\text { regime }\end{array}$ & $\begin{array}{c}\text { number } \\
\text { of cycles }\end{array}$ & $\begin{array}{c}\text { testing } \\
\text { period }\end{array}$ \\
\hline A & prismatic & 300 & 1.85 & - & $1 \mathrm{~h}, 1 \mathrm{C}$ & $>2750$ & 9.5 \\
B & prismatic & 300 & 0.76 & - & $\uparrow$ & $>1100$ & 9 \\
C & cylindrical & 600 & 1.13 & - & $1 \mathrm{~h}, 1 \mathrm{C}$ & 1251 & 4.5 \\
D & cylindrical & 675 & 1.25 & 1090 & $1 \mathrm{~h}, 1 \mathrm{C} ; \uparrow$ & $>850$ & 4.5 \\
\hline
\end{tabular}

") $m(-) / m(+)=$ active mass tatio of the bydride and the nickel electrode.

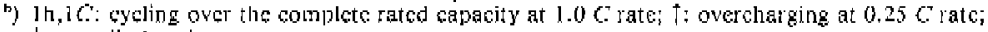
l: overdischarging.

9) testing period expressed in months.

\subsubsection{Cell A; high-rate cycling}

This prismaticedl with a rated capacity of $300 \mathrm{~m}$ Ah was mainly cycled over its complete capacity at $1.0 \mathrm{C}$ rate. In order to activate the electrodes the cell was subjacted to a less exacting charge/discharge regime during the first 43 cycles. In table $X$ the cycle regime of this cell is listed in more detail. The procedure used for the activation was rather arbitrarily chosen and may be shortened considertably.

The storage capacily is plotted as a function of the cycle number in fig. 44. The most remarkable feature of this plot is the almost constant value of both the high-rate capacity and the total capacity during 2750 cycles. With the excess active mass ratio being as large as 1.85 , one obtains a calculated cycle life of 3500 cycles from fig. 41 , if the corrosion rate of the intermetallic compound is taken as $0.03 \%$-eycle ${ }^{4 l}$ (table VI). Since the hydride electrode did not contain ten percent spare charge even a larger cycle life is expected (about 4000 cycles). The 


\section{TABLE $X$}

Cycle regime of cell $A$ ).

\begin{tabular}{c|c|c}
\hline $\begin{array}{c}\text { cycle } \\
\text { numbers }\end{array}$ & $\begin{array}{c}\text { charging } \\
\text { period, rate }\end{array}$ & $\begin{array}{c}\text { discharging } \\
\left.\text { rate, } V_{\text {tq }} \mathrm{b}\right)\end{array}$ \\
\hline $1-30$ & $1 \mathrm{~h}, 0.25 \mathrm{C}$ & $0.25 \mathrm{C}, 0.9 \mathrm{~V}$ \\
$31-33$ & $4 \mathrm{~h}, 0.25 \mathrm{C}$ & $0.25 \mathrm{C}, 0.9 \mathrm{~V}$ \\
$34-43$ & $2 \mathrm{~h}, 0.50 \mathrm{C}$ & $0.50 \mathrm{C}, 0.9 \mathrm{~V}$ \\
$44-965$ & $1 \mathrm{~h}, 1.0 \mathrm{C}$ & $1.0 \mathrm{C}, 0.9 \mathrm{~V}$ \\
$966-1015$ & $8 \mathrm{~h}, 0.125 \mathrm{C}$ & $0.125 \mathrm{C}, 0.9 \mathrm{~V}$ \\
$1016-2750$ & $1 \mathrm{~h}, 1.0 \mathrm{C}$ & $1.0 \quad \mathrm{C}, 0.9 \mathrm{~V}$ \\
\hline
\end{tabular}

4) Additionally to the listad regime, $0.125 \mathrm{C}$ rate discharges were carried out regularly to determine the total storage capacity.

b) $V_{f d}$ : final discharge voltage (= cut off voltage).

curves of fig. 41 are based upon the assumption that only the fraction of the intermetallic compound which participates in the storage process corrodes. When, on the other hand, the excess active mass also corrodes at the same rate, the calculated cycle life of this cell is reduced to only 1400 cycles. Obviously, this is not the case. After 2750 cycles this cell still operated well during repeated charging and discharging. Despite the fact that the number of four thousand cycles has not yet been reached, the cycle life already observed supports our model for the corrosion mechanism of the hydride electrode.

Furthermore, fig. 44 shows the high coulombic efficiency of this cell. Initially, for most cycles more than $95 \%$ of the charge input was recovered. Inefficiencies

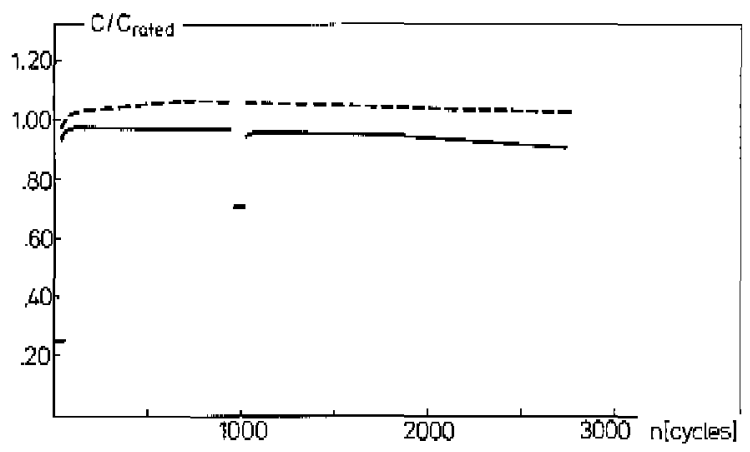

Fig. 44. The high-rate capacity (solid line) and the total storagc capacity (dashed curve) of at 300 mAf prismatic nickel-hydride cell (cell $A$ ) as a function of the cycle number; cf. table $X$. 
were due to oxygen evolution at the nickel electrode (sec. 2.1.3). As a consequence small pressure peaks $(0.03$ atm) were observed at the end of the charging period. After approxinately 1750 cycles a slight degradation of the nickel electrode became noticeable from a decreasing coulombic eficiency. This degradation was accompanied by larger pressure variations per cycle, for instance 0.09 atm for the $2700^{\mathrm{th}}$ cycle.

During fifty cycles (966-1015) the cell was charged and discharged over its complete capacity at $0.125 \mathrm{C}$ rate with a coulombic efficiency of only seventy percent. Although the fraction of the charge input used for oxyget evolution is expected to increase with decreasing cycling rate, seventy percent efficiency is unusually low. Possibly, the history of the cell, being one of conntinuous charging and discharging at a high rate for almost a thousand times, has led to the formation of satalytic sites for the oxygen evolution rcaction.

Three important voltage levels of this nickel-hydride cell are given as a function of the cycle number in fig. 45. The dolled line tepresents the voltages determined at the end of the charge process, $V_{i}(c)$. The open eircuit voltage of the charged battery, $V_{c o}(c)$, was measured 30 seconds alter $V_{r}(c)$. The cell voltage denoted as $V_{\mathrm{os}}(d)$ is the open circuit voltage measured 15 minutes after discharging was completed.

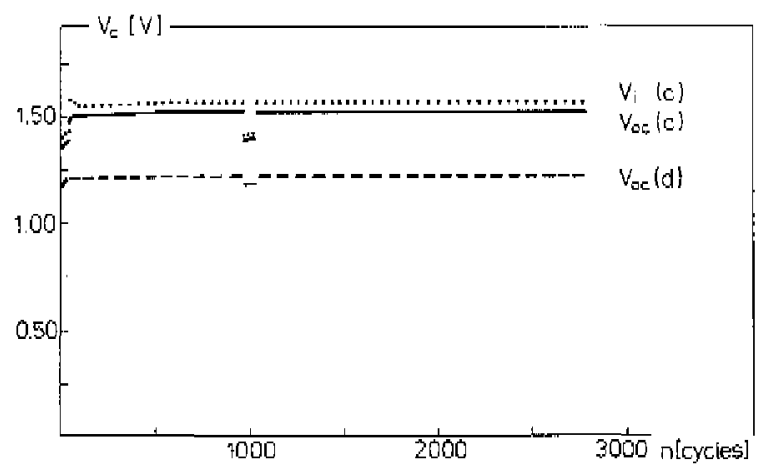

Fig. 45. Characteristic voltages of cell $A$ as a function of the cycle number; $v(c)$ eepresents the cell voluage at the end of charging; $V_{\text {oug }}(e)$ and $V_{\mathrm{cm}}(d)$ stand for the open circuit voltage of the charged and the discharged ecll, respeclively.

The lower voltage levels $V_{i}(c)$ and $V_{o c}(c)$ determined for the first thitty cycles $(1 \mathrm{~h}, 0.25 \mathrm{C})$ and for the fifty cycles from $n=966$ to $n=1015(8 \mathrm{~h}, 0.125 \mathrm{C})$ indicate that the battery was incompletely charged. For the other cyctes the three characteristic cell voltages remained almost constant: $V_{1}(c)=1.56 \mathrm{~V}, V_{\mathrm{ou}}(c)=$ 
$1.52 \mathrm{~V}$ and $V_{\mathrm{oc}}(d)=1.22 \mathrm{~V}$. This demonstrates that the internal resistance did not change during the 9.5 months of testing. The voltage difference between charging and discharging, both at $1.0 \mathrm{C}$ rate, was typically $140 \mathrm{mV}$. The internal resistance calculated from this voltage difference announts to $0.24 \Omega$.

The maximum gas pressure in the cell increased almost linearly from 0.15 atm after 400 cycles to $4.70 \mathrm{~atm}$ after 2700 cycles. So, the average pressure rise was $2 \times 10^{-5}$ atm $\cdot$ cycle $^{-1}$. The pressure rise may be attributed to the incomplete reduction of the evolved oxygen; note that in this cell $2 \times 10^{-8}$ atm $\mathrm{O}_{2}$ corresponds to only $0.23 \mathrm{mAh}$. However, since the pressure increase proceeded after reaching $2.5 \mathrm{~atm}$, this explanation is improbable, as will be discussed in the next section. Alternatively, hydrogen gas might have caused the observed pressure rise. If the hydrogen gas formed by the corrosion of the intermetallic compound is not absorbed, the pressure increases at a rate of $1.3 \times 10^{-3} \mathrm{~atm}^{-6 y c l e}{ }^{-1}$. At the observed low pressures ( $<5 \mathrm{~atm}$ ), absorption of the hydrogen gas might be hincered by the construction of the hydride electrode, which consisted of active mass embedded in a copper matrix with $m_{\text {act }} / m_{\mathrm{Cu}}=0.25$. This seems plausible because a similar pressure increase was not found for cell $C$ and cell $D$.

\subsubsection{Cell B; IEC test}

After the activation of the electrodes, the $C_{a}$ capacity of this prismatic cell was determined from the tenth cycle. This means that the battery was charged for $16 \mathrm{~h}$ at $0.10 \mathrm{C}$ rate, rested for one hour and then was discharged at $0.20 \mathrm{C}$ rate until the cell voltage had declined to $1.0 \mathrm{~V}$. The $C_{5}$ values found, $298 \mathrm{mAh}$, is almost the same as the rated capacity, i.e. $300 \mathrm{mAh}$.

Subsequently, the endurance of this cell was examined in accordance with the IEC procedures Endurance in cycles for testing sealed nickel-cadmium cells ${ }^{2}$ ). The cycle conditions are: discharging of a fully loaded cell for $2 \mathrm{~h}$ and $20 \mathrm{~min}$, immediately followed by charging for $3 \mathrm{~h}$ and $\mathrm{I} 0 \mathrm{~min}$, both at $0.25 \mathrm{C}$ rate Thus, during each cycle the cell is overcharged at $0.25 \mathrm{C}$ rate for 50 min. Every fiftieth cycle the remaining $C_{5}$ capacity has to be determined. The test is terminated when the actual $C_{5}$ capacity becomes less than $60 \%$ of the initial value. The required number of cycles for rickel-çadmium cells is at least four hundrę.

During 1100 cycles we determined for this cell $C_{5}$ capacities between 82 and $88 \%$ of the initial value. Although, during each cycle the cell was $21 \%$ overcharged, the pressure variations were only 0.10 to $0.15 \mathrm{~atm}$.cycle ${ }^{-1}$. The maximum pressure in the cell remained approximately $2.5 \mathrm{~atm}$. This appears to be the pressure level at which the oxygen gas, evolved at the nickel electrode is rapidly reduced at the hydride electrode. After nine months of testing, this cell showed no indication of an approaching failure. 


\subsubsection{Cell $\mathrm{C}$; high-rate lycing}

Analogous to the testing of the prismatic cell $A$, the endurance of the cylindrical cell $C$ was examined by tepeated charging and discharging over its complete, rated capacity at $1.0 \mathrm{C}$ rate. The procedure for the activation of the electrode consisted of twenty lower rate oycles. The precise cyele regime is indicated in table XI.

\section{TABLE XI}

Cycle regimc of cell $C^{(4)}$.

\begin{tabular}{c|c|c}
\hline $\begin{array}{c}\text { cycle } \\
\text { numbers }\end{array}$ & $\begin{array}{c}\text { charging } \\
\text { period, rate }\end{array}$ & $\begin{array}{c}\text { discharging } \\
\text { rate, }\end{array}$ \\
\hline $1-2$ & $10 \mathrm{~h}, 0.05 \mathrm{C}$ & $0.05 \mathrm{C}, 0.9 \mathrm{~V}$ \\
$3-14$ & $4 \mathrm{~h}, 0.25 \mathrm{C}$ & $0.25 \mathrm{C}, 0.9 \mathrm{~V}$ \\
$15-20$ & $2 \mathrm{~h}, 0.50 \mathrm{C}$ & $0.50 \mathrm{C}, 0.9 \mathrm{~V}$ \\
$21-1251$ & $1 \mathrm{~h}, 1.0 \mathrm{C}$ & $1.0 \mathrm{C}, 0.9 \mathrm{~V}$ \\
\hline
\end{tabular}

") Additionally to the listed regime, $0.125 \mathrm{C}$ rate discharges werre carried out regularly to deles'mine the total storage capacily.

7) V/s: final discharge voltage ( . . eut of voltage)

On the assumption that the corrosion rate of the intermetallic compound is only $0.03 \% \cdot c y c e^{-1}$ (table VI), the cycle life of this cell should be 2140 cycles acording to fig. 41. If one accounts for the absence of $10 \%$ spare charge in the hydride electrode, a lifetime of 2580 cycles is calculated. When, on the other hand, not only the fraction of intermetallic compound that participates in the

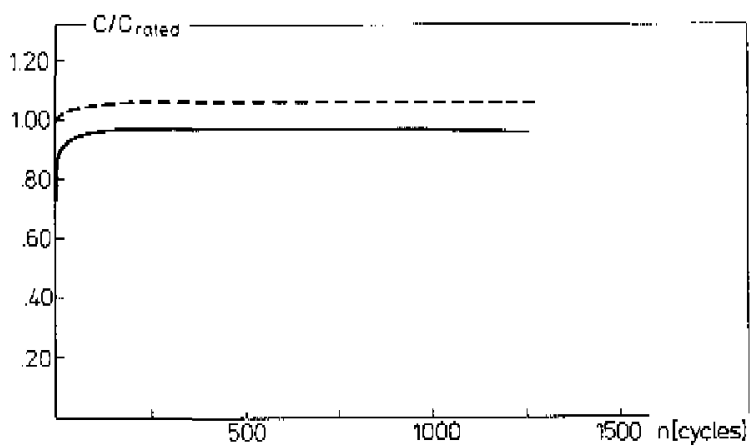

Fig, 46, The high-rate cupacity (coljd line) and the total storage capacity (dashed wirve) of at

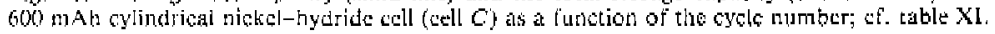




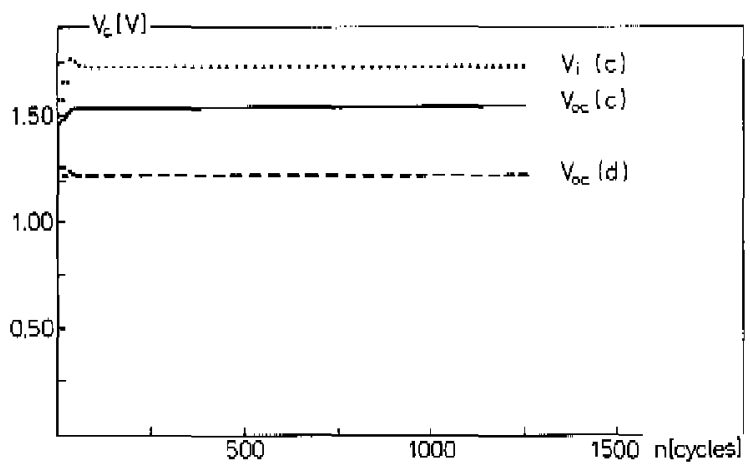

Fig. 47. Characteristic voltages of call $C$ as a fumetion of the cycle number; $V_{4}(c)$ represents the cell voltage at the end of charging; $V_{s ;}(c)$ and $V_{\text {os }}(d)$ stand for the open circuit voltage of the charged and the discharged cell, respectively.

in the storage process corrodes, but the excess active mass of the negative electrode also degrades, the expected cycle life is reduced to only 1200 cycles. The curves for the high-rate capacity and the total storage capacity of this battery are shown in fig. 46 as a function of the cycle number. It is clear that the capacity loss measured over 1251 cycles is negligible.

The oper circuit voltages of both the charged and the discharged cell, $V_{o c}(c)$ and $V_{o s}(d)$, and the cell voltages measured at the end of charging $V_{r}(c)$ are piotted in fig. 47 . These characteristic voltages did not change apprcciably after the activation of the electrodes was completed. The open circuit voltages after charging and discharging, i.e. 1.53 and $1.22 \mathrm{~V}$, respectively, were practically the same as those determined for cell $A$. The internal resistance of cell $C$ was $0.42 \Omega$ for cycling at $1.0 \mathrm{C}$ rate. This rather high value, almost twice the value determined for cell $A$, is due to the use of a thicker separator. The thickness amounted to $0.4 \mathrm{~mm}$ instead of the mostly used $0.2 \mathrm{~mm}$. However, there is no reason for applying a thick separator in a nickel-hydride cell. On the contrary, one should search for a very thin separator, as in such a cell there is no need to store an excess amount of electrolyte (sec. 5.1). The thicker separator, together with the larger $1.0 \mathrm{C}$ current, resulted in a much higher end-of-charge voltage for this cell than that found for cell $A: 1.72$ versus $1.56 \mathrm{~V}$.

As is seen frotm the comparison of the figs 44 and 46 , cell $A$ and cell $C$ operated with the same high coulombic efficiency. This is consistent with what should be expected. For, inefficiencies are due to oxygen evolution at the nickel electrode and are therefore not affected by the construction of the hydride electrode. 
For cell $C$, the height of the cyclic pressure variations grew from 0.35 to $0.70 \mathrm{~atm}$. The peaks coincided with the end of the charging period, which indicates that these variations are due to the evolution and recuction of oxygen. The maximum gas pressure in the cell remained below 1 atm during the ftrst 900 cycles, as shown in fig. 48. Afterwards, the maximum pressure gradually

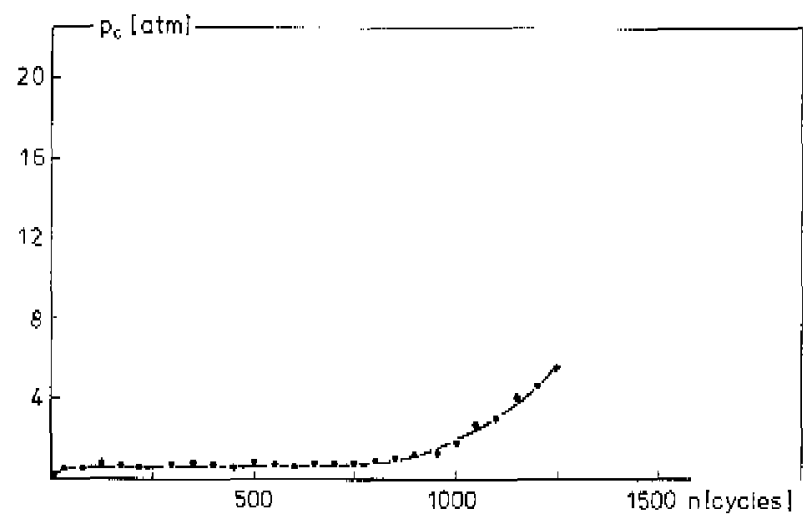

Fig. 48. The muximum gas pressure in cell $C$ un is function of the cycle number.

increased to 5.7 atm at the $1250^{\text {th }}$ cycle. This slow but steady pressure rise is attributed to the presence of a growing amount of hydrogen gas in the void volume of the cell. As follows from the pressure-composition isotherm of the La.8 $\mathrm{Nd}_{.2} \mathrm{Ni}_{3,5} \mathrm{Co}_{2,4} \mathrm{Si}_{.1}-\mathrm{H}_{2}$ system (cf. the figs 28,33 and 39 ), the hydrogen equilibrium pressure increases from approximately 0.4 to 10 atm as the hydrogen concentration in the intermetallic compound increases from $3.4\left(=\beta_{0}\right)$ to $4.8 \mathrm{H} / \mathrm{AB}_{S}$. As a consequence of the excess active mass in the hydride electrode, it will initially only be cycled over the fraction of the storage capacity that corresponds to hydrogen pressures below $0.4 \mathrm{~atm}$. After storage capacity has been lost by corrosion, hydrogen will also be stored at sitcs corresponding to highet cquilibrium pressures.

If it is assumed that after 900 cycles the low-pressure storage capacity of the hydride electrode became insufficient, a corrosion rate of $0.037 \% \cdot \mathrm{cycle}^{-1}$ is calculated. This value agres well with the value determined from the half-cell cxperiments, i.e. $0.03 \% 0$ cycle ${ }^{-1}$.

At the end of cycle 1251 , the cell was overdischarged for 15 h a $1.0 \mathrm{C}$ ate. This was caused by a defect in the measuring equipment and resulted in an increased internal resistance. While normal capacity values were still found for 
$0.25 \mathrm{C}$ rate cycles, discharging at $1.0 \mathrm{C}$ rate had become impossible. Testing of this cell was therefore terminated.

\subsubsection{Cell D; overcharging and overdischarging}

This cylindrical cell differs from cell $C$ by the presence of ten percent spare charge in the hydride electrode and the use of a $0.2 \mathrm{~mm}$ thick separator. Similar to cell $A$ and cell $C$, the applied cycle regime mainly consisted of charging and discharging at $1.0 \mathrm{C}$ rate. Additionally, the performance of this cell during both overcharging and overdischarging was also examined.

A built-in reference electrode enabled us to record simultaneously the potential of the hydride electrode and the cell voltage. The charge/discharge curves of both the cell and the hydride electrode during a $1.0 \mathrm{C}$ rate cycle are depicted in fig. 49. It is seen that the average voltage difference between the charge and the

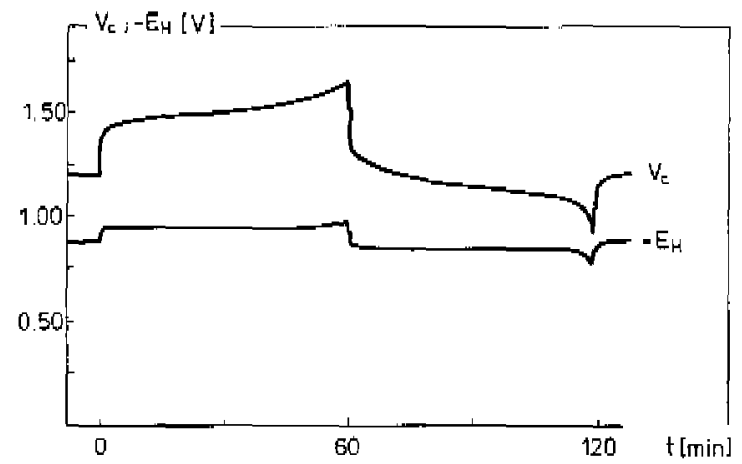

Fig. 49. The variation of the cell voltage $V_{\mathrm{E}}$ and of the hydridc clectrode potential $-E_{\mathrm{H}}$ (in fact: the reverse value of the electrode potential versus the $\mathrm{Hg} / \mathrm{HgO}$ reference electrode) during a complete chargo/discharge cycle at $1.0 \mathrm{C}$ rate.

discharge curve of this cell is approximately $350 \mathrm{mV}$, when compared at the same state of charge. The internal resistance calculated from this value is $0.26 \Omega$. The overpotential for charging and discharging the hydride electrode at this high rate is only $50 \mathrm{mV}$. Fig. 49 also demonstrates the high coulom bic efficiency of this nickel-hydride cell. For this particular cycle the coulom bic efficiency was $98 \%$. Generally, more than $85 \%$ of the charge input was recovered during discharging.

Prior to overdischarging, this cell was overcharged for eighty cycles primarily to test the gas transport in the wound electrode package used. The IEC cycle regine discussed in sec. 5.4 .2 was applied. Whercas the height of the pressure 
variations during each cycle was approximately 0.4 atm, the maximum pressure in the cell remained below $2.5 \mathrm{~atm}$. The $C_{5}$ capacity after eighty overcharge cycles was $92^{0}$ of the initial value. The oxygen recombination cycle thus proceeded as well in this cell as it did in cell $B$, despite the difference in cell construction.

We performed four overdischarge experinents at 0.1 Crate and with theoverdischarge period varying from 2 to 3 hours. In each case, the already discharged cell (with an oper circuit potential of aboul $1200 \mathrm{mV}$ ) was further discharged at $0.1 C$ rate. The actual overdischarge process is considered to begin when the ecll voltage has declined to $900 \mathrm{mV}$. After 20 to 30 minutes of overdischarging, the cell voltage reversed and hydrogen gas evolution started. The reversed cell voltage was initially $-140 \mathrm{mV}$ and increased to $-300 \mathrm{mV}$ after 3 hours of overdischarging. In the four experiments of this kind the pressure rise varied from 0.9 to $1.35 \mathrm{~atm}$ hour ${ }^{-1}$. Should hydrogen gas be formed and completely stored in the gas space al $0.1 C$ rate, a pressure inerease of $10.14 \mathrm{~atm}^{-h o u}{ }^{-1}$ would be observed. Thus, during overdischarging at $0.1 \mathrm{Crate} 87$ to $91 \%$ of the evolved hydrogen was directly oxidized at the hydride electrode. The remaining $91013 \%$ of the current at the hydride electrode was supplied by the oxidation of the spare charge of this electrode, as indicated by the gradual increase of the reversed cell voltage. When charge/discharge cycling was resumed immediately after these experiments, the gas pressure was seen to decrease to normal levels and no loss of storage capacity was observed.

Next, three overdischarge experiments at $0.05 \mathrm{C}$ rate were carried out. During these experiments, the complete rated capacity was forced through the cell in the

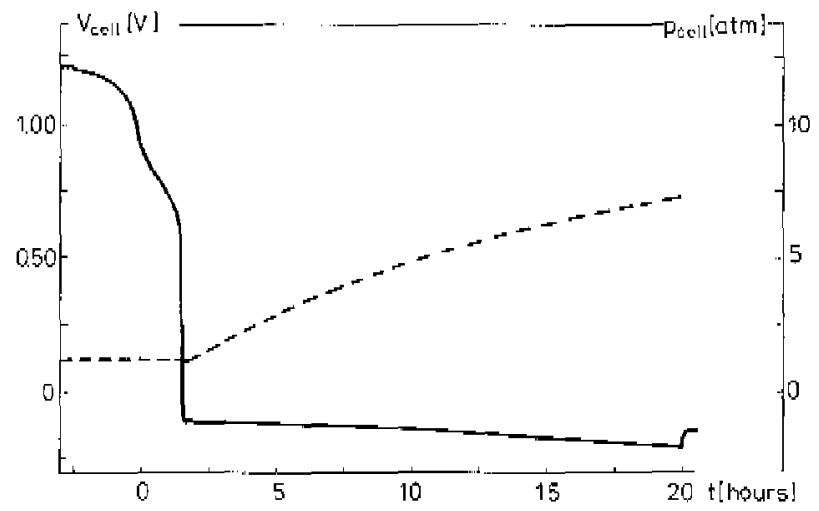

[ing. 50. The variation of the cell wotage (solid line) and of the prossure in the cell (dushed line) during overdischarging at $0.05 \mathrm{C}$ rate as a function of the time. 
reverse direction. The variation of the cell voltage and of the pressure is presented for one of these experiments in tig. 50 . Almost identical results were found for the two other experiments. Again, the discharged cell was additionally discharged, now at $0.05 \mathrm{C}$ rate, and the actual overdischarge process was considered to start from $900 \mathrm{mV}$. Only after 2,5 hours, the cell voltage had declined to $900 \mathrm{mV}$ and it took another 1.5 hours before the voltage reversed and the pressure began to rise. Similar to the overdischarge experiments at $0.1 \mathrm{C}$ rate, the reversed cell voltage increased, but now from -110 to $-210 \mathrm{mV}$. The initial pressure in the cell was $1.2 \mathrm{arm}$; this value resulted from repeated cycling at $1.0 \mathrm{C}$ rate. The average pressure rise amounted to $0.33 \mathrm{~atm} \cdot \mathrm{h}^{-1}$. This means that $93 \%$ of the hydrogen evolved at the nickel electrode was simultaneously oxidized at the hydride electrode. Moreover, the pressure curve flattened as the hydrogen gas pressure increased.

In all cases, the hydrogen pressure in the cell decreased, even when cycling at $1.0 \mathrm{C}$ rate was immediately resumed, and the space charge in the hydride electrode thus restored. The value of the storage capacity, determined from the first cycle after the twenty hours of overdischarging was still $79 \%$ of the rated capacity. Normal storage capacities were measures for the next cycles.

\subsection{Conclusions}

Four sealed nickel-hydride cells have been tested with the emphasis on the durability of the hydride electrode. The intermetallic compound $\mathrm{La} .{ }_{.8} \mathrm{Nd}_{.2} \mathrm{Ni}_{2.5} \mathrm{Co}_{2.4} \mathrm{Si}_{1}$ was used as active negative electrode material. The results obtained from these cells confirm that only the fraction of the intermetallic compound that participates in the cycling process corrodes. Moreover, these results indicate that the corrosion rate during cycling in sealed cells is approximately the same as the tate determined from half-cell experiments. Nickelhydride cells, which comprise one of the newly developed stable intermetallic compounds, are therefore expected to withstand the standard endurance tests for rechargeable batteries. For instance, the cell which was examined in accordance with the IEC procedure exceeded the required cycle life by a factor of three without any indication of an approaching failure.

Moreover, it was shown that sealed nickel-hydride cells can be overcharged and overdischarged without building up an unacceptably high gas pressure. Both the oxygen recombination cycle during overcharging and the hydrogen recombination cycle during overdischarging proceed well provided that the cell is adequately designed.

The tested cells had been constructed with normal components but were not optimized for maximum energy density and/or maximum power density. However, a sealed nickel-hydride cell comprising a wound package made of a 
$56 \mathrm{~cm}^{2}$ nickel electrode with $5.0 \mathrm{~g} \mathrm{Ni}(\mathrm{OH})_{2}$ and of a $60 \mathrm{~cm}^{2}$ hydride electrode with $8.4 \mathrm{~g} \mathrm{La} .8 \mathrm{Nd}_{.2} \mathrm{Ni}_{2.8} \mathrm{Co}_{2.4} \mathrm{Si}_{1 .}$, which fits in a sub $\mathrm{C}$ size battery can, may be constructed in the same way. The capacity of such a nickel-hydride cell is 1.25 Al and according to fig. 41 its lifetime will considerably exceed one thousand cycles.

\section{REFERENCES}

1) H. J. H. ván Deutekom, W.S. Patent 4,214,043 (1980).

*) Intemational Electrotechnical Commission, Sub-Committee 21 A: Alkaline Accumulators, publication 285 . 


\section{FINAL CONCLUSIONS}

The intermetallic compounds $\mathrm{LaNi}_{5}$ and $\mathrm{LaNi}_{4} \mathrm{Cu}$ are not suitable for ap" plication in rechargeable battery electrodes. The corrosion of these materials çauses a strong decline of the storage capacity. However, by means of further alloying several very stable pseudo-binary $\mathrm{AB}_{5}$ compounds have been found. For instance the eapacity loss of a $\mathrm{La}_{8} \mathrm{Nd}_{2} \mathrm{Ni}_{2.5} \mathrm{Co}_{9.4} \mathrm{Si}_{11}$ electrode is only thirty percent after one thousand cycles.

The stability of hydride electrodes may be explained in terms of an unique transport process. The rate-determining step in the corrosion reaction is the transport of the lanthanide elements to the solid-liquid interface layer. Normally, the mobility of the atoms in intermetallic compounds is practically zero at room temperature. However, a zone of enhanced mobility induced by the distorted lattices is present in the intermetallic compound particles and located at the boundary between the hydrogen poor and the hydrogen rich phase. During charging and discharging, this zone travels through the particles, enhancing the transport of the rare earth elements to the suffacec. As a consequence, the corrosion takes only place during cycling and the corrion rate changes in proportion to the lattice distortion. Thus, intermetallic compounds are more stable as they expand less during hydrogen absorption. Moreover, the stability of intermetallic compounds which contain small amounts of silicon or aluminium is further improved by the formation of an oxide layer which functions as an additional hindrance for the transport of the lanthanide elements to the solid-liquid interface.

Now that a viable hydride electrode has been found, sealed nickel-hydride batteries with a durability of more than one thousand sycles can be constructed. As both electrodes operate via a fast solid state transition mechanism, these batteries are capable of being charged and discharged completely in less than one hour, while still functioning at high efficiencies. An oxygen recombination cycle cnables repeated overcharging of sealed nickel-hydride batteries. As a result of the absorption and oxidation of hydrogen gas by the hydride electrode, prolonged overdischarging is also possible without detrimental conseguences for the further use of the battery.

In addition to the advantages already mentioned, the absence of poisonous heavy metals, such as cadmium and metcury, is expected to facilitate the widespread application of sealed nickel-hydride batteries. 


\section{ACKNOWLEDGEMENT}

The research reported in this dissertation has been done at the Philips Rescarch Laboratorics, Eindhoven, The Netherlands. I am indebted to the management of that laboratory for allowing me to complete this thesis.

In particular I wish to thank Messrs. J. R. van Beek and $H$. C. Donkersioot for our fruitful cooperation. Without their contribution in the field of electrochemical and metallurgical research of hydride forming materials this thesis would not have been realized.

The technical support by Mrs. A. C. Reynders and Messrs. L. Kerkhofs and I. J. F. Heuts was irvaluable for the numerous experiments charactcristic for this type of battery research. I appreciate their dedication very much.

Finally, $I$ wish to express my gratitude to Dr. G. Frens for the inspiring discussions and his support of the investigations and to prof. E. Barendrecht and prof. Dr. A. R. Miedema for their critical revicwing of the manuscript. 


\section{LIST OF SYMBOLS}

\begin{tabular}{|c|c|c|}
\hline$A$ & Surface area & $\left(\mathrm{m}^{2}\right)$ \\
\hline$a ; b ; c$ & Lattice parameters & (A) \\
\hline$C$ & Storage capacity & $\left(\mathrm{mAh} \cdot \mathrm{g}^{-1}\right)$ \\
\hline$C_{0}$ & Initial storage capacity & $\left(\mathrm{mAh} \cdot \mathrm{g}^{-1}\right)$ \\
\hline$C_{1}$ & Total storage capacity & $\left(\mathrm{mAh} \cdot \mathrm{g}^{-1}\right)$ \\
\hline$D$ & Diffusion coefficient & $\left(\mathrm{cm}^{2} \cdot \mathrm{s}^{-1}\right)$ \\
\hline$d$ & Particle diameter & (cm or $\mu \mathrm{m})$ \\
\hline$E ;\left(E_{n}\right)$ & (Reversible) electrode potential & $(m V)$ \\
\hline$E_{\varepsilon}$ & Open circuit potential of a charged electrode & $(\mathrm{mV})$ \\
\hline$E_{\text {d }}$ & Open circuit potential of a discharged electrode & $(\mathrm{mV})$ \\
\hline$E_{\text {Id }}$ & Final discharge potential & $(\mathrm{mV})$ \\
\hline$E_{\mathrm{he}}$ & Hydrogen evolution potential & $(m V)$ \\
\hline$F$ & Faraday constant $=96485$ & $\left(C \cdot c q^{-1}\right)$ \\
\hline$\Delta G^{\circ}$ & Standard free enthalpy change & $\left(\mathrm{kJ} \cdot \mathrm{mole}^{\mathrm{m} 1}\right)$ \\
\hline$\Delta H_{\text {\% }}^{\circ} / \beta$ & Standard enhalpy change for the $\alpha / \beta$ transition & $\left(\mathrm{kJ} \cdot\left(\text { mole } \mathrm{H}_{2}\right)^{-1}\right)$ \\
\hline & Current magnitude & $(\mathrm{mA})$ \\
\hline$j:(j 0)$ & (Exchange) current density & $\left(\mathrm{mA} \cdot \mathrm{cm}^{-2}\right)$ \\
\hline$k^{\circ}$ & Standard heterogeneous rate constant & $\left(\mathrm{cm} \cdot \mathrm{s}^{-1}\right)$ \\
\hline$m$ & Mass & (g) \\
\hline$M_{\mathrm{AB}_{\mathrm{s}}}$ & Molecular weight of the $\mathrm{AB}_{5}$ compound & $\left(\mathrm{g} \cdot \mathrm{mole}^{-1}\right)$ \\
\hline$n$ & Cycle number & (cycles) \\
\hline$n_{i}$ & Calculated cycle life & (cycles) \\
\hline$n^{*}$ & Stability constant & (cycles) \\
\hline$n_{t}$ & $\begin{array}{l}\text { number of electrons involved in the electrode } \\
\text { reaction }\end{array}$ & (eq-mole $\left.{ }^{-1}\right)$ \\
\hline$p ;\left(p_{\mathrm{H}_{n}}\right)$ & $\begin{array}{l}\text { (Hydrogen) pressure; } \\
1 \text { atm. }=1.013 \times 10^{5} \mathrm{~Pa} \\
1 \text { torr }=133 \mathrm{~Pa}\end{array}$ & (Pa) \\
\hline$Q$ & State of charge & $\left(\mathrm{m} A h \cdot \mathrm{g}^{-1}\right)$ \\
\hline$R$ & Molar gas constant $=8.3144$ & $\left(\mathrm{~J}(\text { mole } \mathrm{K})^{-1}\right)$ \\
\hline$R$ & Internal resistance of a battcry & $(\Omega)$ \\
\hline$R_{\mathrm{u}}$ & Uncompensated clectrolyte resistance & (a) \\
\hline RHE & Reversible hydrogen electrode potential & $(m V)$ \\
\hline$\Delta S_{\alpha / 0}^{0}$ & Standard cntropy change for the $\alpha / \beta$ transition & $\left(\mathrm{J} \cdot\left(\mathrm{K} \text {-mole } \mathrm{H}_{z}\right)^{-1}\right)$ \\
\hline$S_{400}$ & Stability parameter & \\
\hline$S A$ & Specific surface area & $\left(m^{2}-g^{-1}\right)$ \\
\hline$T$ & Temperature & $\left(\mathrm{K}\right.$ or $\left.{ }^{\circ} \mathrm{C}\right)$ \\
\hline$V$ & Cell voltage & (V) \\
\hline
\end{tabular}




\begin{tabular}{|c|c|c|}
\hline$V_{1}(c)$ & Cell voltage at the end of charging & $(V)$ \\
\hline$V_{\mathrm{od}}(c)$ & Open circuit voltage of a charged cell & $(\mathrm{V})$ \\
\hline$V_{\text {od }}(d)$ & Open circuit voltage of a discharged cell & $(\mathrm{V})$ \\
\hline$y$ & Unit cell volume & $\left(A^{3}\right)$ \\
\hline $\boldsymbol{V}$ & Gas volume & $(\mathrm{ml})$ \\
\hline$x$ & Hydrogen content $=\mathrm{H} /$ M-ratio & \\
\hline$y$ & (dis-)charge rate & (hours $^{-1}$ ) \\
\hline$z$ & $\begin{array}{l}\text { Composition parameter indicating the cobalt } \\
\text { content. }\end{array}$ & \\
\hline$a$ & Transfor coefficient in Talel equation & \\
\hline$a ;(\alpha)$ & Hydrogen poor phase (saturated) & \\
\hline$\beta ;\left(\beta_{0}\right)$ & Hydrogen rich phase (inilially formed) & \\
\hline$\delta$ & Diffusion layer thickness & $(\mathrm{cm}$ or $\mu \mathrm{m})$ \\
\hline$n$ & Overpotential & $(\mathrm{m} V)$ \\
\hline The & $\begin{array}{l}\text { Overpotential for the hydrogen evolution } \\
\text { reaction }\end{array}$ & $(\mathrm{mV})$ \\
\hline $5 \eta_{\mathrm{a} / \mathrm{a}}$ & $\begin{array}{l}\text { Sum of overpotentials for charging and dis- } \\
\text { charging }\end{array}$ & $(\mathrm{mV})$ \\
\hline 0 & $\mathrm{X}$-гay diffraction angle & (degré) \\
\hline$\theta$ & Density & $\left(\mathrm{g} \cdot \mathrm{cm}^{-3}\right)$ \\
\hline$\sigma^{\circ}$ & Cross sectional area & $\left(\hat{A}^{2}\right)$ \\
\hline
\end{tabular}




\section{SUMMARY}

In the present battery research, we aimed at a rechargeable cell, which could be charged and discharged at high rates and would function in any position for several years and without reguiring maintenance. The metal hydride electrode is a rechargeable negative battery electrode based upon the reversible storage of hydrogen in metals. During the charging of such an electrode, hydrogen is formed by the electrochemical reduction of water and is subsequently absorbed by the metal. During discharging, the stored hydrogen is released and oxidized.

The intermetallic compounds $\mathrm{LaNi}_{5}$ and $\mathrm{LaNi}_{4} \mathrm{Cu}$, both belonging to the group of metals which is capable of absorbing and desorbing large guantities of hydrogen at pressures around 1 atm and near room temperature have been considered most-promising materials for application in rechargeable batteries. However, during repeated charging and discharging the storage capacity of both $\mathrm{LaNi}_{5}$ and $\mathrm{LaNi}_{4} \mathrm{Cu}$ electrodes declines exponentially as a result of corrosion of these intermetallic compounds. Consequently, the durability of these electrodes is limited to approximately 100 cycles.

$X$-ray diffraction analysis and electron microscopy studies showed that during electrochemical charging and discharging intermetallic $\mathrm{AB}_{5}$ compounds are converted into hydroxide needles of $\mathrm{A}(\mathrm{OH})_{3}$ and metallic precipitates of $\mathrm{B}$. No further substantial reduction of the particle size occurs during electrochemical cycling, if one starts with metal powder with a specific surface area of about $0.25 \mathrm{~m}^{2} \cdot \mathrm{g}^{\mathrm{m}}$, as determined by the BET method. The exponential decay of the storage capacity suggests that the corrosion reaction is affected by the repeated expansion and shrinkage of the intermetallic compound particles, which accompanies the charge/discharge cycles. We therefore hypothesized that hydride electrodes, made of an intermetallic compound which shows less lattice expansion than LaNis on hydriding, should be more stable than $\mathrm{LaNi}_{5}$ electrodes.

More than twenty different intermetallic compounds, in which lanthanum and nickel had been partially replaced by other elements, have been prepared to examine this hypothesis. As a result several multicomponent electrodes which exhibit an excellent stability have been found. For instance, the capacity loss of a $\mathrm{La}_{18} \mathrm{Nd}_{2} \mathrm{Ni}_{2.5} \mathrm{Co}_{2.4} \mathrm{Si}_{1.1}$ electrode is only thirty percent after one thousand cycles.

Comparison of the volume expansion of these $\mathrm{LaNi}_{5}$-related compounds and the stability of the corresponding electrodes demonstrates that the stability indecd increases in proportion to the decreasing volume expansion. The improvement in stability is considerably larger for intermetallic compounds which contain small amounts of aluminium or silicon. We have also established that cor- 
rosion only occurs during charging and discharging and not during rest. These observations may be explained in terms of a unique mass transport process in the intermetallic conpound particles.

Now that a viable hydride electrode has been found, sealed nickel-hydride batteries with a durability of more than one thousand cycles can be const ructed. The properties of these batteries are measured. Sealed nickeluhydride batteries are capable of being charged and discharged in less than one hour. Both prolonged overcharging and overdischarging are possible. Furthermore, they do not contain poisonous heavy metals such as cadmium and mercury. 


\section{SAMENVATTING}

Dit batterijenonderzoek was gericht op de ontwikkelingen van een gesloten herlaadbare cel, die snel geladen en ontladen kan worden en die gedurende meerdere jaren goed funktioneert in elke stand en zonder dat onderhoud vereist is. De metaalhydride-elektrode is een herlaadbare, negatieve batterijelektrode, die gebaseerd is op de revcrsibele opslag van waterstof in metalen. Tijdens het laden van een dergelijke elektrode wordt waterstof gevormd door de elektrochemische reduktie van water en vervolgens geabsorbeerd door het metal. Tijdens ontladen komt de opgeslagen waterstof vrij en wordt geoxideerd.

De intermetallische verbindingen $\mathrm{LaNi}_{5}$ en $\mathrm{LaNi}_{4} \mathrm{Cu}_{3}$, die beide behoren tot de groep van metalen die in staat is grote hoeveelheden waterstof te absorberen en desorberen bij kamertemperatuur en drukken van ongeveer l atm, leken aanvankelijk veel belovende materialen voor toepassing in herlaadbare batterijen. Echter, als gevolg van korrosie van deze intermetallische verbindingen neemt de opslagkapaciteit van zowel $\mathrm{LaNi}_{5}$ als $\mathrm{LaNi}_{4} \mathrm{Cu}$ elektroden exponentieel af tijdens herhaald laden en ontladen. Hierdoor is de levensduur van deze elektroden beperkt tot slechts circa 100 cycli.

Met Röntgen-diffraktie analyse en elektronenmicroscopie is aangetoond dat de intermetallische $A_{B} B_{5}$ verbindingen tijdens elektrochemische laad/ontlaadcycli ongezet worden in naaldvormig $\mathrm{A}(\mathrm{OH})$, hydroxide en metallische $\mathrm{B}$ precipitaten. Uitgaande van metaalpoeder met een specifiek oppervlak van ongeveer $0.25 \mathrm{~m}^{2}-\mathrm{g}^{-1}$ (BET methode) treedt vrijwel geen verdere verkleining van de decttjesgrootte op tijdens elektrochemisch laden en ontladen. De exponentiële aftame van de opslagkapaciteit doet vermoeden dat de korrosiereaktie beïnvloed wordt doot de herhaalde uityetting en inkrimping van de netaaldeeltjes, waarmee de laad/ontlaad-cycli gepaard gaan. Daarom hebben wij verondersteld dat hydride-elektroden, die gemaakt zijn van een intermetallische verbinding waarvan het volume door waterstofabsorptie minder toeneemt dan dat van LaNi.5, stabieler zouden zijn dan LaNis elektroden.

Met deze veronderstelling als werkhypothese zijn meer dan twintig verschillende intermetallische verbindingen, waarin lanthaan en nikkel gedeeltelijk zijn vervangen door andere elementen, bereid. Hierbij zijn meerdere multikomponenten elektroden met een uitstekende stabiliteit gevonden, Zo is bijvoorbeeld her kapaciteitsverlies van cen $\mathrm{La}_{18} \mathrm{Na}_{12} \mathrm{Ni}_{2,6} \mathrm{Co}_{2,4} \mathrm{Si}_{11}$ elektrode slechts dertig procent na duizend cycli.

Uit een vergelijking van de volume-uitzetting van deze $\mathrm{LaNi}_{5}$-achtige verbindingen met de stabiliteit van de korresponderende elektroden blijkt dat de stabiliteit inderdaad evenredig toeneent met afnemende volume-expansie. De 
stabiliteitsverbetering is aanzienlijk groter voor intermetallische verbindingen, die kleine hoeveelheden aluminjum of silicium bevatten. Ook is vastgesteld dat korrosie alleen optreedt tijdens laden en ontladen en niet tijdens rust. Deze waarnemingen kunnen verklaard worden in termen van een uniek massatransport-proces in de metaaldeeltjes.

Door de vinding van een levensvatbare hydride-elektrode kunnen gesloten nikkel-hydride batterijen met een levensduur van meer dan duizend laad/ontlaad-cycli worden gemaakt. $\mathrm{Dc}$ cigenschappen van deze batterijen zijn gemeten. Gesloten zikkel-hydride batterijen kunnen in minder dan 1 uur geladen en ontladen worden en zijn langdurig overlaadbaar en overontlaadbaar. Bovendien bevatten ze geen giftige zware metalen zoals cadmium en kwik. 


\section{LEVENSLOOP}

Han Willems werd op 6 mei 1955 te Eindhoven geboren, en behaalde het diploma HBS-B aan het Rythovius College te Eersel in 1972. In hetzelfde jaar begon hij met zijn studie Scheikundige Technologie aan de Technische Hogcschool Eindhoven. Het kandidaatsexamen werd in 1976 afgelegd, waarna op 25 april 1979 deze studie met lof werd afgesloten. Zijn afstudeeronderzoek verrichtte hij in de vakgroep Elektrochemie onder leiding van prof. $\mathrm{E}$. Barendrecht. Daarnaast vervulde bij in deze vakgroep diverse studentassistententschappen.

Van mei 1979 tot juli 1984 was hij werkzaan als wetenschappelijk medewerker van het Philips Natuurkundig Laboratorium te Eindhoven. Hier werd in de groep Grensvlakchemie, die geleid wordt door Dr. G. Frens, het onderzoek verricht op grond waarvan dit proefschrift tot stand kwam.

Sinds augustus 1984 maakt hij deel uit van de Philips' produktdivisie Verlichting en Batterijen. 


\section{DANKWOORD}

Het onderzoek waarover in dit proelsehrift gerapporteerd wordt, is verricht. in het Philips Natuurkundig Laboratorium te Eindhoven. Ik ben de direktie van dit Laboratorium zeer erkentelijk voor de gelegenheid die zij mij geboden heeft on dit proetschrift te voltooien.

Ook dank $\mathrm{ik}$ in het bijzonder de heren J. R. van Beek en H. C. Donkersloot voor onze vruchtbare samenwerking. Zonder hurn bijdragen, respektievelijk op het gebied van het cicktrochenisch en het metallurgisch onderzoek van hydride-vormende materialen had dit proefschrift niet tot stand kunnen komen.

Voor het goed verlopen van de vele experimenten was de technisehe ondersteuning door Mevr. A. C. Reynders en de heren L. Kcrkhofs en I. J. F. Heuts onmisbaar. Voor hun grote toewijding ben ik hen zeer erkentelijk.

Tot slot wil ik ook mijn dank uitspreken aan Dr. G. Trens voor de inspircrende diskussies en zijn ondersteuning van het werk en aan mijn beide promotoren prof. E. Barendrecht en prof. Dr. A. R. Miedema voor het kritisch bespreken văi hè manuscript. 
Stêllingen bij het proeischrift:

\section{Metal Hydride Electrodes} Stability of LaNi ${ }_{5}$-related Compounds 
Het anomale autodoteringsgedrag van boor tijdens de epitaxiale groei van silicium kan verklaard worden door rekening te houden met chemische reakties in de gasfase.

S, B. Kulkarni and A. A. Korul, Eilcotrohom. Soc. Meating 80-2, Hollywood, Florida, Ext, Absir. No. 540 (1980).

2.

De stabiliteil van de, door Schoonman en medewerkers gebruikte sonde voor de elektrochemische bepaling van het waterstofgehalte in metalen zal aanzienlijk toenemen indien bij kamertemperatuur het palladiumhydride $\mathrm{PdH}_{.6}$ wordt gebruikt als referentie-elektrode.

J. Schoonman, D. L. Franceschetri and J. W. Hanncken, Ber, Bunsenges. Pbys. Chem. 86, 701 (1982).

3.

In ionogene kristallen is altijd ruintelading aanwezig. De overmaat aan lading, die onmiddelijk orider het oppervlak is gelokaliseerd in een dunne laag, word gekompenseerd door extra lading van tegengestcld teken, die zich dicper in het kristal in een meer uitgestrekte laag bevindt.

4.

De mogelijke toepassing vả perfluoroverbindingen ter verbetering van de waterhuishouding in zink-lucht-cellen biedt interessante voortuizichten.

5.

Het verschil in snelheid waarmee het etsproces van het halfgeleidermateriaal InP verloopt in zoutzulur, enerzijds, en in oplossingen van $\mathrm{HCl}$ in gekonsentreerd azijnzuur, anderzijds, kan niel verklaard worden met een zuiver elektrochemisch oxydatiemechanisme.

S. Adachi and H. Kawaguchi, J, Electochem, Soc. 128, 1342 (1981).

P. H. L. Notten, .I. Elcctrochem. Soo, verschinit najaar 1984. 
6.

Uit het waterstofabsorptiegedrag volgt dat anorf $\mathrm{LaNi}_{5}$ opgebouwd gedacht kan worden uit vele mikrogebiedjes, die zich onderscheiden door verschillende lanthaan/nikkel-ratio's.

7.

Tegen de, door Stadler en Boehm getrokken konklusie dat de deeltjesgrootte van fotochemisch neergeslagen platina op $\mathrm{TiO}_{2}$ eenvoudig beheersbaar is, bestaan ernstige bedenkingen.

K,-H, Stadler and H. P, Boehin, Proc, $8^{\text {th }}$ Inc, Congress on Catalysis, Berlin, 2-6 July 1984, Vol, IV, p. 803-\$14,

8.

Een herlaadbare batterij is een chemische reaktor waarin chemische energie onkeerbaar wordt ongezet in elektrische energie. Vanwege hun gekompliceerdheid verdienen de processen in dergelijke reaktoren ook de aandacht van proceskundige chemici.

9

Het verdient aanbeveling om in leerlingendossiers niet langer het beroep van de vader op te nemen.

10.

De opdracht van een proefschrift aan geliefde personen wekt de indruk dat het proefschrift voor hen is gesschteven. 